\title{
Common Factors in Commodity Futures Curves *
}

\author{
Dennis Karstanje ${ }^{\dagger}$, Michel van der Wel, and Dick van Dijk
}

February 15, 2015

\begin{abstract}
We examine the comovement of factors driving commodity futures curves. We adopt the framework of the dynamic Nelson-Siegel model, enabling us to examine not only comovement in price levels but also futures curve shapes, as characterized by their slope and curvature. Our empirical results based on 24 commodities over the period 1995-2012 demonstrate that the individual commodity futures curves are driven by common components. The commonality is mostly sector specific, which implies that commodities are a heterogeneous asset class. The common components in the level of the curve have become more important over time, coinciding with the financialization of the commodities market. The market-wide level component, which is common to all commodities, is related to economic output variables, exchange rates and hedging pressure. Factors driving the shape of the futures curve are related to inventory data (theory of storage), hedging pressure (theory of normal backwardation) and interest rates. The use of full curve data alters findings on comovement, compared to the use of only first-nearby contract data. The full curve commonality results give more insight in the market dynamics and can help in the construction of commodity futures portfolios and hedging decisions.
\end{abstract}

JEL classification: G12; G13.

Keywords: Commodity futures prices; comovement; term structure; dynamic Nelson Siegel model.

${ }^{*}$ Karstanje is from Erasmus University Rotterdam and the Tinbergen Institute. Van Dijk is from Erasmus University Rotterdam, Tinbergen Institute and ERIM. Van der Wel is from Erasmus University Rotterdam, CREATES, Tinbergen Institute and ERIM. The authors thank participants at the 51st Meeting of the EWGCFM, the MMF workshop on "Empirical Modelling of Financial Markets", the Workshop on "Factor Analysis in Economics and Finance" at the Canadian Economics Association Conference 2013, the SoFiE Annual Conference 2013, the SIRE Conference on "Finance and Commodities" 2013, the 19th International Conference on Computing in Economics and Finance, the SoFiE Large-Scale Factor Models in Finance Conference, a seminar at CREATES, the 2014 FMA European Conference, and the CAMP workshop on Commodity Dynamics and Financialisation. We are grateful to Marcin Jaskowski, John Hunter and Christian Stepanek for their detailed comments. Michel van der Wel is grateful to Netherlands Organisation for Scientific Research (NWO) for a Veni grant; and acknowledges support from CREATES, funded by the Danish National Research Foundation. The computational tests of this research were performed on the Dutch National LISA cluster, and supported by NWO. We are responsible for all errors.

${ }^{\dagger}$ Corresponding author. Address: Econometric Institute, Erasmus University Rotterdam, PO Box 1738, Rotterdam, 3000DR, The Netherlands. Tel.: +31104081264. E-mail: dennis@karstanje.com. Other author's e-mail addresses: vanderwel@ese.eur.nl (van der Wel), djvandijk@ese.eur.nl (van Dijk). 


\section{Introduction}

Commodities have become a popular asset class among investors in recent years, as they offer interesting diversification opportunities in the context of broader investment portfolios as well as a useful hedge against inflation. ${ }^{1}$ While commodity characteristics vary, there are comovements in their prices, as seen in the price boom during the period 20062008 and the downturn during the second half of 2008. As commodity prices are important from an economic, sociological, and political perspective, it is important to understand their dynamics and their interrelations. This makes it interesting to look into the possibility to characterize commodity price comovements.

In this paper we examine commonality among commodities in terms of factors driving their entire futures curve, i.e. the collection of all available futures contracts of a particular commodity. By including futures information we can examine not only comovement in the price level of different commodities but also comovement in the shape of their curves. This additional analysis of important futures curve characteristics such as slope and curvature sheds light on the beliefs of market participants about commodity price fundamentals. For example, the theory of storage states that the slope of the futures curve is related to the level of inventories (Kaldor, 1939; Working, 1949; Fama and French, 1987). Our approach enables us to directly link these slopes across commodities.

We investigate the 24 commodities that constitute the Goldman Sachs Commodity Index (GSCI). These commodities can be split into five sectors: energy, metals, softs, grains, and meats. As a large part of these commodities are also included in the Dow Jones-UBS Commodity Index (DJ-UBSCI), ${ }^{2}$ and as we include at each point in time all available futures contracts, our data covers a large part of total exchange-related commodity trading. We use monthly futures prices for the period January 1995 to September 2012.

\footnotetext{
${ }^{1}$ See e.g. Gorton and Rouwenhorst (2006). Note that the usefulness to act as a hedging instrument varies across individual commodities because of their heterogeneous nature, see Erb and Harvey (2006), Brooks and Prokopczuk (2013), and Daskalaki, Kostakis, and Skiadopoulos (2014), among others.

${ }^{2}$ This index was formerly known as the Dow Jones-AIG Commodity Index (DJ-AIGCI). Together, the GSCI and DJ-AIGCI are the two commodity indexes that have emerged as industry benchmarks (Stoll and Whaley, 2010).
} 
We use an enhanced version of the Nelson and Siegel (1987) model to extract the factors that drive the commodity futures curves. The Nelson and Siegel (1987) model has good ability to fit the term structure of interest rates (see also Diebold and Li, 2006). As the statistical features of commodity futures curves resemble those of bond yields, the model can be used to characterize commodity futures prices. Although the base model can deal with all kinds of curve shapes we adjust it to be able to handle pronounced seasonal patterns, which are typical for commodities.

To investigate the comovement among commodity futures curves we adopt the framework of Diebold, Li, and Yue (2008) with several extensions. Diebold, Li, and Yue (2008) introduce an additional layer in the Nelson and Siegel (1987) model consisting of unobserved common components that underlie the extracted factors that drive the individual commodity futures curves. We make use of two types of common components, i.e. a market-wide component that is common to all commodities and sector components that are only common to commodities within the same sector. The heterogeneous nature of commodities motivates the inclusion of the sector specific components. Besides the common components there are idiosyncratic components to allow for commodity-specific behavior. In the end we are interested in the relative importance of the common components versus the idiosyncratic components, which is our definition of the degree of commonality.

Our empirical results show that our enhanced version of the Nelson-Siegel model is suited to model commodity futures curves and that there are important common components in the level, slope and curvature factors that characterize these curves. For the commodity level factors, the percentage of explained variation by a combination of the market-wide and sector components is on average $62 \%$. For the slope and curvature factors, these percentages are around $74 \%$. In all cases the commonality is mostly driven by the sector components (between 39\% and 50\%), which implies that commodities are not an homogeneous asset class. When we investigate commonality over time, we find that common components in our level factors have become increasingly important over our sample period. The percentage of explained variation by common components starts at 
$53 \%$ in 1995 and increases to $68 \%$ in 2012 . The slope and curvature factors show almost no variation in results over time.

To give a better interpretation to the unobserved components, we investigate their relation with observed economic variables. The market-wide level factor is related to hedging pressure, equity prices and exchange rates. When the net short positions of hedgers increase, the curves' price levels also increase (in line with Gorton et al., 2013). A rise in in equity prices or a weakening of the US dollar also lead to an increase in the common level factor. These findings are in line with, among others, Vansteenkiste (2009), Byrne, Fazio, and Fiess (2012), and Chen, Rogoff, and Rossi (2010). Regarding our market-wide slope component, we find that it increases when the net short positions of hedgers increase. This results in a more backwardated futures curve, which is in line with the theory of normal backwardation (see e.g. Bessembinder, 1992). ${ }^{3}$ Furthermore, the slope of the futures curves is negatively related to commodity inventories. This relation between the slope of the futures curve (i.e. convenience yield) and commodity inventories is in line with the theory of storage and findings of Gorton, Hayashi, and Rouwenhorst (2013) and Deaton and Laroque (1992). Thus, using the proposed modeling framework we confirm many findings of existing literature and get additional insights in the commonality of the entire commodity futures curves.

Some papers already use the Nelson-Siegel approach to fit individual commodity futures curves. West (2012) uses it to obtain price estimates for OTC forward contracts beyond the longest available maturity of exchange traded futures contracts. Hansen and Lunde (2013) focus on forecasting and use the Nelson-Siegel framework to predict the term structure of oil futures. An alternative approach to model the commodity futures curve is to express it in terms of unobserved factors and derive futures prices under noarbitrage conditions (see Gibson and Schwartz, 1990; Schwartz, 1997; Geman, 2005). This approach is more restrictive because it requires many assumptions on the market factors and it has difficulty incorporating seasonal patterns (West, 2012). Furthermore, the model complexity makes it difficult to jointly model multiple commodities. Cortazar, Milla, and

\footnotetext{
${ }^{3}$ Or, e.g., Carter, Rausser, and Schmitz (1983); Chang (1985); de Roon, Nijman, and Veld (2000)
} 
Severino (2008), Ohana (2010) and Casassus, Liu, and Tang (2013) propose joint models for two commodities but these cannot easily be extended to larger dimensions. ${ }^{4}$ As both approaches extract unobserved factors from the futures curve, it is possible that these factors are alike. For all individual commodities, our level and slope factors are similar to their corresponding unobserved spot price and convenience yield factors of the Schwartz (1997) three-factor model, while our curvature factor explains part of his residuals.

There is a large existing literature on comovement of commodity prices. Some work focuses on the drivers of comovement and the macroeconomy. Pindyck and Rotemberg (1990) state in their excess comovement hypothesis that seemingly unrelated commodities comove more than expected, after correcting for macroeconomic influences. Other papers find weaker evidence or reject this excess comovement hypothesis after accounting for model misspecification, conditional heteroskedasticity, and non normality (Deb, Trivedi, and Varangis, 1996) or after incorporating inventory and harvest information (Ai, Chatrath, and Song, 2006). We focus on quantifying the level of commonality across commodities and do not split this commonality in a "normal" and "excess" part.

More closely related to our work is the strand of literature that documents common unobserved factors among individual commodity prices. Vansteenkiste (2009) and Byrne, Fazio, and Fiess (2012) use principal component techniques to extract a latent factor that drives non-fuel commodity prices and link this factor to observed economic variables, like exchange rates or real interest rates. We differ by investigating the comovement of the entire futures curve of commodity prices instead of one price series per commodity. This allows us to investigate comovement, besides levels, in the shapes of futures curves. Furthermore, it allows for a more accurate correction of seasonality effects.

Besides commonality in commodity prices, many papers investigate commonality in commodity returns or their volatilities. Christoffersen, Lunde, and Olesen (2014) docu-

\footnotetext{
${ }^{4}$ Cortazar, Milla, and Severino (2008) propose a multi-commodity version of the Cortazar and Naranjo (2006) model for two oil related commodities that uses common and commodity specific factors. Ohana (2010) captures the joint evolution of correlated futures curves by incorporating both the local and global dependence structures between slopes and levels. Casassus, Liu, and Tang (2013) jointly model the convenience yields of two commodities using a multi-commodity feedback affine (MCFA) model to match observed futures correlations.
} 
ment a clear factor structure in both returns and volatilities. The asset pricing literature focuses on factors that can explain the cross-section of commodity futures returns. Szymanowska, de Roon, Nijman, and van den Goorbergh (2014) show that cross-sectional variation in commodity futures (portfolio) returns can be attributed to a single basis factor for spot premia and to two additional basis factors for term premia. In contrast, Daskalaki, Kostakis, and Skiadopoulos (2014) document that there are no macro, equity or commodity-motivated factors that can price the cross-section of commodity futures.

The rest of this paper is organized as follows. In the next section we present the methodology, followed by Section 3 where we present the data and the descriptive statistics. Section 44 and 5 discuss the empirical results, while Section 6 concludes.

\section{Methodology}

In this section we show how the individual commodity futures curves are decomposed into level, slope, curvature, and seasonal factors, and how commonality in these factors across commodities is modeled. The first subsection discusses our model. In the second subsection, we discuss the applied estimation procedure.

\subsection{Model}

We model a collection of futures prices for $N$ different commodities. The futures price with maturity $\tau$ (measured in years) for commodity $i$ at time $t$ is denoted by $f_{i, t}(\tau)$. Our starting point is the dynamic version of the Nelson and Siegel (1987) model, as introduced in Diebold and Li (2006), to describe the futures curve of each individual commodity $i$, for $i=1,2, \ldots, N$, as

$$
f_{i, t}(\tau)=l_{i, t}+s_{i, t}\left(\frac{1-\exp ^{-\lambda_{i} \tau}}{\lambda_{i} \tau}\right)+c_{i, t}\left(\frac{1-\exp ^{-\lambda_{i} \tau}}{\lambda_{i} \tau}-\exp ^{-\lambda_{i} \tau}\right)+\nu_{i, t}(\tau)
$$

where $l_{i, t}, s_{i, t}, c_{i, t}$ are interpreted as time-varying unobserved factors, the decay parameter $\lambda_{i}>0$ is assumed to be constant over time, and $\nu_{i, t}(\tau)$ is a disturbance term, where 
$\Sigma_{\nu}$ is the covariance matrix of $\left(\nu_{i, t}\left(\tau_{1}\right), \nu_{i, t}\left(\tau_{2}\right), \ldots, \nu_{i, t}\left(\tau_{J_{i}}\right)\right)^{\prime}$. The interpretation of the unobserved factors $l_{i, t}, s_{i, t}$, and $c_{i, t}$ is determined by their loadings. The loading on the first factor is a constant such that $l_{i, t}$ affects all futures prices in the same way irrespective of their maturity, hence the name level factor. The loading on the second factor is a decreasing function of the futures contract maturity $\tau$ and $s_{i, t}$ can therefore be regarded as the slope of the futures curve. The loading on the third factor is a concave function of $\tau$, which allows to fit humped-shaped futures curves, and $c_{i, t}$ can thus be interpreted as a curvature factor. ${ }^{5}$

We make two adjustments to the base model given in (1). First, we enhance the model to account for seasonality. Commodity futures curves display pronounced seasonal patterns due to seasonal supply and demand effects, for example related to crop cycles and weather conditions (see e.g. Milonas, 1991). We account for seasonality by including a trigonometric function that depends on the expiry month $g_{i}(t, \tau)$ of the contract. ${ }^{6}$ Trigonometric functions are often used to model seasonality, see for instance Sorensen (2002). We thus enhance the model in (1) with a seasonal term given by $\kappa_{i} \cos \left(\omega g_{i}(t, \tau)-\omega \theta_{i}\right)$, where the parameter $\kappa_{i}$ determines the commodity-specific exposure to the seasonal, the constant $\omega$ determines the cycle length, and the parameter $\theta_{i}$ indicates the peak of the seasonal term.

Second, for small values of $\lambda_{i}$, the loadings of the slope factor only slowly decline towards zero as the maturity increases. While this helps to fit futures curves that are very smooth, it becomes difficult to identify the level and slope factors when the termstructure dimension is limited. By re-centering the loadings of the slope and curvature factors to zero at the one year maturity, we make sure that the slope factor does not absorb movements of the curve's level. In this case, the level factor represents the price level of the one year futures contract, while the slope and curvature factor have a similar

\footnotetext{
${ }^{5}$ The loading for slope starts at 1 for $\tau \rightarrow 0$ and monotonically declines towards zero as the maturity $\tau$ increases. The loading for $c_{i, t}$ is equal to 0 for $\tau \rightarrow 0$ and $\tau \rightarrow \infty$, and reaches a maximum value for maturity $\tau^{*}$, which depends on the value of $\lambda_{i}$.

${ }^{6}$ The mathematical expression for the expiration month is $g_{i}(t, \tau)=t+\tau-S\left\lfloor\frac{t+\tau}{S}\right\rfloor$, with $S=12$ the number of distinct "seasons" and the function $\lfloor x\rfloor$ returns the largest integer not greater than $x$. Therefore, $g_{i}(t, \tau)$ results in the integers $\{0,1, \ldots, 11\}$. Our sample starts in January with $t=0$ such that the integers $\{0,1, \ldots, 11\}$ represent the expiry months January, February, .., December.
} 
interpretation as before. The curve is given by

$$
\begin{aligned}
f_{i, t}(\tau)= & l_{i, t}+s_{i, t}\left[\left(\frac{1-\exp ^{-\lambda_{i} \tau}}{\lambda_{i} \tau}\right)-\left(\frac{1-\exp ^{-\lambda_{i}}}{\lambda_{i}}\right)\right] \\
& +c_{i, t}\left[\left(\frac{1-\exp ^{-\lambda_{i} \tau}}{\lambda_{i} \tau}-\exp ^{-\lambda_{i} \tau}\right)-\left(\frac{1-\exp ^{-\lambda_{i}}}{\lambda_{i}}-\exp ^{-\lambda_{i}}\right)\right] \\
& +\kappa_{i} \cos \left(\omega g_{i}(t, \tau)-\omega \theta_{i}\right)+\nu_{i, t}(\tau)
\end{aligned}
$$

The constants we subtract from the slope and curvature loadings are commodity specific (due to $\lambda_{i}$ ) but fixed over time. The constant only has an effect when $\lambda_{i}$ becomes small as for large values of $\lambda_{i}$ is close to zero.

We investigate the comovement of commodity prices by linking the futures curves of the individual commodities. This link across commodities is accomplished by decomposing the level, slope, and curvature factors into latent market-wide, sector, and idiosyncratic components. We define the factor decompositions

$$
\begin{aligned}
& l_{i, t}=\alpha_{i}^{L}+\beta_{i}^{L} L_{\text {market }, t}+\gamma_{i}^{L} L_{\text {sector }, t}+L_{i, t}, \\
& s_{i, t}=\alpha_{i}^{S}+\beta_{i}^{S} S_{\text {market }, t}+\gamma_{i}^{S} S_{\text {sector }, t}+S_{i, t}, \\
& c_{i, t}=\alpha_{i}^{C}+\beta_{i}^{C} C_{\text {market }, t}+\gamma_{i}^{C} C_{\text {sector }, t}+C_{i, t},
\end{aligned}
$$

where $\alpha_{i}^{X}$ for $X=\{L, S, C\}$ are constant terms, $\beta_{i}^{X}$ are loadings on the latent marketwide component $X_{\text {market }, t}, \gamma_{i}^{X}$ are loadings on sector components $X_{\text {sector }, t}$, and $X_{i, t}$ are idiosyncratic components. The (absolute) magnitude of the coefficients $\beta_{i}^{X}$ and $\gamma_{i}^{X}$ determines the degree of comovement across all commodities and across commodities within a specific sector, respectively.

We include sector components besides the market-wide components, because we may expect that commodities in the same sector are more closely related than commodities across different sectors. The three-way decomposition of the futures curve factors is reminiscent of Kose, Otrok, and Whiteman (2003), who let business cycles in different countries depend on global, regional, and an idiosyncratic part, but do not work in the 
Nelson-Siegel framework. In contrast, Diebold, Li, and Yue (2008) use the Nelson-Siegel framework but decompose the country yield factors only in a global and idiosyncratic component.

The market-wide, sector, and idiosyncratic components are assumed to have first-order autoregressive dynamics

$$
\left(\begin{array}{c}
\Delta L_{y, t} \\
S_{y, t} \\
C_{y, t}
\end{array}\right)=\left(\begin{array}{ccc}
\phi_{11}^{y} & \phi_{12}^{y} & \phi_{13}^{y} \\
\phi_{21}^{y} & \phi_{22}^{y} & \phi_{23}^{y} \\
\phi_{31}^{y} & \phi_{32}^{y} & \phi_{33}^{y}
\end{array}\right)\left(\begin{array}{c}
\Delta L_{y, t-1} \\
S_{y, t-1} \\
C_{y, t-1}
\end{array}\right)+\left(\begin{array}{c}
\eta_{y, t}^{L} \\
\eta_{y, t}^{S} \\
\eta_{y, t}^{C}
\end{array}\right)
$$

where $y=\{$ market, sector, idiosyncratic $\}$, and the disturbances $\eta_{y, t}=\left(\eta_{y, t}^{L}, \eta_{y, t}^{S}, \eta_{y, t}^{C}\right)$ are normally distributed with covariance matrix $\Sigma_{\eta_{y}}$. The choice for $\operatorname{VAR}(1)$ dynamics for the components is in line with Diebold and Li (2006) and Diebold et al. (2008). One difference is that we assume the level factors to be non-stationary and model them as first differences. Duffee (2011) makes a similar assumption for yield data, while Hansen and Lunde (2013) do the same for oil commodity futures.

To facilitate tractable estimation in our applications and to let all covariance come from common factors, we use a restricted version of the model given by (2)-(4). That is, we do not allow for cross-correlation of the shocks $\nu_{i, t}(\tau)$ across maturities and commodities, and for the shocks $\eta_{y, t}$ across market-wide, sector, and idiosyncratic components. In other words, all the covariance disturbance matrices $\Sigma_{\nu}$ and $\Sigma_{\eta_{y}}$ are diagonal. Also the autoregressive matrices in (4) are assumed to be diagonal.

As often with factor models, we need to make sure that our unobserved factors are uniquely identified. Here, we have two identification issues as neither the signs nor the scales of the market-wide and sector factors and their factor loadings are separately identified. We follow Sargent and Sims (1977) and Stock and Watson (1989) to identify the scales by assuming that each disturbance variance is equal to a constant, i.e. $\Sigma_{\eta_{z}}(j, j)=0.01$ for $z=\{$ market, sector $\}$ and $j=1,2,3 .{ }^{7}$ We identify the factor signs by

\footnotetext{
${ }^{7}$ The value of 0.01 is in line with the estimated variance of the idiosyncratic factor' disturbances, as will become clear in the results section.
} 
restricting one of the loadings for each of the market-wide and sector components to be positive.

\subsection{Estimation}

The model as given by (2)-(4) can be estimated either using a two-step approach (see, e.g., Diebold et al., 2008) or a one-step approach (see, e.g., Diebold et al., 2006). In the two-step approach one first extracts the latent factors $l_{i, t}, s_{i, t}$, and $c_{i, t}$ in $(2)$ at each point in time for each commodity and in the second step decomposes the extracted factors into the marketwide, sector and idiosyncratic components. We use the one-step approach where we cast the complete model in a state space representation and use the Kalman filter to estimate all parameters as well as the latent factors and their decomposition simultaneously. The advantage of this procedure is that it takes the estimation uncertainty in the extracted factors into account in their decomposition. Furthermore we can use both time series and cross-sectional observations to accurately estimate the parameters. To initialize the one-step approach we can use estimation results of smaller versions of our full model, e.g. a variant without market-wide or sector components.

The state space representation follows naturally from the model given by (2)-(4). The measurement equation (A.1) is given in Appendix A and based on (2) and (3). The individual latent level $l_{i, t}$, slope $s_{i, t}$, and curvature $c_{i, t}$ factors do not appear in the measurement equation, as we can link the observed futures prices $f_{i, t}(\tau)$ directly to the unobserved market-wide, sector and idiosyncratic components. The transition equations of the latent states are given by (4).

Our model can be presented in stacked form if we treat the multivariate series as univariate series, following Koopman and Durbin (2000). We can consider the futures prices separately since we assume that there is no cross-correlation across different commodities (all commonality is absorbed by the factors). The univariate treatment gives us not only computational gains but also allows the number of term-structure observations $J_{i}$ to be time-varying and deal with our unbalanced panel. We collect all unknown coefficients in the parameter vector $\Psi$, i.e. the commodity specific parameters in (2) and (3) 
$\left(\lambda_{i}, \kappa_{i}, \theta_{i}, \alpha_{i}^{X}, \beta_{i}^{X}, \gamma_{i}^{X}\right)$, and the diagonal elements of the VAR coefficient matrices $\Phi^{y}$, and the variance matrices $\Sigma_{\nu}$ and $\Sigma_{\eta_{y}}$. Estimation of $\Psi$ is based on the numerical maximization of the loglikelihood function that is constructed via the prediction error decomposition.

\section{Data}

We study futures curves for 24 commodities. We consider the period January 1995 to September 2012 and use all individual futures contracts that expire between January 1995 and December 2030. ${ }^{8}$ Our commodity selection is based on the composition of the S\&P Goldman Sachs Commodity Index (GSCI). The GSCI constituents can be split in five sectors: energy, metals, softs, grains, and meats. An overview of the data (as obtained from Thomson Reuters Datastream) is given in Table 1. All our analyses are done at the monthly frequency, and for this we use month-end log settlement prices. All prices are standardized since the pricing grid of the commodities is quite diverse. ${ }^{9}$ To avoid liquidity issues we do not consider price information of (i) contracts with a monthly return that equals zero, and (ii) contracts in the expiration month. Furthermore, we filter out data errors by excluding contracts that have abnormal returns compared to adjacent contracts. These filters lead to exclusion of approximately $1.3 \%$ of the data.

\footnotetext{
${ }^{8}$ The start of the sample period is based on the availability of the metal commodities traded on LME, which are only available from July 1993 onward.

${ }^{9}$ We standardize prices by setting the first nearby contract price in January 1995 of all commodities equal to 100. All other prices are adjusted such that (time series and term structure) returns remain unchanged.
} 


\section{Table 1 Commodity data overview}

The table presents an overview of the 24 commodity futures series that are all present in the S\&P Goldman Sachs Commodity Index (GSCI). The sector classification is the same as GSCI. We consider the period January 1995 to September 2012. We show the number of cross-sectional contracts that are available in the first and last year of our dataset. Furthermore we show the average annualized return and its volatility of both the first maturing futures contract and the futures contract with 12 months to maturity.

\begin{tabular}{|c|c|c|c|c|c|c|c|}
\hline \multirow[b]{2}{*}{ Sector } & \multirow[b]{2}{*}{ Commodity } & \multicolumn{2}{|c|}{ \# contracts } & \multicolumn{2}{|c|}{ 1st nearby contract } & \multicolumn{2}{|c|}{$12 \mathrm{M}$ contract } \\
\hline & & Begin & End & $\bar{r}$ & $\sigma(r)$ & $\bar{r}$ & $\sigma(r)$ \\
\hline \multirow[t]{6}{*}{ Energy } & Brent crude oil & 12 & 56 & $12.9 \%$ & $32.3 \%$ & $13.4 \%$ & $19.3 \%$ \\
\hline & WTI crude oil & 26 & 67 & $9.0 \%$ & $32.8 \%$ & $7.8 \%$ & $17.1 \%$ \\
\hline & Gasoil & 14 & 30 & $12.8 \%$ & $32.8 \%$ & $7.3 \%$ & $20.7 \%$ \\
\hline & Heating oil & 17 & 19 & $10.7 \%$ & $34.8 \%$ & $6.6 \%$ & $25.2 \%$ \\
\hline & Natural gas & 20 & 83 & $-20.6 \%$ & $53.1 \%$ & $-1.4 \%$ & $17.4 \%$ \\
\hline & Gasoline & 10 & 24 & $18.8 \%$ & $39.2 \%$ & $7.6 \%$ & $23.3 \%$ \\
\hline \multirow[t]{7}{*}{ Metals } & Gold & 19 & 19 & $5.9 \%$ & $16.4 \%$ & $4.8 \%$ & $15.9 \%$ \\
\hline & Silver & 19 & 19 & $8.4 \%$ & $30.6 \%$ & $8.5 \%$ & $29.8 \%$ \\
\hline & Aluminum & 11 & 60 & $-4.9 \%$ & $19.9 \%$ & $7.8 \%$ & $17.1 \%$ \\
\hline & Copper & 11 & 60 & $7.5 \%$ & $27.6 \%$ & $20.5 \%$ & $31.4 \%$ \\
\hline & Lead & 11 & 29 & $4.7 \%$ & $30.2 \%$ & $10.8 \%$ & $35.1 \%$ \\
\hline & Nickel & 11 & 30 & $4.2 \%$ & $36.4 \%$ & $10.3 \%$ & $33.7 \%$ \\
\hline & Zinc & 11 & 30 & $-2.2 \%$ & $27.6 \%$ & $14.2 \%$ & $29.7 \%$ \\
\hline \multirow[t]{4}{*}{ Softs } & Cocoa & 8 & 10 & $0.6 \%$ & $31.4 \%$ & $-4.6 \%$ & $24.9 \%$ \\
\hline & Coffee & 7 & 10 & $-5.3 \%$ & $36.7 \%$ & $-5.6 \%$ & $28.9 \%$ \\
\hline & Cotton & 9 & 11 & $-6.9 \%$ & $29.9 \%$ & $-2.0 \%$ & $18.1 \%$ \\
\hline & Sugar & 7 & 8 & $0.5 \%$ & $38.2 \%$ & $8.6 \%$ & $18.6 \%$ \\
\hline \multirow{4}{*}{ Grains } & Corn & 8 & 14 & $-4.4 \%$ & $29.0 \%$ & $6.6 \%$ & $12.6 \%$ \\
\hline & Soybeans & 11 & 17 & $7.3 \%$ & $26.6 \%$ & $3.1 \%$ & $17.8 \%$ \\
\hline & Chicago wheat & 7 & 10 & $-10.2 \%$ & $30.3 \%$ & $4.4 \%$ & $17.5 \%$ \\
\hline & Kansas wheat & 5 & 9 & $-0.2 \%$ & $29.3 \%$ & $1.3 \%$ & $21.5 \%$ \\
\hline \multirow[t]{3}{*}{ Meats } & Feeder cattle & 8 & 8 & $1.5 \%$ & $14.5 \%$ & $4.2 \%$ & $10.3 \%$ \\
\hline & Lean hogs & 8 & 9 & $-7.2 \%$ & $28.0 \%$ & $7.4 \%$ & $14.1 \%$ \\
\hline & Live cattle & 7 & 7 & $0.5 \%$ & $14.9 \%$ & $3.8 \%$ & $8.5 \%$ \\
\hline
\end{tabular}

Table 1 shows that the number of available contracts (term-structure observations) varies per commodity. This is caused by differences in (i) the number of distinct expiration months a year or (ii) the maximum time-to-maturity. Energy and industrial metal commodities have an expiring futures contract each month and also contracts with long dated maturities. In contrast, agricultural commodities have a small number of active futures because they have only five to eight distinct expiry months a year. Furthermore, the maximum maturity of these contracts is between one and two years, which is in line with the length of their crop cycles and storability of these commodities. The variation in 
the number of contracts and the maximum time to maturity indicate that it is important to use a commodity specific decay parameter $\lambda_{i}$ in (2). Besides differences in the number of available contracts across commodities, we notice the same within commodities over time. Especially the number of contracts for energy and industrial metal commodities greatly increases over our 17 years sample. Even though our estimation methods can deal with this increase of available contracts over time, our choice to use a fixed $\lambda$ parameter limits the model flexibility. Instead of allowing $\lambda$ to vary over time (see e.g. Koopman, Mallee, and Van der Wel, 2010), we choose to introduce a maturity bound to exclude longdated contracts. By limiting the term-structure dimension variation within a commodity, we can keep using a fixed $\lambda$ value. Furthermore, these long-dated contracts are possibly less liquid and hence have more noisy price information, which could otherwise affect our results. The introduced maturity bound excludes on average $10 \%$ of our observations. ${ }^{10}$

The summary statistics in Table 1 show that there are large return differences both across commodities and along their futures curves. The returns of the contracts range between $-20.6 \%$ to $20.5 \%$ and are more extreme for the first nearby contract. The volatility of the returns confirms this as in almost all cases the 12 month contract returns are less volatile than the returns of the first nearby contract, also known as the Samuelson (1965) effect.

\footnotetext{
${ }^{10}$ Appendix B provides additional details on the introduced maturity bound.
} 


\section{Figure 1 Commodity futures curves}

These figures gives insight in the data by showing the complete set of available futures prices for natural gas and coffee. The figures show the commodity futures curves at each month in time.

(a) Natural gas

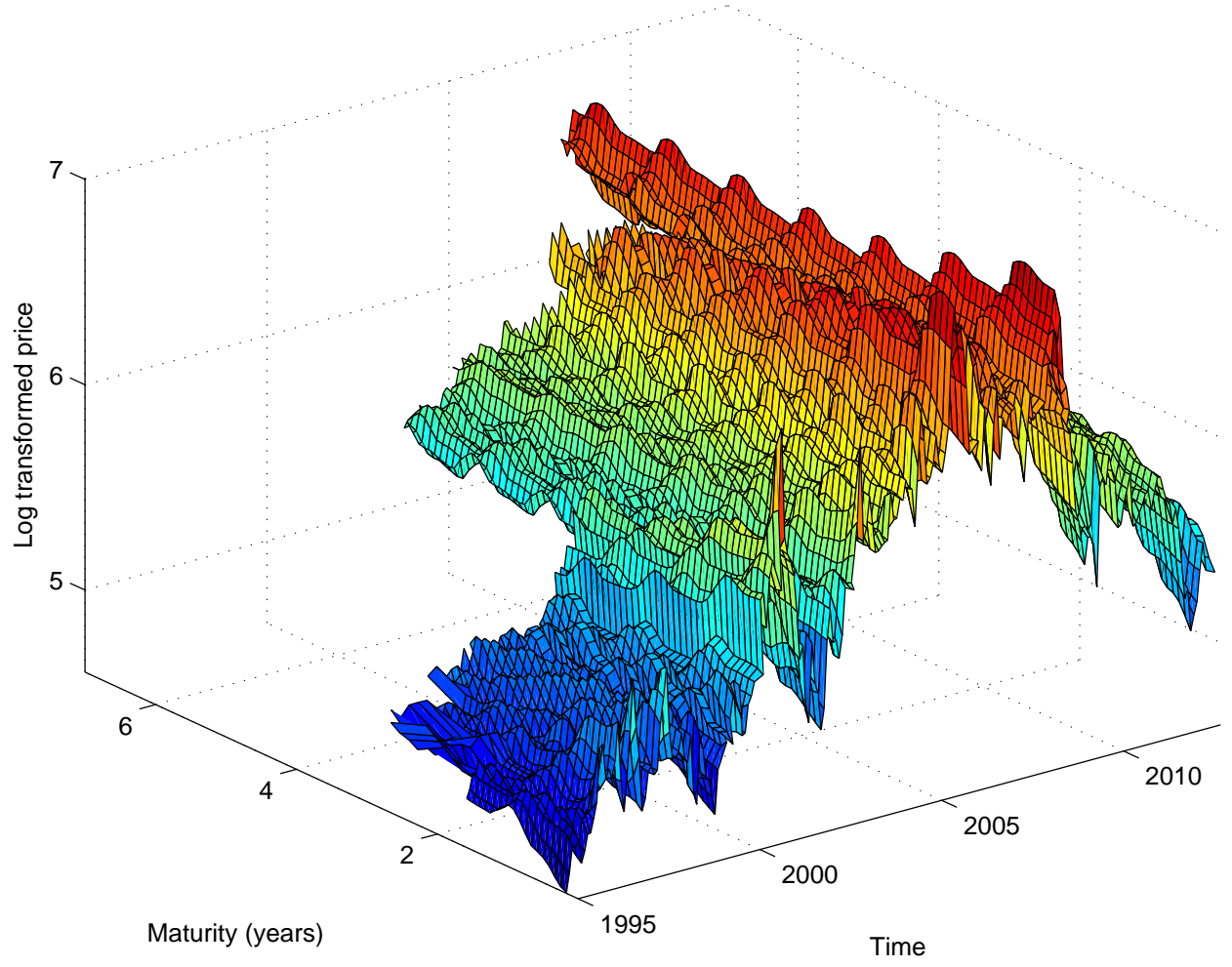

(b) Coffee

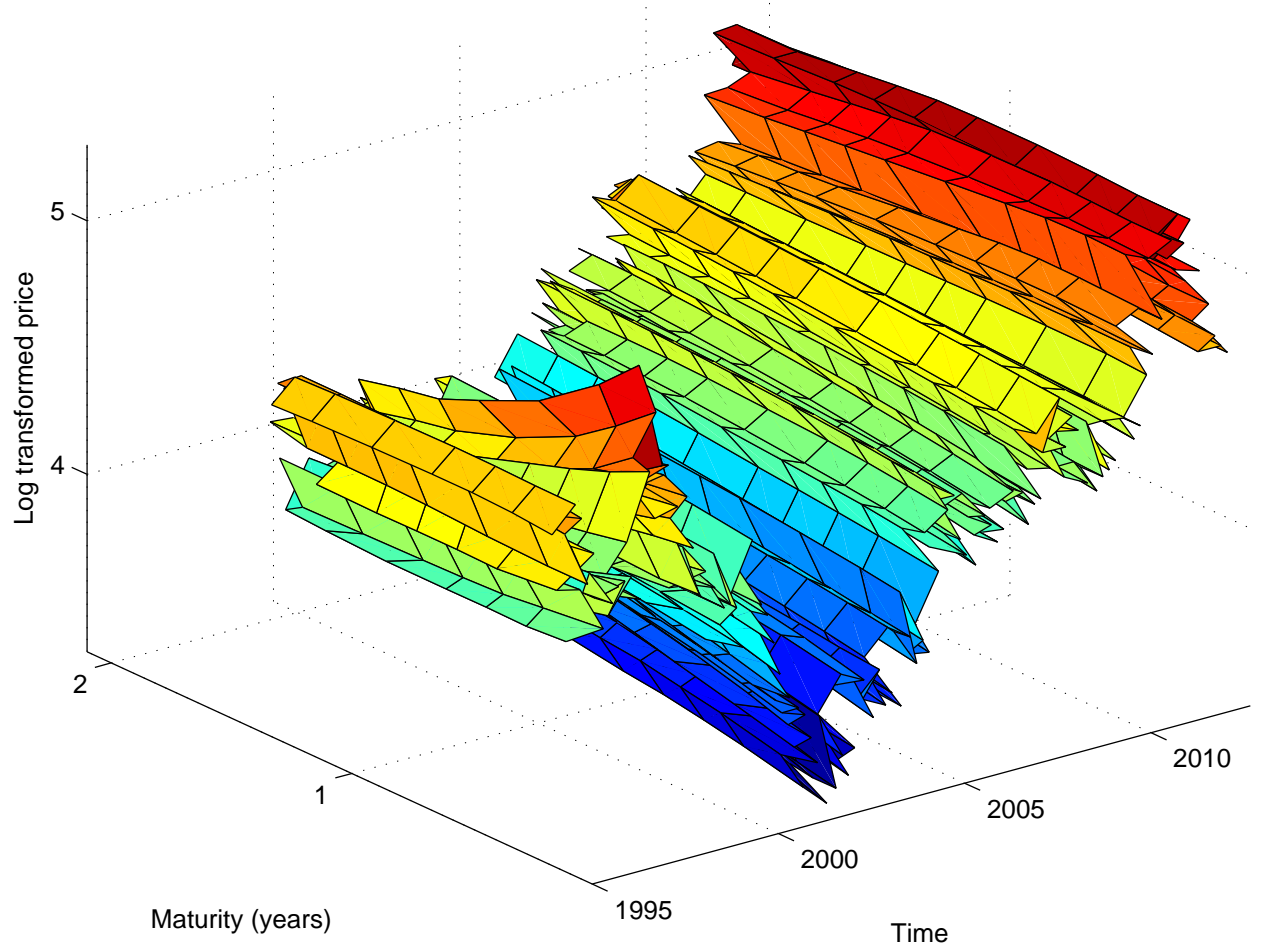


Figure 1 gives some insight in the data we use by showing the complete set of available futures prices for natural gas and coffee. For both commodities we observe that the shape of the futures curve varies substantially over time, with alternating periods of pronounced contango and backwardation especially for natural gas. ${ }^{11}$ Both futures curves also clearly show the large increase in the general price level during the period 2005-2008. A notable difference between these commodities is that the futures curve of natural gas displays a strong periodic pattern with spikes occurring for expiry months during the winter, while the curve of coffee does not show any signs of seasonality. Finally, Figure 1 illustrates that the number of available contracts varies over time. For both natural gas and coffee (and in fact also for most other commodities), contracts with longer maturities only have become available in the most recent years of our sample period.

\section{Individual commodity results}

Before we estimate the full market-wide state space model, we start with analyzing the individual commodities separately. We apply our Nelson-Siegel set-up to each individual commodity, i.e. we leave out the market-wide and sector components in (3). We decide on the exact model specification to be used for each commodity based on the parameter estimates and the extracted factors. Furthermore, we show that our framework is suitable for modeling commodity futures data and compare our unobserved level and slope factors with the latent spot price and convenience yield in the Schwartz (1997) three-factor model.

\subsection{Estimation results individual factors}

In Section 2, we presented the model in general form, where all commodity curves are built up from a level, slope, and curvature factor combined with a seasonal term. However, not all commodity curves may show dynamics for which the flexibility of three factors is needed. Furthermore, not necessarily all commodities display periodic behavior. Based

\footnotetext{
${ }^{11}$ An upward sloping commodity futures curve is said to be in contango, while a downward sloping curve is in backwardation.
} 
on the features of each specific commodity we decide on the number of factors to include and whether to include the seasonal term or not.

\section{Table 2 Individual commodity state space results}

The table presents the estimation results and the fit of the individual commodity state space models. We show the final specification we use for each individual commodity, whereby $2 \mathrm{~F}$ stands for a model with only a level and slope factor, 3F also includes a curvature factor, and 3FS adds a seasonal correction term. The model fit is shown in terms of $R^{2}$. The estimated parameter values for the decay parameter $\lambda$, the exposure $\kappa$ to the seasonal term, and the most expensive contract expiry month $\theta$, where $\theta=0$ corresponds to January. The last column presents the volatility of errors $\sigma(\nu)$. Standard errors of all estimates are provided between brackets. For models that do not contain a seasonal component, the $\kappa$ and $\theta$ parameters are irrelevant, which is represented by a horizontal dash.

\begin{tabular}{|c|c|c|c|c|c|c|c|c|c|c|}
\hline \multirow{2}{*}{$\begin{array}{l}\text { Sector } \\
\text { Energy }\end{array}$} & \multirow{2}{*}{$\begin{array}{c}\text { Commodity } \\
\text { Brent crude oil }\end{array}$} & \multirow{2}{*}{$\frac{\text { Model }}{3 \mathrm{~F}}$} & \multirow{2}{*}{$\frac{R^{2}}{99.99 \%}$} & \multicolumn{2}{|c|}{$\lambda$} & \multicolumn{2}{|c|}{$\kappa$} & \multicolumn{2}{|r|}{$\theta$} & \multirow{2}{*}{$\begin{array}{l}\sigma(\nu) \\
0.65 \%\end{array}$} \\
\hline & & & & 1.144 & $(0.01)$ & - & - & 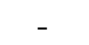 & - & \\
\hline & WTI crude oil & $3 \mathrm{~F}$ & $99.99 \%$ & 1.272 & $(0.01)$ & - & . & - & - & $0.79 \%$ \\
\hline & Gasoil & $3 \mathrm{FS}$ & $99.98 \%$ & 1.688 & $(0.04)$ & 0.92 & $(0.02)$ & 0.4 & $(0.00)$ & $1.03 \%$ \\
\hline & Heating oil & $3 \mathrm{FS}$ & $99.97 \%$ & 3.600 & $(0.03)$ & 2.80 & $(0.01)$ & 0.8 & $(0.00)$ & $1.21 \%$ \\
\hline & Natural gas & $3 \mathrm{FS}$ & $99.40 \%$ & 1.137 & $(0.02)$ & 6.38 & $(0.01)$ & 0.9 & $(0.00)$ & $3.56 \%$ \\
\hline & Gasoline & $3 \mathrm{FS}$ & $99.94 \%$ & 3.285 & $(0.04)$ & 4.78 & $(0.01)$ & 6.2 & $(0.00)$ & $1.52 \%$ \\
\hline \multirow[t]{7}{*}{ Metals } & Gold & $2 \mathrm{~F}$ & $99.99 \%$ & 0.011 & $(6.36)$ & - & - & - & - & $0.44 \%$ \\
\hline & Silver & $2 \mathrm{~F}$ & $99.99 \%$ & 0.026 & $(1.79)$ & - & - & - & - & $0.54 \%$ \\
\hline & Aluminum & $2 \mathrm{~F}$ & $99.91 \%$ & 0.187 & $(0.04)$ & - & - & - & - & $0.77 \%$ \\
\hline & Copper & $2 \mathrm{~F}$ & $99.97 \%$ & 0.111 & $(0.10)$ & - & - & - & - & $1.13 \%$ \\
\hline & Lead & $2 \mathrm{~F}$ & $99.99 \%$ & 0.324 & $(0.13)$ & - & - & - & - & $0.57 \%$ \\
\hline & Nickel & $2 \mathrm{~F}$ & $99.98 \%$ & 0.095 & $(0.28)$ & - & - & - & - & $0.91 \%$ \\
\hline & Zinc & $2 \mathrm{~F}$ & $99.97 \%$ & 0.059 & $(0.19)$ & - & - & - & - & $0.69 \%$ \\
\hline \multirow{4}{*}{ Softs } & $\mathrm{Coco}$ & $3 \mathrm{H}$ & $99.97 \%$ & 1.413 & $(0$. & - & - & - & - & $0.58 \%$ \\
\hline & Coffee & $3 \mathrm{~F}$ & $99.98 \%$ & 1.468 & $(0.03)$ & - & - & - & - & $0.57 \%$ \\
\hline & Cotton & $3 \mathrm{FS}$ & $99.74 \%$ & 3.482 & $(0.03)$ & 0.91 & $(0.06)$ & 5.9 & $(0.01)$ & $1.21 \%$ \\
\hline & Sugar & $3 \mathrm{FS}$ & $99.91 \%$ & 3.272 & $(0.04)$ & 1.13 & $(0.05)$ & 2.5 & $(0.01)$ & $1.32 \%$ \\
\hline \multirow[t]{4}{*}{ Grains } & Corn & $3 F S$ & $99.81 \%$ & 2.743 & $(0.04)$ & 1.80 & $(0.0$ & 5.7 & $(0.00)$ & $1.56 \%$ \\
\hline & Soybeans & $3 \mathrm{FS}$ & $99.89 \%$ & 3.350 & $(0.03)$ & 1.30 & $(0.03)$ & 5.7 & $(0.00)$ & $1.19 \%$ \\
\hline & Chicago whea & $3 \mathrm{FS}$ & $99.84 \%$ & 1.496 & $(0.17)$ & 1.53 & $(0.04)$ & 2.0 & $(0.00)$ & $1.51 \%$ \\
\hline & Kansas wheat & $3 \mathrm{FS}$ & $99.86 \%$ & 2.461 & $(0.08)$ & 1.44 & $(0.05)$ & 2.2 & $(0.01)$ & $1.35 \%$ \\
\hline \multirow[t]{3}{*}{ Meats } & Feeder cattle & $3 \mathrm{FS}$ & $99.91 \%$ & 5.221 & $(0.07)$ & 0.73 & $(0.07)$ & 10.0 & $(0.01)$ & $0.71 \%$ \\
\hline & Lean hogs & $3 \mathrm{FS}$ & $97.80 \%$ & 4.109 & $(0.07)$ & 7.78 & $(0.02)$ & 6.1 & $(0.00)$ & $3.09 \%$ \\
\hline & Live cattle & $3 \mathrm{FS}$ & $99.60 \%$ & 4.487 & $(0.10)$ & 2.32 & $(0.03)$ & 1.9 & $(0.00)$ & $1.29 \%$ \\
\hline
\end{tabular}

Table 2 presents the final model choice and the estimated parameter values for each of the commodities. The final model choice is given in column 3 and is based on several criteria. ${ }^{12}$ First, we compare the results of three factor models with and without seasonal term, to see if the exposure $\kappa$ to the seasonal correction is significantly different from

\footnotetext{
${ }^{12}$ Appendix $\mathrm{C}$ provides more detailed results.
} 
zero. The 13 commodities with the label "3FS" have highly significant $\kappa$ parameters, ranging between 0.73 and 7.78. Most of these commodities have a clear crop cycle, i.e. a seasonal supply, while others, like natural gas, have well-known seasonal demand. We include three factors for all commodities with periodic behavior because even after the seasonal correction their curves display a large variety of shapes. Second, we need to decide if we include a curvature factor for the remaining 11 commodities. Based on Akaike Information Criterion or Bayesian Information Criterion values, we should choose to include all three factors. However, low $\lambda$ values for metal commodities lead to slope and curvature loadings that are highly correlated, which lead to identification problems. Hence, we decide to exclude the curvature factor for the metal commodities.

The fourth column in Table 2 shows the in-sample fit of our models. With the exception of lean hogs all $R^{2}$ values are above $99.7 \%$, which supports the use of the Nelson-Siegel framework for commodity futures prices. Figure 2 shows representative examples of the model fit for three of the 24 commodities. Subfigures A and B correspond to the gold futures curve, Subfigures C and D correspond to the curve of WTI crude oil, while Subfigures $\mathrm{E}$ and $\mathrm{F}$ correspond to natural gas data. The crosses represent the observed price data while the lines correspond to the fitted values of our models. Note that the presented figures are snapshots at one particular point in time. For each of these three commodities, we use a different version of our model. The futures curves of gold are almost straight lines. Hence, we can easily fit the prices with only a level and slope factor and we do not need a curvature factor or a seasonal term. The futures curves of WTI crude oil do not show seasonal patterns but do have a curved shape. In a static case, it would be possible to fit this curve with just a level and a slope factor. However, curves change over time and a two factor model is not flexible enough to cope with these changes. Below in Figure 4 and 5 we show that a three factor model is more suitable. The natural gas futures curve displays a pronounced seasonal pattern. Therefore, we use all three factors (level, slope and curvature) plus a seasonal term. In general our fitted values are close to the real prices, with some exceptions at the short end of the curve. The inclusion of the seasonal term seems an appropriate solution to model the periodic behavior. 


\section{Figure 2 Model fit commodity futures curves}

These figures show example of the fit of our individual models. The crosses represent the observed price data while the lines correspond to the fitted values of our models. The raw prices are first standardized and thereafter we apply a log-transformation. The horizontal axis shows the time to maturity $(\tau)$ in years.

(a) Gold January 2000

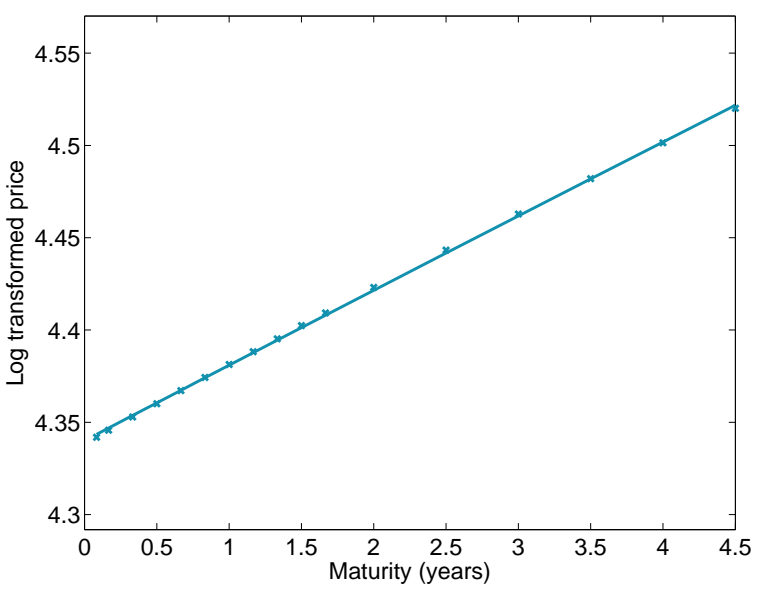

(c) WTI crude oil January 2000

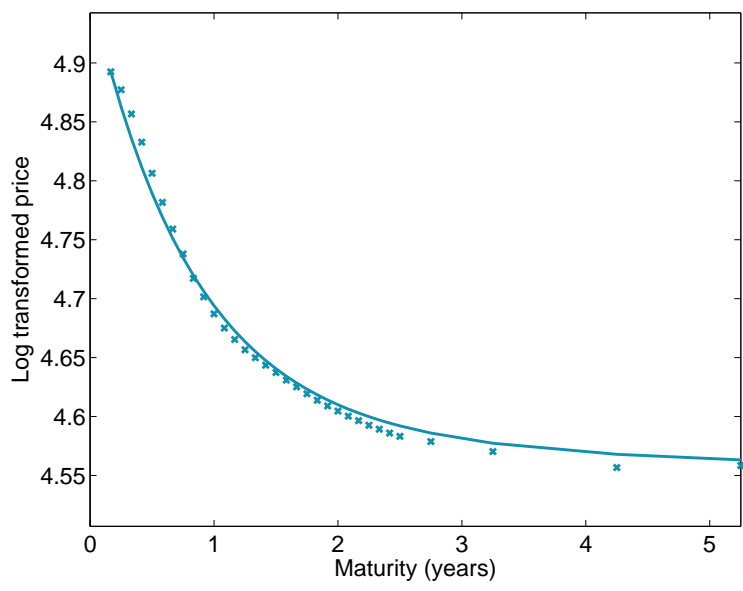

(e) Natural gas January 2000

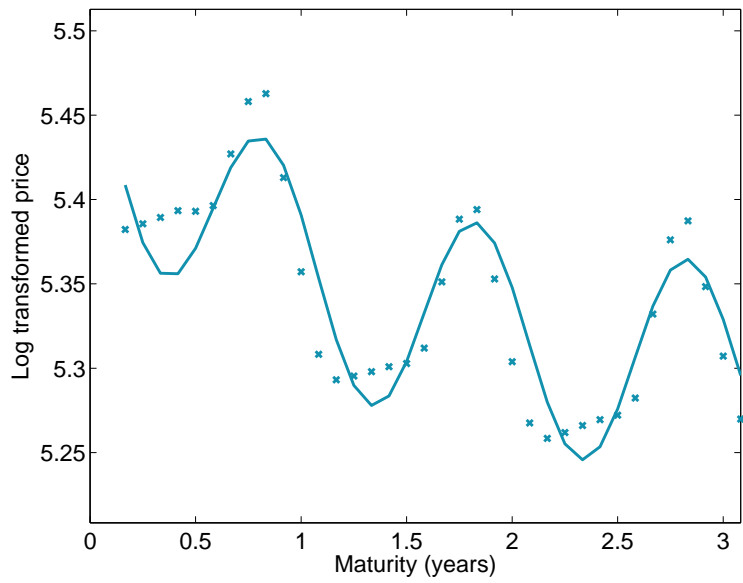

(b) Gold November 2008

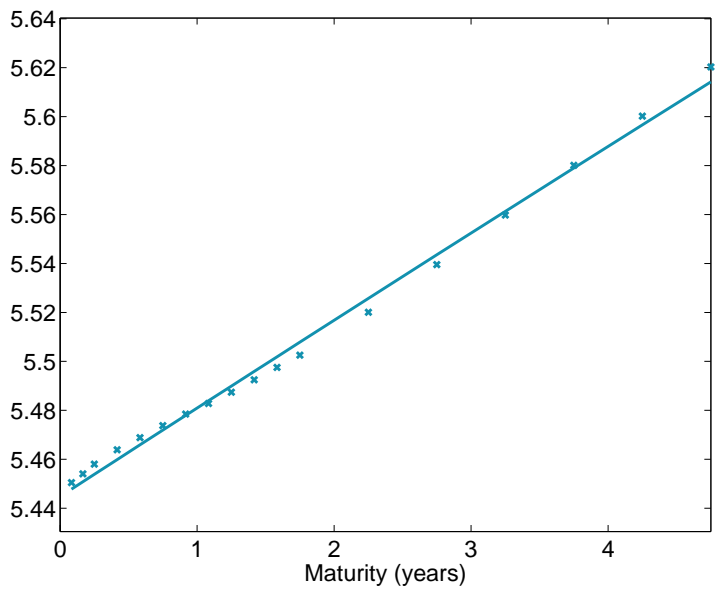

(d) WTI crude oil November 2008

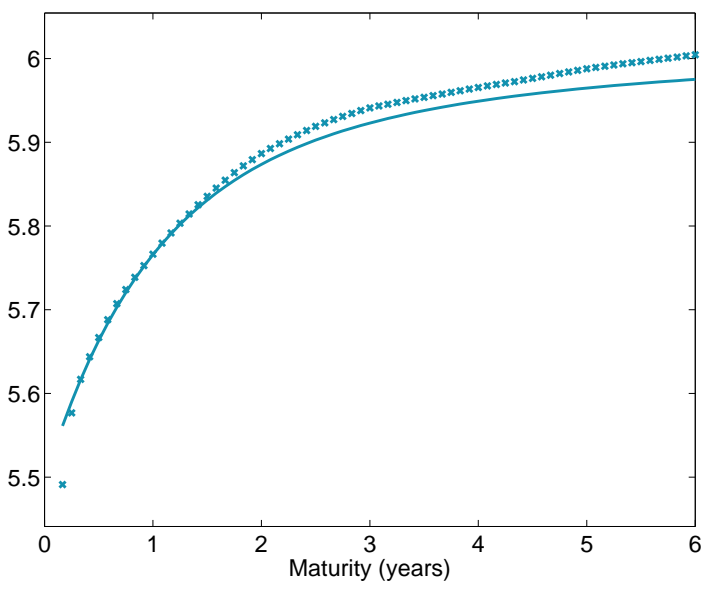

(f) Natural gas November 2008

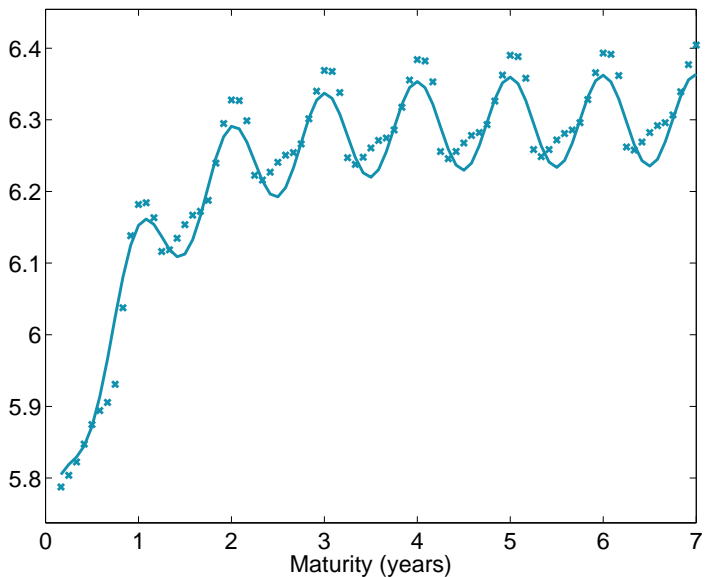


The remaining columns of Table 2 show the parameter estimates with corresponding standard errors. The decay parameter $\lambda$ determines the shape of the slope and curvature loadings. Large values of $\lambda$ lead to quickly declining slope loadings and move the peak of the curvature loadings to the short-end of the curve. When $\lambda=2$, the slope loading starts at 0.49 , it declines to zero for $\tau=1$ (by construction), and is equal to -0.19 and -0.33 , for $\tau=2$ and $\tau=5$ years, respectively. The curvature loading peaks at 11 months maturity. By contrast, when lambda is equal to 0.01 the slope loading starts at 0.005 , it gradually declines towards zero for $\tau=1$, and is equal to -0.005 and -0.020 , for $\tau=2$ and $\tau=5$ years, respectively. The curvature loadings are almost a mirror image of the slope loadings, which is why we exclude the third factor for the metal commodities. The maximum curvature loading (when lambda is equal to 0.01) is achieved for $\tau=179.33$, i.e. 179 years and 4 months, which is way beyond the highest maturity that is included in our sample. The decay parameter $\lambda$ varies substantially across commodities, ranging from 0.011 for gold to 5.2 for feeder cattle. A value of 0.010 is the lowest value we allow to prevent that the loadings of the level and slope factor become too similar. The variation in $\lambda$ is both due to differences in curve shapes and maximum contract maturity. The effect of different futures' curves shapes on $\lambda$ becomes clear when we compare results for commodities with a similar maximum contract maturity. Gasoil and soybeans both have futures up to 2.5 years until maturity, while their $\lambda$ values differ greatly (1.688 versus 3.350 , respectively). Related to the seasonal correction term are the exposure $\kappa$ and the location parameter $\theta$. The $\theta$ estimates imply that gasoil, heating oil and natural gas contracts are most expensive between January and February, while most agricultural commodities are more expensive two months before their harvest. The last column shows the volatility of the errors. The volatilities of the errors are small, especially compared to the highly volatile observed prices. 
Figure 3 Individual models - extracted commodity level factors

These figures show the extracted level factors based on individual models applied to all 24 commodities. Each subfigure shows the estimated level factors for the commodities of a specific sector.

(a) Level - energy

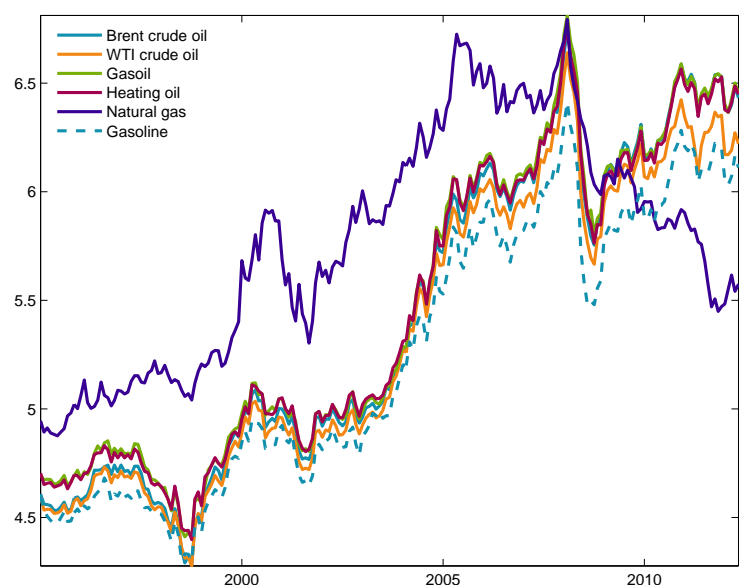

(c) Level - softs

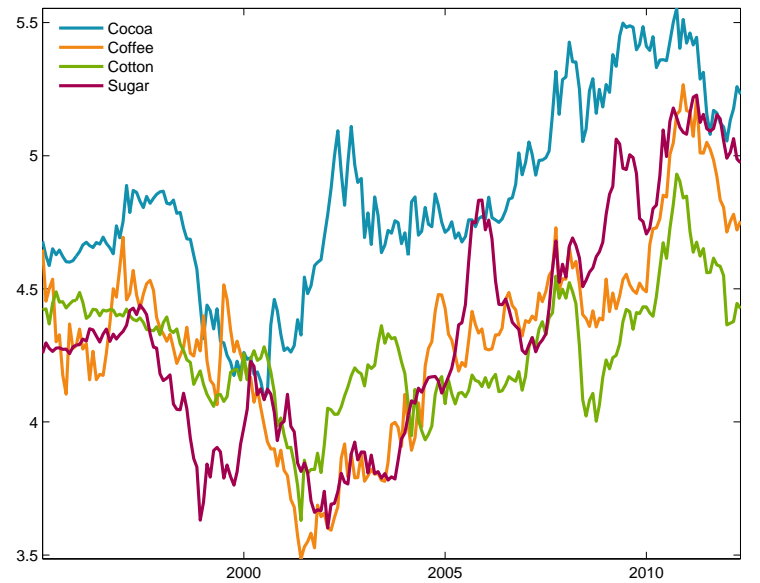

(b) Level - metals

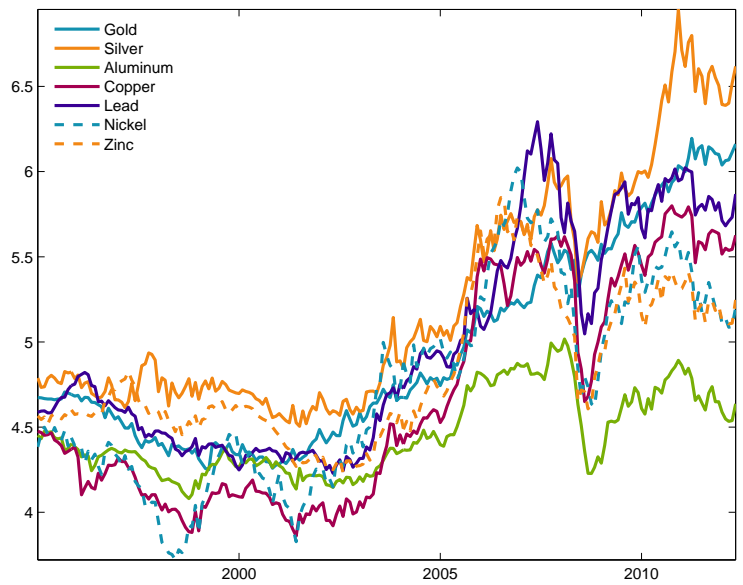

(d) Level - grains

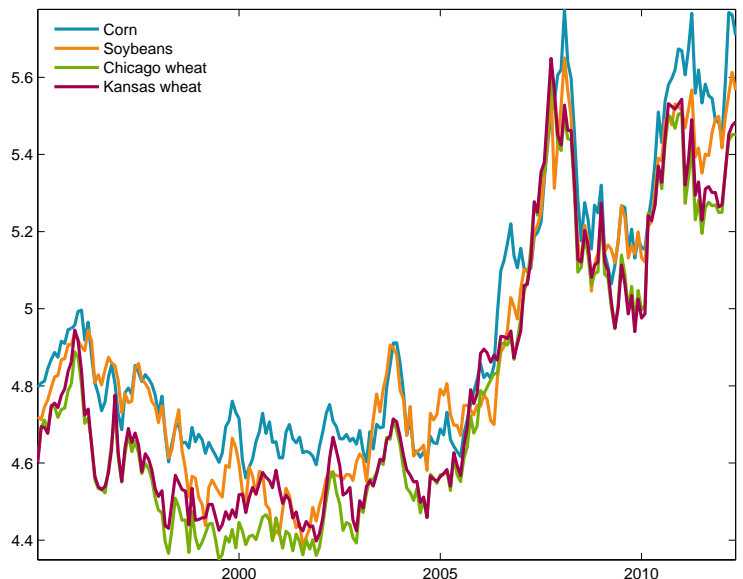

(e) Level - meats

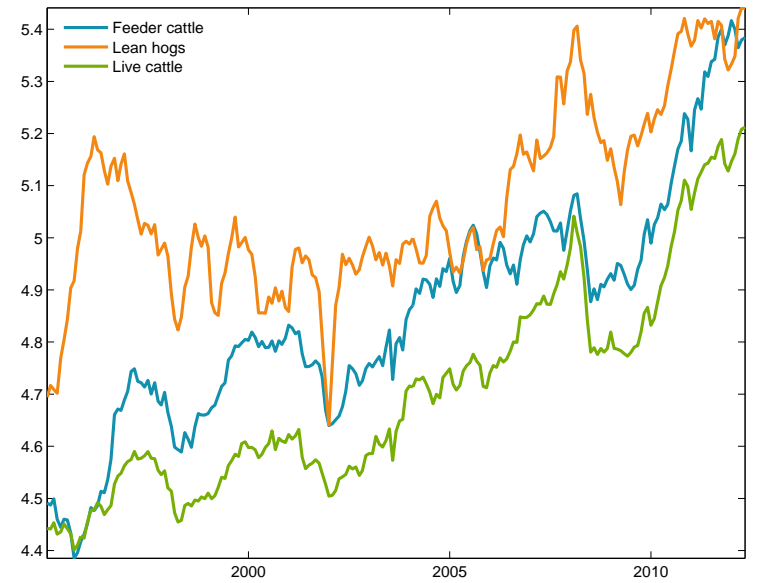


Figure 4 Individual models - extracted commodity slope factors

These figures show the extracted slope factors based on individual models applied to all 24 commodities. Each subfigure shows the estimated slope factors for the commodities of a specific sector.

(a) Slope - energy

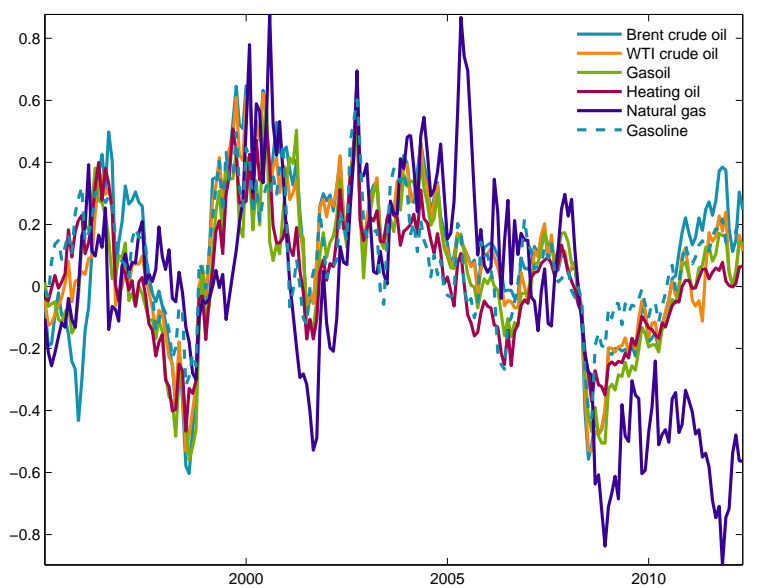

(c) Slope - softs

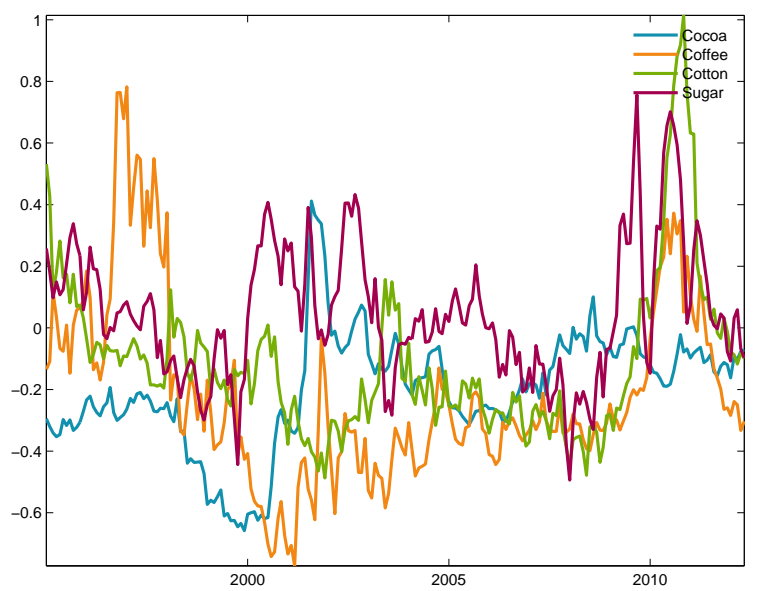

(b) Slope - metals

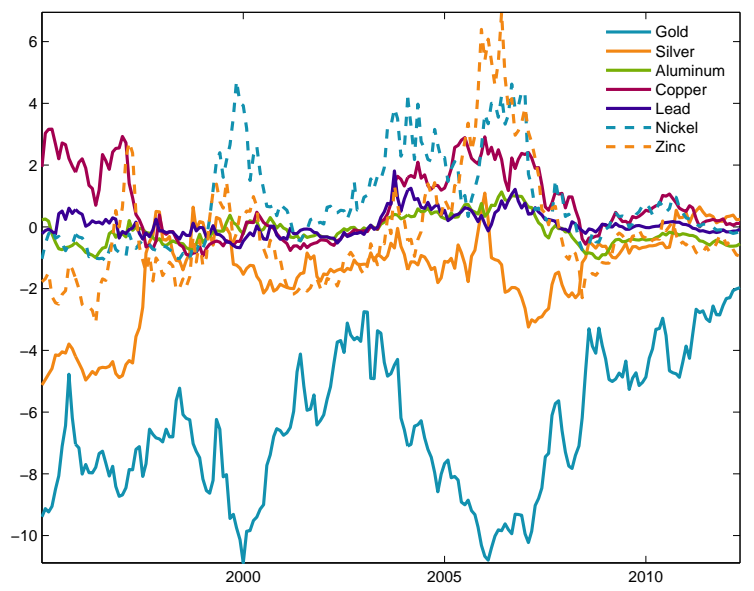

(d) Slope - grains

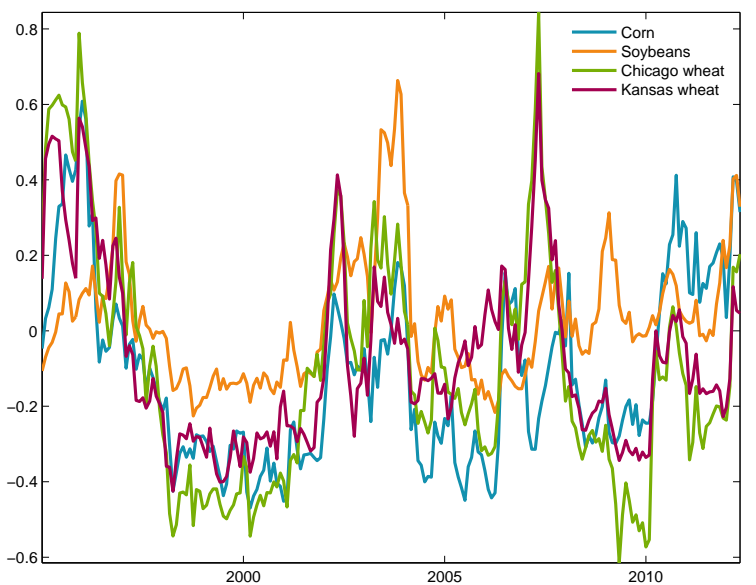

(e) Slope - meats

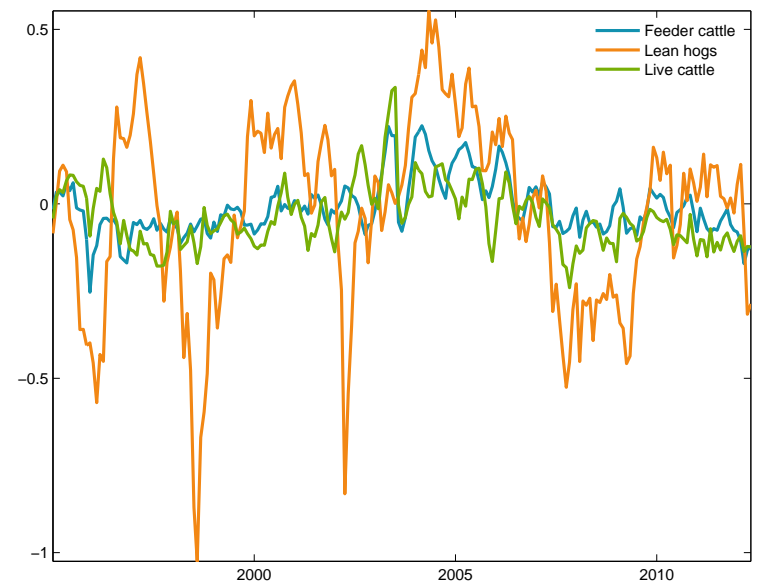


Figure 5 Individual models - extracted commodity curvature factors

These figures show the extracted curvature factors based on individual models applied to all 24 commodities. Each subfigure shows the estimated curvature factors for the commodities of a specific sector.

(a) Curvature - energy

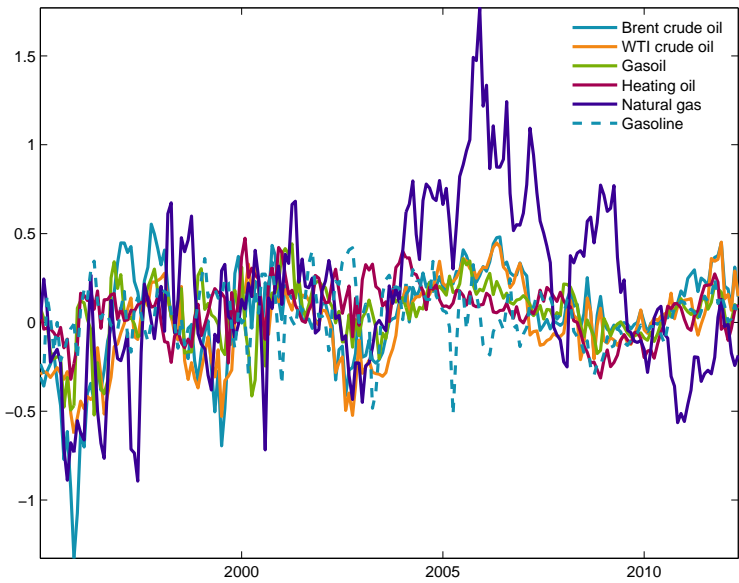

(c) Curvature - grains

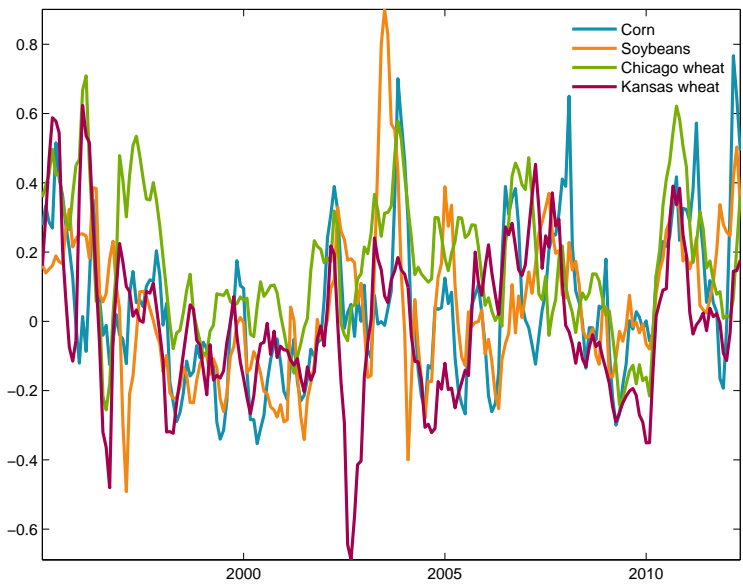

(b) Curvature - softs

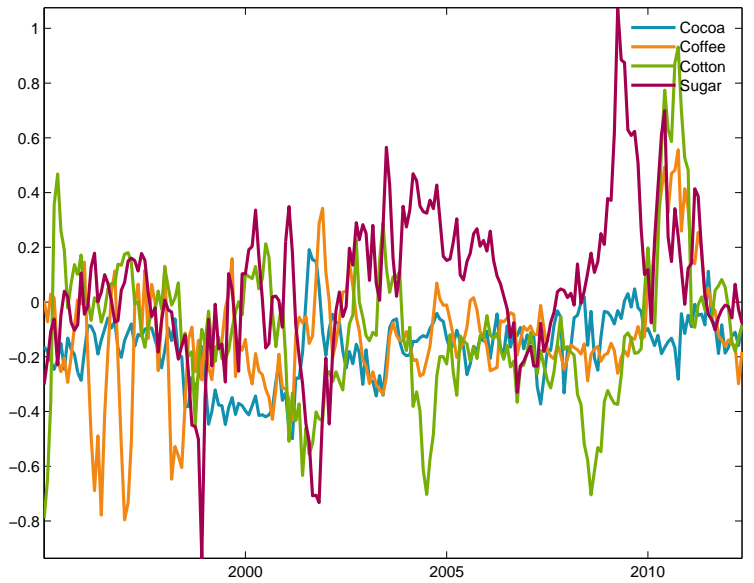

(d) Curvature - meats

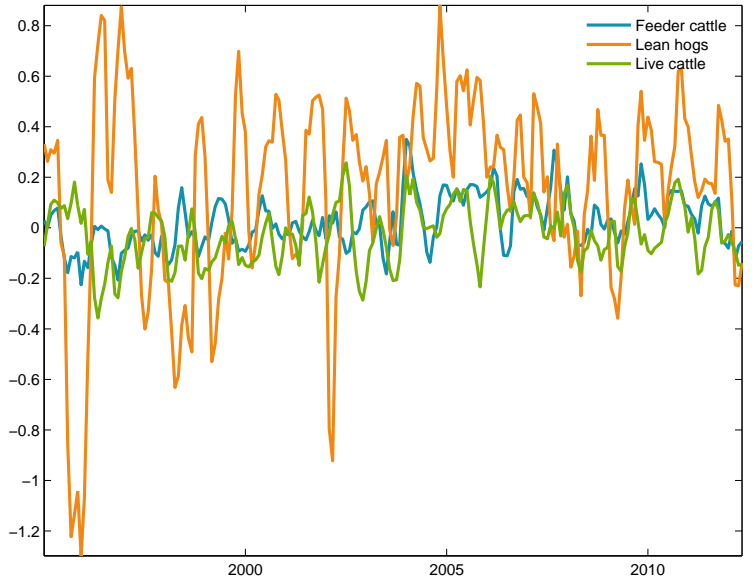

Figures 3, 4, and 5 show the extracted level, slope, and curvature factors per commodity sector. In general, we see a similar pattern in all level factors. Until 2004 they are relatively constant, then they increase until they peak in 2008, whereafter they again remain constant. The level factors within the energy, metals and grains sectors seem to comove the most. The slope factors in Figure 4 show some peaks and troughs. Especially for the energy commodities we see a sharp decline in 2008 and a gradual increase thereafter. As the Nelson-Siegel loading on the slope factor in (2) is a decreasing function of 
maturity, a negative factor estimate signifies an upward sloping (i.e. contangoed) futures curve. This implies that in 2008 all the backwardated energy futures curves quickly went into contango, and only gradually returned back to being backwardated. Last, the curvature factors in Figure 5 show again some degree of comovement. Note that the metal commodities are missing, as we find that two factors are enough to capture their curve dynamics. Of the four sectors the energy commodities have the strongest comoving curvature factors. Based on the plots of the individual factors, there seems to be commonality across commodities. The advantage of our framework is that we can easily accommodate this. ${ }^{13}$

\subsection{Comparison with the Schwartz (1997) three-factor model}

Existing models like in Gibson and Schwartz (1990), Schwartz (1997) and Schwartz and Smith (2000) all begin by assuming a functional form for a set of underlying state variables. The futures curve can be derived from these state variables under no arbitrage conditions. Even though our framework is different, both approaches assume that commodity prices are driven by unobserved factors. Hence it is possible that the extracted unobserved factors from both methods are similar, e.g. through factor rotation. In this section we compare the results of our Nelson-Siegel type model with the three-factor model described in Schwartz (1997).

Extending the model of Gibson and Schwartz (1990), Schwartz (1997) assumes that commodity prices are driven by three stochastic factors namely the commodity spot price, the convenience yield and the interest rate. ${ }^{14}$ Variations on this approach are given by many subsequent papers on commodity prices (see among others Schwartz and Smith, 2000; Casassus and Collin-Dufresne, 2005). Both the log spot price and the convenience yield are assumed to be mean reverting. Also the instantaneous interest rate is assumed to follow a mean reverting process as in Vasicek (1977).

\footnotetext{
${ }^{13}$ As a preliminary approach we apply Principal Component Analysis (PCA) both on all commodities and on subgroups that correspond to the commodity sectors. We find commonality across all commodities and within subgroups. Detailed results are shown in Appendix C

${ }^{14}$ Brennan (1991) defines the convenience yield as "the flow of services which accrues to the owner of a physical inventory but not to the owner of a contract for future delivery"
} 
Schwartz (1997) estimates a simplified version of his three factor model by assuming that the interest rate process is independent of both commodity processes. He first estimates the interest rate parameters and then plugs these into the model. ${ }^{15}$ The loadings on the unobserved log spot price and the instantaneous convenience yield show great resemblance with the loadings on our level and slope factors.

Figure 6 shows the unobserved level factor of our model and the unobserved spot price of the three-factor Schwartz (1997) model, while Figure 7 compares our slope factor with the unobserved convenience yield. Both models are estimated using the same dataset. The similarities are very clear in both figures. The level factor and the spot price both show, in general, an increasing trend with a pronounced dip around the recent financial crisis. The slope and convenience yield factors show more peaks and troughs, which implies upward and downward sloping futures curves. The resemblance of all lines is confirmed by the pair-wise correlations. The average (median) correlation is $0.67(0.79)$ between the level factor and the spot price, and $0.76(0.86)$ between the slope factor and the convenience yield, respectively. Concluding, our statistical factors level and slope are strongly related to the spot price and convenience yield.

Although our level and slope factors show great resemblance with Schwartz' factors, we have an additional third factor, namely curvature. This gives us additional flexibility to better fit the observed futures prices. In terms of $R^{2}$ we increase the model fit by $5.6 \% .{ }^{16}$ When we examine the residuals of the Schwartz (1997) model, we find that for most commodities there is a strong common factor present. These common factors have on average a correlation of 0.20 with our corresponding curvature factors.

\footnotetext{
${ }^{15}$ For the complete model specification we refer to page 933 in Schwartz (1997). The interest rate process is estimated separately from the spot price and convenience yield processes, and is based on an observed 3-month Treasury Bill series. Essentially, this simplified version contains only two unobserved states, while still allowing for a time-varying interest rate. When estimating his model we follow the same estimation methodology.

${ }^{16}$ Additional comparison results are presented in Appendix D.
} 


\section{Figure 6 Comparison level factor and spot price}

These figures show the unobserved level factor of our Nelson-Siegel type models and the unobserved spot price series of the three-factor Schwartz (1997) model. The blue line is the unobserved spot price series and the orange line is our level factor.

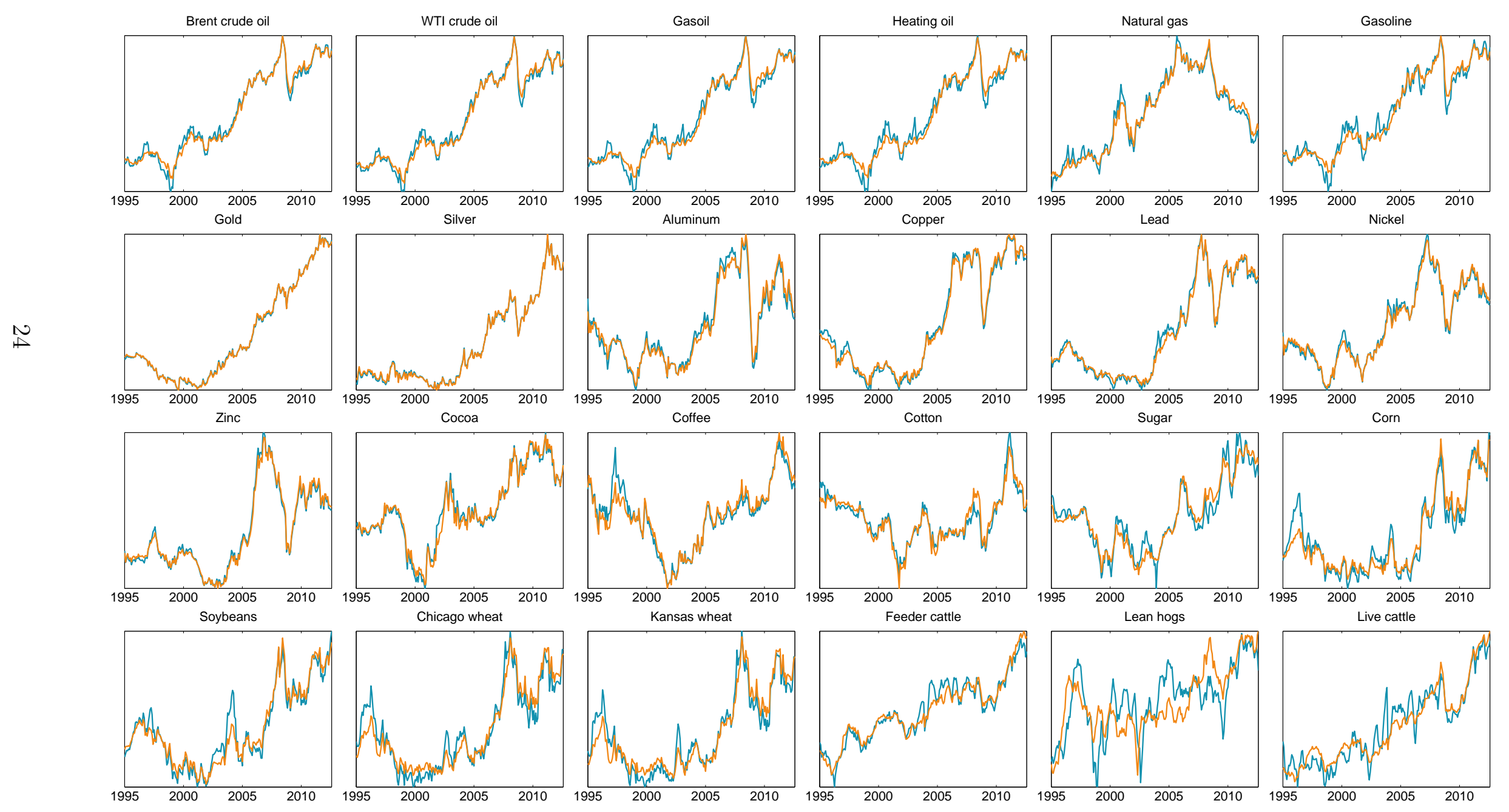


Figure 7 Comparison slope factor and convenience yield

These figures show the unobserved slope factor of our Nelson-Siegel type model and the unobserved convenience yield series of the three-factor Schwartz (1997) model. The blue line is the unobserved convenience yield and the orange line is our slope factor.
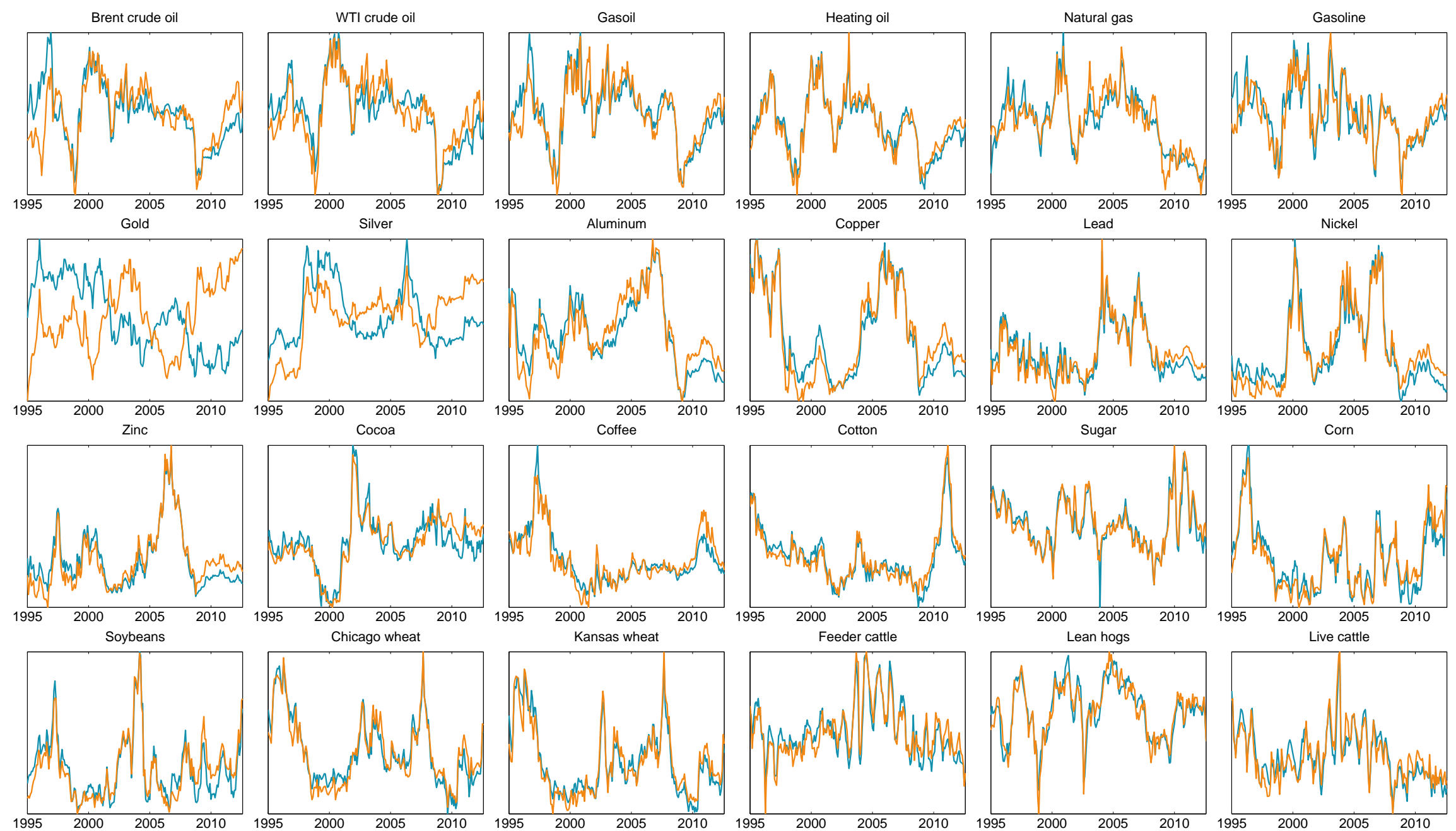


\section{Joint model for commodity curves}

In this section we return to the market-wide state space model given by (2)-(4). First, we discuss the commonality across commodities and investigate the importance of the various components using variance decompositions. Thereafter, we investigate the unobserved factors' dynamics and give an interpretation to the unobserved common components. We end this section with the examination of possible variation in the degree of commonality over time and the importance of term structure information.

\subsection{Commonality results}

When we estimate our full model, we fix the $\lambda, \kappa$, and $\theta$ parameters to their estimates based on commodity specific data. This reduces the computational burden as parts of the measurement equation are now constant. All other parameters are estimated using the Kalman filter and maximum likelihood.

The commonality across commodities is expressed by their loadings on market-wide and sector components, see also (3). Table 3 shows for each commodity level, slope, and curvature factor the estimated constant $\alpha$, the loading on the market-wide component $\beta$, and the loading on the sector component $\gamma$. The $\alpha$-parameters make sure that the idiosyncratic components have mean zero. All $\alpha$ level estimates are between 4 and 5 , due to our standardization procedure, and are highly significant. The $\alpha$ estimates corresponding to slope and curvature are almost all not significantly different from zero. Two noteworthy exceptions are gold and cocoa. The negative $\alpha$ parameter for gold is in line with our expectations because its futures curve is often in contango. 


\section{Table 3 Joint model factor loadings}

The table presents the estimated loadings on various components in our joint model. Each level, slope, and curvature factor is decomposed in a constant part $\alpha$, a market-wide part with loading $\beta$, a sector part with loading $\gamma$, and a commodity specific part. Standard errors of all estimates are provided between brackets. The commodity specific variance estimates, $\sigma_{\nu_{i}}^{2}$, are multiplied by 1,000 for readability reasons. Note that we do not include a curvature factor for the metal commodities, which is represented by a horizontal dash.

\begin{tabular}{|c|c|c|c|c|c|c|c|c|c|c|c|c|c|c|c|c|c|c|c|c|}
\hline \multirow{3}{*}{$\frac{\text { Commodity }}{\text { Brent crude oil }}$} & \multicolumn{6}{|c|}{ Level } & \multicolumn{6}{|c|}{ Slope } & \multicolumn{6}{|c|}{ Curvature } & \multirow{2}{*}{\multicolumn{2}{|c|}{$\begin{array}{c}\text { Variance } \\
\sigma_{\nu_{i}}^{2}\end{array}$}} \\
\hline & \multicolumn{2}{|c|}{$\alpha$} & \multicolumn{2}{|c|}{$\beta$} & \multicolumn{2}{|c|}{$\gamma$} & \multicolumn{2}{|c|}{$\alpha$} & \multicolumn{2}{|c|}{$\bar{\beta}$} & \multicolumn{2}{|c|}{$\gamma$} & \multicolumn{2}{|c|}{$\alpha$} & \multicolumn{2}{|c|}{$\beta$} & \multicolumn{2}{|c|}{$\gamma$} & & \\
\hline & 4.59 & $(0.06)$ & 0.81 & $(0.09)$ & 1.79 & $(0.09)$ & 0.10 & $(0.08)$ & 2.99 & $(0.03)$ & -0.90 & $(0.43)$ & 0.06 & $(0.07)$ & 0.11 & $(4.23)$ & 3.88 & $(0.20)$ & 0.01 & $(0.55)$ \\
\hline WTI crude oil & 4.58 & $(0.06)$ & 0.78 & $0.15)$ & 1.79 & $.10)$ & 0.08 & $(0.08)$ & 2.92 & $(0.18)$ & -0.70 & $(0.43)$ & -0.02 & $(0.06)$ & 0.36 & $(0.79)$ & 3.26 & $(0.23)$ & 0.02 & $(0.34)$ \\
\hline Gasoil & 4.70 & $(0.06)$ & 0.78 & $(0.15)$ & 1.82 & $(0.09)$ & 0.03 & $(0.08)$ & 2.83 & $(0.17)$ & -0.10 & $(0.42)$ & 0.05 & $(0.04)$ & 1.32 & $(0.53)$ & 1.81 & $(0.29)$ & 0.06 & $(0.35)$ \\
\hline Heating oil & 4.69 & $(0.06)$ & 0.75 & $(0.15)$ & 1.78 & $(0.09)$ & 0.02 & $(0.07)$ & 2.44 & $(0.21)$ & 1.25 & $(0.38)$ & 0.07 & $(0.05)$ & 1.34 & $(0.54)$ & -0.54 & $(0.34)$ & 0.12 & $(0.24)$ \\
\hline Natural gas & 4.84 & $(0.07)$ & 0.46 & $(0.16)$ & 0.81 & $(0.09)$ & -0.06 & $(0.11)$ & 1.51 & $(0.39)$ & 1.43 & $(0.15)$ & 0.19 & $(0.13)$ & 0.83 & $(0.86)$ & 0.54 & $(0.64)$ & 1.15 & $(0.04)$ \\
\hline Gasoline & 4.57 & $(0.06)$ & 0.79 & $(0.15)$ & 1.79 & $(0.10)$ & 0.08 & $(0.06)$ & 2.10 & $(0.18)$ & 0.51 & $(0.36)$ & 0.05 & $(0.03)$ & -0.95 & $(0.60)$ & 0.12 & $(0.40)$ & 0.17 & $(0.23)$ \\
\hline Gold & 4.66 & $(0.05)$ & 0.50 & $(0.10)$ & 0.40 & $(0.10)$ & 6.78 & $(1.67)$ & -3.09 & $(1.34)$ & -2.51 & $(1.61)$ & - & - & - & - & - & - & 0.02 & $(0.59)$ \\
\hline Silver & .71 & $(0.08)$ & 1.12 & $(0.17)$ & 0.90 & (0. & 2.12 & $(1.51)$ & -1.60 & $(0.83)$ & 1.30 & $(0.9$ & - & - & - & - & - & - & 0.02 & $(0.53)$ \\
\hline Aluminum & 4.60 & $(0.05)$ & 0.49 & $(0.11)$ & 1.06 & $(0.0$ & -0.15 & $(0.19)$ & 0.30 & $(0.33)$ & 3.26 & $(0.05)$ & - & - & - & - & - & - & 0.03 & 29) \\
\hline Copper & 4.50 & $(0.07)$ & 0.78 & $(0.16)$ & 1.81 & $(0.13)$ & 0.60 & $(0.40)$ & 0.47 & $(0.50)$ & 3.77 & $(0.57)$ & - & - & - & - & - & - & 0.09 & $(0.17)$ \\
\hline Lead & 4.63 & $(0.08)$ & 0.60 & $(0.17)$ & 1.41 & $(0.15)$ & 0.05 & $(0.20)$ & -0.86 & $(0.53)$ & 3.08 & $(0.55)$ & - & - & - & - & - & - & 0.02 & $(0.65)$ \\
\hline Nickel & 4.62 & $(0.09)$ & 0.69 & $(0.21)$ & 1.66 & $(0.1$ & 0.65 & $(0.55)$ & 2.26 & (1.18) & 8.71 & $(1.22)$ & - & - & - & - & - & - & 0.04 & $(0.36)$ \\
\hline Zinc & 4.65 & $(0.07)$ & 0.65 & $(0.16)$ & 1.67 & $(0.13)$ & -0.34 & $(0.86)$ & -0.34 & $(1.34)$ & 13.57 & $(1.49)$ & - & - & - & - & - & - & 0.04 & $(0.35)$ \\
\hline $\mathrm{C}$ & & 0.0 & 0.78 & ) & 0.37 & & 0.20 & $(0.08)$ & -0.17 & $0.12)$ & 0.17 & $(0$. & 0.17 & $(0.03)$ & -0.17 & $(0.33)$ & -0.29 & $(03$ & 0.02 & $1.07)$ \\
\hline Coffee & 4.64 & $(0.08)$ & 0.85 & $(0.18)$ & 0.70 & $(0.21)$ & -0.19 & $(0.11)$ & -0.46 & $(0.25)$ & 3.43 & $(0.03)$ & -0.11 & $(0.06)$ & -0.58 & $(0.53)$ & 0.83 & $(0.56)$ & 0.01 & $(1.34)$ \\
\hline Cotton & 4.42 & $(0.06)$ & 1.02 & $(0.13)$ & 0.54 & $(0.25)$ & -0.06 & $(0.13)$ & -0.10 & $(0.21)$ & -0.31 & $(0.22)$ & -0.10 & $(0.08)$ & -0.67 & $(0.58)$ & 4.29 & $(4.54)$ & 0.17 & $(0.31)$ \\
\hline Sugar & 4.50 & $(0.07)$ & 0.61 & $(0.15)$ & 0.36 & $(0.21)$ & 0.05 & $(0.07)$ & -0.13 & $(0.27)$ & 0.20 & $(0.27)$ & 0.06 & $(0.08)$ & -1.54 & $(0.64)$ & 0.23 & $(0.79)$ & 0.17 & $(0.37)$ \\
\hline Corn & 0 & .0 & 1.65 & 1 & 1 & $(0.26)$ & 0.10 & $(0.1$ & 0.04 & $(0$. & 1.60 & $(0.0$ & 0.06 & $(0.05)$ & -0.57 & $(0$. & 2.79 & $(0$. & 0.26 & (0.2) \\
\hline Soybea & 4.67 & $(0.06)$ & 1.48 & $(0.11)$ & 0.14 & $(0.1$ & 0.03 & $(0.06)$ & 0.05 & $(0.16)$ & 0.90 & $(0.1$ & 0.05 & $(0.05)$ & -1.93 & $(0.66)$ & 2.49 & $(0$. & 0.15 & $(0.29)$ \\
\hline Chicago wheat & 4.53 & $(0.06)$ & 1.34 & $(0.13)$ & 1.42 & $(0.1$ & -0.07 & $(0.12)$ & 0.08 & $(0.27)$ & 3.72 & $(0.22)$ & 0.16 & $(0.05)$ & 2.08 & $(0.71)$ & 3.04 & $(0.52)$ & 0.28 & $(0.27)$ \\
\hline Kansas wheat & 4.52 & $(0.06)$ & 1.32 & $(0.13)$ & 1.42 & $(0.10)$ & -0.05 & $(0.09)$ & 0.10 & $(0.21)$ & 2.61 & $(0.18)$ & -0.00 & $(0.05)$ & 2.78 & $(0.80)$ & 3.73 & $(0.58)$ & 0.23 & $(0.32)$ \\
\hline Feede & 58 & $(0.03)$ & -0.02 & ) & 0 & $(0.0$ & 01 & $(0.1$ & -0.02 & $(0.11)$ & 1 & $(0$. & 0.02 & $(0$ & 0.93 & $(0$. & 0.87 & $(0$ & 0.03 & $(0.9$ \\
\hline & 4.71 & $(0.04)$ & 0.43 & $(0.10)$ & 0.34 & (1) & 0.04 & $(0.07)$ & 0.69 & $(0.33)$ & 0.86 & $(0.3$ & 0.14 & $(0.11)$ & 0.55 & $(1.28)$ & -1.68 & (1. & 1.09 & \\
\hline Live cattle & 4.48 & $(0.02)$ & 0.34 & $(0.05)$ & 0.61 & $(0.04)$ & -0.03 & $(0.03)$ & -0.06 & $(0.15)$ & 1.37 & $(0.25)$ & -0.03 & $(0.03)$ & 1.03 & $(0.48)$ & 3.91 & $(0.39)$ & 0.17 & $(0.39)$ \\
\hline
\end{tabular}


All loadings on the market-wide level component ( $\beta$ 's) are positive (or not significantly different from zero), which indicates that there exists a link between the levels of different commodity prices. The loadings on the market-wide slope component are positive for energy commodities, negative for most of the metal commodities, and close to zero for all other commodities. The loadings on the market-wide curvature component are all very different, ranging from -1.93 to 2.78. Most of them are not significantly different from zero. The loadings on the sector components give more insight in intra-sector commonality. In general, all sector loadings have the same sign within the corresponding sector, which implies commonality. The few slope and curvature loadings that have opposite signs are not significant. In line with previous results, all loadings on common components point in the direction of commonality.

The last column of Table 3 shows the variance estimates of the measurement equation errors. We assume that these variances are commodity specific but within each commodity they are the same for all different contract maturities. We believe this assumption is appropriate because the factor structure can already account for volatility differences along the term-structure dimension due to the time-to-maturity dependent factor loadings. Almost all estimated variances are well below the variances of the factor disturbances.

\section{$5.2 \quad$ Importance of common factors}

The loading estimates indicate that there is commonality across commodities. Using variance decompositions we investigate the importance of the common components. We decompose the variation in commodity level, slope, and curvature factors into parts driven by the market-wide, sector, and idiosyncratic components. As mentioned in Kose, Otrok, and Whiteman (2003) and Diebold, Li, and Yue (2008), the market-wide, sector, and commodity-specific components may be correlated as they are extracted from a finite sample. Hence we orthogonalize the extracted components using a Cholesky decomposi- 
tion to ensure that they add up. ${ }^{17}$ Then, we can use (3) to write

$$
\begin{aligned}
\operatorname{var}\left(\Delta l_{i, t}\right) & =\left(\beta_{i}^{L}\right)^{2} \operatorname{var}\left(\Delta L_{\text {market-wide }, t}\right)+\left(\gamma_{i}^{L}\right)^{2} \operatorname{var}\left(\Delta L_{\text {sector }, t}\right)+\operatorname{var}\left(\Delta L_{i, t}\right), \\
\operatorname{var}\left(s_{i, t}\right) & =\left(\beta_{i}^{S}\right)^{2} \operatorname{var}\left(S_{\text {market-wide, },}\right)+\left(\gamma_{i}^{S}\right)^{2} \operatorname{var}\left(S_{\text {sector }, t}\right)+\operatorname{var}\left(S_{i, t}\right), \\
\operatorname{var}\left(c_{i, t}\right) & =\left(\beta_{i}^{C}\right)^{2} \operatorname{var}\left(C_{\text {market-wide }, t}\right)+\left(\gamma_{i}^{C}\right)^{2} \operatorname{var}\left(C_{\text {sector }, t}\right)+\operatorname{var}\left(C_{i, t}\right) .
\end{aligned}
$$

For the level factors we decompose the variances of the first differenced series as the variance of a non-stationary series is undefined. The fraction of, e.g., the WTI crude oil level factor variance driven by the market-wide component is given by

$$
\frac{\left(\beta_{W T I}^{L}\right)^{2} \operatorname{var}\left(\Delta L_{\text {market-wide, },}\right)}{\operatorname{var}\left(\Delta l_{\text {WTI }, t}\right)}
$$

The fractions of explained variance per component are shown in Table 4. The marketwide level component explains on average $23.3 \%$ of the variance of the commodity level factors, while the sector component explains 38.6\%. However, the differences across commodities are large. For example, in the case of feeder cattle the market-wide component explains close to nothing of its level variation while for corn the market-wide component explains $72.1 \%$ of its variation. Overall, the market-wide component explains quite some variation of the silver, softs and grains levels. The energy sector component explains around $65 \%$ of all energy commodities, except natural gas. Similar observations can be made for the metal commodities (precious metals versus industrial metals) and the grain commodities (wheat versus corn and soybeans).

\footnotetext{
${ }^{17}$ We put the market-wide component first, followed by the sector component, and last the idiosyncratic component.
} 


\section{Table 4 Variance decompositions}

The table presents the percentage of explained variation of the level, slope and curvature factors by the market-wide, sector, and idiosyncratic components. As the level factors are non-stationary, their analysis is done on first differences.

\begin{tabular}{crrrrrrrrr}
\hline & \multicolumn{3}{c}{$\Delta$ Level } & \multicolumn{3}{c}{ Slope } & \multicolumn{3}{c}{ Curvature } \\
\hline Commodity & Market & Sector & Idio. & Market & Sector & Idio. & Market & Sector & Idio. \\
\hline Brent crude oil & $13.5 \%$ & $65.8 \%$ & $20.7 \%$ & $83.2 \%$ & $7.5 \%$ & $9.3 \%$ & $0.1 \%$ & $93.7 \%$ & $6.2 \%$ \\
WTI crude oil & $12.6 \%$ & $66.6 \%$ & $20.8 \%$ & $85.1 \%$ & $4.9 \%$ & $10.0 \%$ & $1.1 \%$ & $90.4 \%$ & $8.5 \%$ \\
Gasoil & $12.3 \%$ & $67.3 \%$ & $20.5 \%$ & $88.8 \%$ & $0.1 \%$ & $11.1 \%$ & $28.8 \%$ & $54.6 \%$ & $16.6 \%$ \\
Heating oil & $11.9 \%$ & $66.9 \%$ & $21.3 \%$ & $69.8 \%$ & $18.4 \%$ & $11.7 \%$ & $58.0 \%$ & $9.5 \%$ & $32.5 \%$ \\
Natural gas & $11.2 \%$ & $35.1 \%$ & $53.7 \%$ & $43.0 \%$ & $38.4 \%$ & $18.6 \%$ & $34.5 \%$ & $15.0 \%$ & $50.5 \%$ \\
Gasoline & $12.9 \%$ & $66.3 \%$ & $20.8 \%$ & $77.8 \%$ & $4.5 \%$ & $17.7 \%$ & $47.1 \%$ & $0.8 \%$ & $52.1 \%$ \\
\hline Gold & $17.9 \%$ & $11.6 \%$ & $70.5 \%$ & $56.8 \%$ & $37.4 \%$ & $5.8 \%$ & - & - & - \\
Silver & $40.6 \%$ & $26.7 \%$ & $32.7 \%$ & $50.1 \%$ & $32.7 \%$ & $17.2 \%$ & - & - & - \\
Aluminum & $10.2 \%$ & $47.9 \%$ & $42.0 \%$ & $0.8 \%$ & $90.7 \%$ & $8.5 \%$ & - & - & - \\
Copper & $12.3 \%$ & $67.1 \%$ & $20.6 \%$ & $1.5 \%$ & $92.2 \%$ & $6.3 \%$ & - & - & - \\
Lead & $10.6 \%$ & $59.5 \%$ & $29.8 \%$ & $6.7 \%$ & $84.4 \%$ & $8.9 \%$ & - & - & - \\
Nickel & $11.4 \%$ & $64.9 \%$ & $23.7 \%$ & $6.3 \%$ & $92.5 \%$ & $1.2 \%$ & - & - & - \\
Zinc & $10.0 \%$ & $66.3 \%$ & $23.7 \%$ & $0.1 \%$ & $99.4 \%$ & $0.5 \%$ & - & - & - \\
\hline Cocoa & $34.6 \%$ & $8.0 \%$ & $57.4 \%$ & $2.7 \%$ & $2.8 \%$ & $94.4 \%$ & $2.6 \%$ & $7.5 \%$ & $89.9 \%$ \\
Coffee & $32.7 \%$ & $22.0 \%$ & $45.4 \%$ & $1.6 \%$ & $90.7 \%$ & $7.7 \%$ & $16.8 \%$ & $34.2 \%$ & $49.1 \%$ \\
Cotton & $44.3 \%$ & $12.6 \%$ & $43.1 \%$ & $1.0 \%$ & $9.0 \%$ & $90.0 \%$ & $2.3 \%$ & $92.7 \%$ & $5.0 \%$ \\
Sugar & $24.6 \%$ & $8.7 \%$ & $66.7 \%$ & $1.5 \%$ & $3.8 \%$ & $94.7 \%$ & $69.2 \%$ & $1.6 \%$ & $29.3 \%$ \\
\hline Corn & $72.1 \%$ & $1.2 \%$ & $26.7 \%$ & $0.0 \%$ & $71.6 \%$ & $28.4 \%$ & $3.6 \%$ & $85.4 \%$ & $11.0 \%$ \\
Soybeans & $68.2 \%$ & $0.6 \%$ & $31.2 \%$ & $0.1 \%$ & $44.6 \%$ & $55.3 \%$ & $34.1 \%$ & $56.8 \%$ & $9.1 \%$ \\
Chicago wheat & $37.2 \%$ & $41.9 \%$ & $20.9 \%$ & $0.0 \%$ & $93.2 \%$ & $6.8 \%$ & $29.7 \%$ & $63.4 \%$ & $6.9 \%$ \\
Kansas wheat & $36.3 \%$ & $42.7 \%$ & $21.0 \%$ & $0.1 \%$ & $87.0 \%$ & $12.9 \%$ & $34.2 \%$ & $61.4 \%$ & $4.4 \%$ \\
\hline Feeder cattle & $0.0 \%$ & $42.4 \%$ & $57.6 \%$ & $0.0 \%$ & $61.2 \%$ & $38.8 \%$ & $32.9 \%$ & $28.8 \%$ & $38.3 \%$ \\
Lean hogs & $14.3 \%$ & $8.7 \%$ & $76.9 \%$ & $21.5 \%$ & $33.4 \%$ & $45.1 \%$ & $7.3 \%$ & $68.6 \%$ & $24.1 \%$ \\
Live cattle & $7.7 \%$ & $24.6 \%$ & $67.7 \%$ & $0.1 \%$ & $65.3 \%$ & $34.6 \%$ & $6.1 \%$ & $88.1 \%$ & $5.8 \%$ \\
\hline & & & & & & & & &
\end{tabular}

The variance decomposition results for the slope factor are again diverse. The marketwide, sector, and idiosyncratic components explain on average $24.9 \%, 48.6 \%$, and $26.5 \%$, respectively, of the commodities' slope factors. The market-wide component explains more than $70 \%$ of the energy commodities slope variation, with the exception of natural gas. Also the precious metals are driven by a common market component for more than $50 \%$. All other slope factors are mostly explained by a sector component, except for cocoa, cotton, sugar and soybeans.

The market-wide curvature component explains on average $24.0 \%$ of the commodities' curvature factors, although there is no clear pattern in these results. The energy sector component is mostly tilted towards crude oils and gasoil. For the soft commodities the 
idiosyncratic component explain on average most of the variation, while for the grains and meats it is the sector curvature component.

The variance decomposition results indicate that $61.9 \%$ of the level variation, $73.5 \%$ of the slope variation and $74.2 \%$ of curvature variation is explained by common factors. In all three cases the market-wide component explains a quarter of the variation and the remainder is due to sector commonality.

\subsection{Factor dynamics}

Now we have established that there are common factors that drive commodities futures curves and that these common factors explain a large part of individual commodities variations, we focus on the dynamics of these factors. Table 5 shows the estimates related to the state equations in (4). Recall that we have assumed that both the autoregressive coefficient matrices and the covariance matrices are diagonal. Furthermore, the marketwide, sector and idiosyncratic level components are assumed to be non-stationary. We model their first differences as an AR(1) process. The first three columns in Table 5 show the autoregressive coefficients and the last three columns show the variances of the factor disturbances. Focusing on the market-wide and sector components, all $\phi$ estimates are positive (except for one insignificant grains sector parameter). The slope factors are more persistent than the curvature components. The parameter estimates for the idiosyncratic factors are in line with the corresponding common factors. Most of the level $\phi$ coefficients are not significantly different from zero, which implies that levels evolve as pure random walk processes. The AR parameters of the slope factors range between 0.61 and 0.99 . The only exception is heating oil with an $\mathrm{AR}(1)$ parameter of -0.33 . The curvature factors show similar coefficients as those of the slope factors but are slightly less persistent. 


\section{Table 5 Joint model factor dynamics}

The table presents the dynamics of the unobserved states by showing the parameter estimates of the state equations. The autoregressive parameters are the diagonal elements of the $\Phi$-matrices. All level factors are modeled in first differences due to their non-stationary behavior. The disturbance variances correspond to elements in $\Sigma_{\eta_{y}}$, which are multiplied by 1,000 for readability reasons. Note that the disturbance variances of the market-wide and sector components are fixed for identifications purposes. Note that we do not include a curvature factor for the metal commodities, which is represented by a horizontal dash.

\begin{tabular}{|c|c|c|c|c|c|c|c|c|c|c|c|c|c|}
\hline \multirow{3}{*}{ Sector } & \multirow{3}{*}{$\frac{\text { Factor }}{\text { Market-wide }}$} & \multicolumn{6}{|c|}{ Autoregressive parameters $(\phi)$} & \multicolumn{6}{|c|}{ Disturbance variances } \\
\hline & & \multicolumn{2}{|c|}{$\Delta$ Level } & \multicolumn{2}{|c|}{ Slope } & \multicolumn{2}{|c|}{ Curv. } & \multicolumn{2}{|c|}{$\Delta$ Level } & \multicolumn{2}{|c|}{ Slope } & \multicolumn{2}{|c|}{ Curv. } \\
\hline & & 0.11 & $(0.05)$ & 0.93 & $(0.46)$ & 0.78 & $(0.26)$ & 1.00 & - & 1.00 & - & 1.00 & - \\
\hline & Energy & 0.12 & $(0.04)$ & 0.79 & $(0.22)$ & 0.88 & $(0.29)$ & 1.00 & - & 1.00 & - & 1.00 & - \\
\hline & Metals & 0.12 & $(0.05)$ & 0.96 & $(0.94)$ & - & - & 1.00 & - & 1.00 & - & - & - \\
\hline & Softs & 0.45 & $(0.28)$ & 0.93 & $(0.53)$ & 0.87 & $(0.63)$ & 1.00 & - & 1.00 & - & 1.00 & - \\
\hline & Grains & -0.12 & $(0.06)$ & 0.94 & $(0.54)$ & 0.88 & $(0.35)$ & 1.00 & - & 1.00 & - & 1.00 & - \\
\hline & Meats & 0.05 & $(0.05)$ & 0.88 & $(0.38)$ & 0.72 & $(0.18)$ & 1.00 & - & 1.00 & - & 1.00 & - \\
\hline \multirow[t]{6}{*}{ Energy } & Brent crude oil & -0.07 & $(0.09)$ & 0.92 & $(0.75)$ & 0.83 & $(3.20)$ & 0.11 & $(1.95)$ & 0.20 & $(6.64)$ & 0.03 & $(66.53)$ \\
\hline & WTI crude oil & 0.11 & $(0.07)$ & 0.82 & $(0.32)$ & 0.83 & $(0.23)$ & 0.16 & (1.39) & 0.72 & $(0.97)$ & 4.81 & $(0.23)$ \\
\hline & Gasoil & -0.60 & $(0.15)$ & 0.77 & $(0.20)$ & 0.64 & $(0.14)$ & 0.16 & (1.46) & 1.62 & $(0.50)$ & 13.23 & $(0.19)$ \\
\hline & Heating oil & -0.53 & $(0.16)$ & -0.33 & $(0.37)$ & 0.83 & $(0.24)$ & 0.08 & $(2.72)$ & 0.28 & $(6.88)$ & 12.52 & $(0.21)$ \\
\hline & Natural gas & -0.03 & $(0.05)$ & 0.91 & $(0.40)$ & 0.88 & $(0.32)$ & 3.92 & $(0.22)$ & 19.60 & $(0.12)$ & 53.52 & $(0.11)$ \\
\hline & Gasoline & 0.06 & $(0.06)$ & 0.61 & $(0.12)$ & 0.60 & $(0.11)$ & 0.35 & $(0.88)$ & 5.82 & $(0.21)$ & 34.36 & $(0.12)$ \\
\hline \multirow[t]{7}{*}{ Metals } & Gold & -0.09 & $(0.05)$ & 0.98 & $(2.10)$ & - & - & 1.73 & $(0.33)$ & 299.85 & $(86.52)$ & - & - \\
\hline & Silver & -0.24 & $(0.06)$ & 0.99 & $(2.91)$ & - & - & 4.96 & $(0.20)$ & 133.71 & $(0.09)$ & - & - \\
\hline & Aluminum & 0.01 & $(0.06)$ & 0.85 & $(0.40)$ & - & - & 0.98 & $(0.52)$ & 11.67 & $(0.21)$ & - & - \\
\hline & Copper & 0.09 & $(0.08)$ & 0.97 & $(1.05)$ & - & - & 1.10 & $(0.72)$ & 34.54 & $(0.12)$ & - & - \\
\hline & Lead & 0.04 & $(0.05)$ & 0.82 & $(0.23)$ & - & - & 3.31 & $(0.26)$ & 51.64 & $(0.09)$ & - & - \\
\hline & Nickel & -0.02 & $(0.05)$ & 0.86 & $(0.32)$ & - & - & 5.23 & $(0.20)$ & 205.89 & $(0.20)$ & - & - \\
\hline & Zinc & -0.07 & $(0.07)$ & 0.91 & $(0.53)$ & - & - & 1.67 & $(0.45)$ & 200.08 & $(0.25)$ & - & - \\
\hline \multirow[t]{4}{*}{ Softs } & Cocoa & -0.14 & $(0.06)$ & 0.96 & $(0.81)$ & 0.80 & $(0.21)$ & 5.05 & $(0.21)$ & 2.80 & $(0.28)$ & 8.37 & $(0.21)$ \\
\hline & Coffee & -0.14 & $(0.07)$ & 0.96 & $(0.76)$ & 0.82 & $(0.22)$ & 5.70 & $(0.23)$ & 0.03 & $(31.22)$ & 20.69 & $(0.15)$ \\
\hline & Cotton & -0.12 & $(0.09)$ & 0.96 & $(0.81)$ & 0.82 & $(0.72)$ & 2.17 & $(0.48)$ & 7.85 & $(0.18)$ & 6.87 & $(9.71)$ \\
\hline & Sugar & 0.09 & $(0.05)$ & 0.88 & $(0.30)$ & 0.85 & $(0.26)$ & 3.77 & $(0.24)$ & 13.97 & $(0.13)$ & 28.52 & $(0.14)$ \\
\hline \multirow[t]{4}{*}{ Grains } & Corn & 0.04 & $(0.09)$ & 0.92 & $(0.47)$ & 0.76 & $(0.19)$ & 0.66 & $(1.26)$ & 5.82 & $(0.22)$ & 16.20 & $(0.21)$ \\
\hline & Soybeans & -0.19 & $(0.08)$ & 0.92 & $(0.47)$ & 0.81 & $(0.32)$ & 1.14 & $(0.60)$ & 4.40 & $(0.23)$ & 7.71 & $(0.79)$ \\
\hline & Chicago wheat & -0.25 & $(0.68)$ & 0.89 & $(4.13)$ & 0.88 & $(0.53)$ & 0.01 & $(88.34)$ & 0.03 & $(88.67)$ & 2.79 & $(1.54)$ \\
\hline & Kansas wheat & 0.20 & $(0.09)$ & 0.87 & $(0.32)$ & 0.92 & $(1.63)$ & 0.15 & $(2.77)$ & 1.60 & $(0.61)$ & 0.73 & (12.67) \\
\hline \multirow[t]{3}{*}{ Meats } & Feeder cattle & 0.28 & $(0.21)$ & 0.81 & $(0.43)$ & 0.75 & $(0.18)$ & 0.04 & $(24.97)$ & 0.53 & $(5.93)$ & 6.37 & $(0.28)$ \\
\hline & Lean hogs & 0.12 & $(0.05)$ & 0.88 & $(0.32)$ & 0.80 & $(0.22)$ & 1.26 & $(0.47)$ & 16.42 & $(0.15)$ & 104.90 & $(0.13)$ \\
\hline & Live cattle & 0.29 & $(0.16)$ & 0.82 & $(0.28)$ & 0.69 & (1.63) & 0.02 & (29.99) & 1.94 & (1.08) & 0.18 & (89.28) \\
\hline
\end{tabular}


The right-hand side of Table 5 shows the estimated variances of the factor disturbances. The variances of the common factor disturbances are fixed for identification purposes. The estimates of the idiosyncratic disturbance variance cannot be compared across commodities or factors because the magnitude of the factor loadings is not the same. This can be seen in Appendix A Equation (A.1) where all idiosyncratic states are premultiplied by the matrix $A$, which contains the commodity specific factor loadings. For metal commodities the $\lambda_{i}$ parameter is small, which results in close to zero loadings on the slope factor for most maturities and hence seemingly large error variances.

Figures 8, 9, and 10 show the unobserved level, slope, and curvature factors and their different components. In Subfigure A of each figure we show the market-wide component together with the five sector components. In Subfigures B-F we show the sector components together with the corresponding idiosyncratic commodity components. The market-wide level factor shows an increase in 2006-2007 and 2011, in line with patterns observed in all major commodity indices. The energy and metal sectors show similar behavior although the factors peak at different points in time, in line with subindices like GSCI Energy, Precious Metals and Industrial Metals. The other subfigures show that the scale of the idiosyncratic level factors varies across commodities but is in line with the size of the estimated disturbance variances. The slope factors in Figure 9 show quite some variability. They are both negative and positive, which indicates that the futures curves interchange between contango and backwardation. The scale of the metals' slope factors is large compared to the other commodities due to the $\lambda$-dependent loading correction we have introduced in (2). Last, the curvature factors in Figure 10 show more mean-reversion compared to the slope factors. 
Figure 8 Joint model - extracted commodity level factors

These figures show the extracted level factors of our joint model estimated using all 24 commodities. Subfigure A shows the market-wide and sector components. Subfigures B-F show the estimated idiosyncratic level factors for the commodities of a specific sector.

(a) Level - market-wide

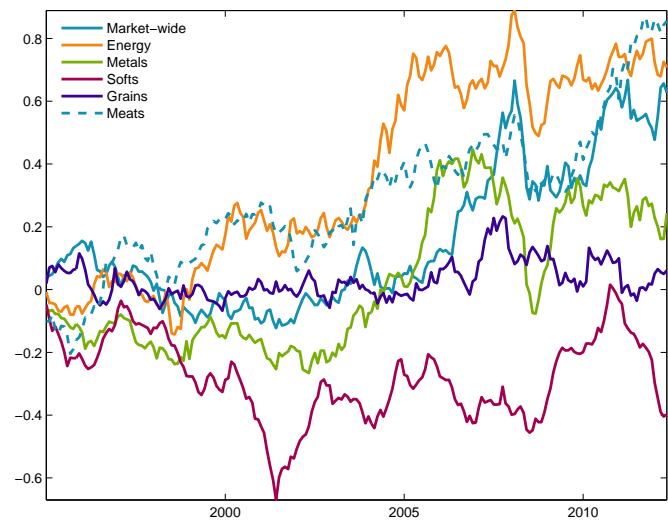

(c) Level - metals

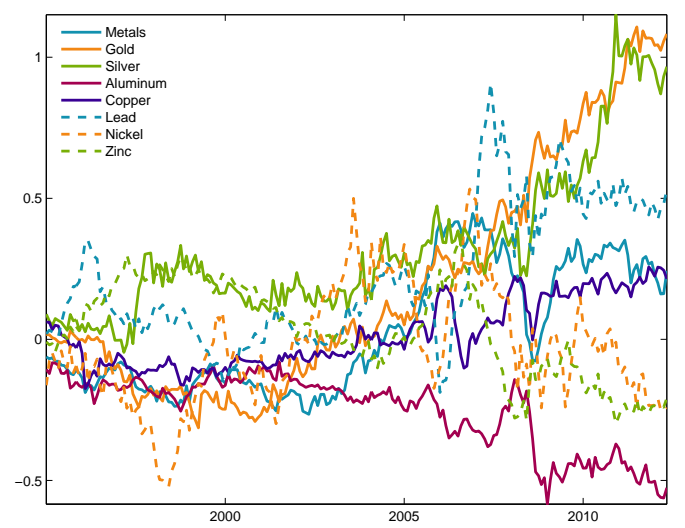

(e) Level - grains

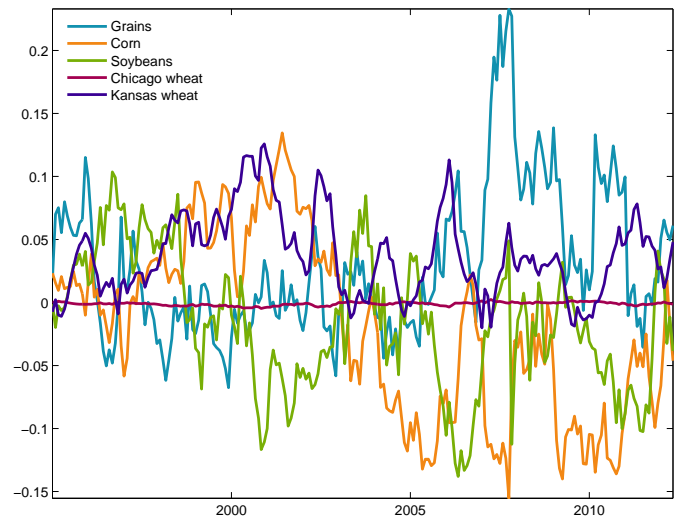

(b) Level - energy

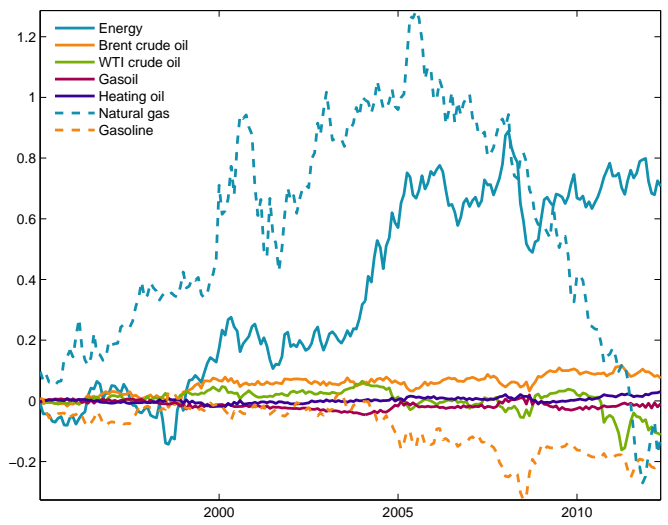

(d) Level - softs

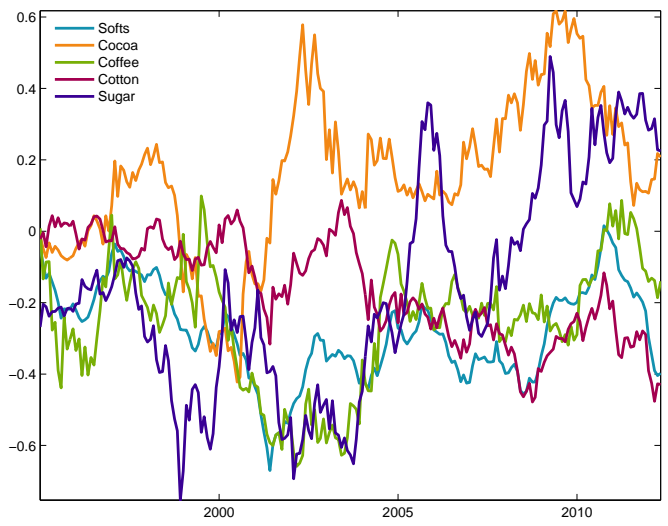

(f) Level - meats

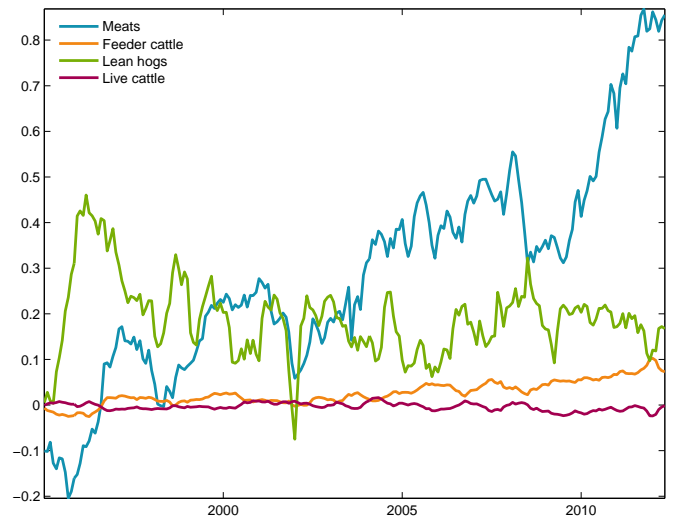


Figure 9 Joint model - extracted commodity slope factors

These figures show the extracted slope factors of our joint model estimated using all 24 commodities. Subfigure A shows the market-wide and sector components. Subfigures B-F show the estimated idiosyncratic slope factors for the commodities of a specific sector.

(a) Slope - market-wide

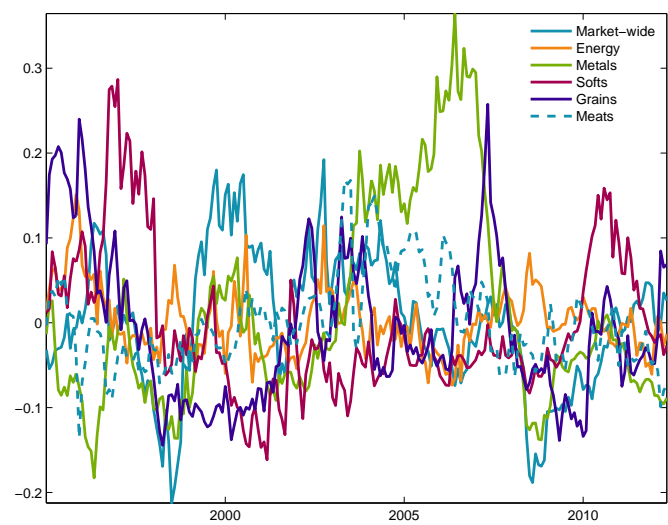

(c) Slope - metals

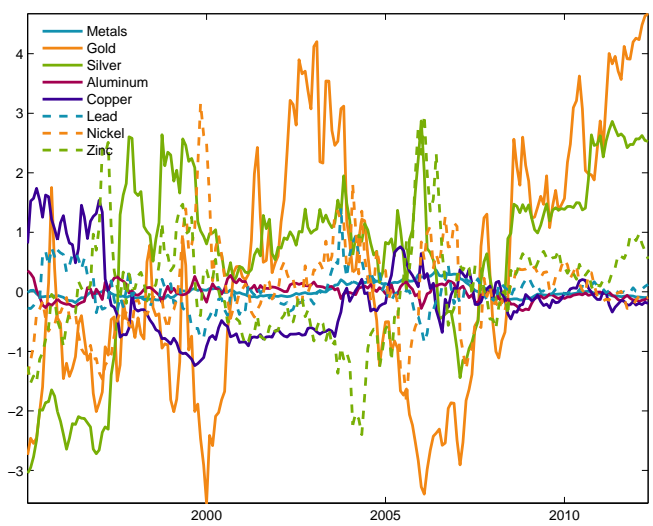

(e) Slope - grains

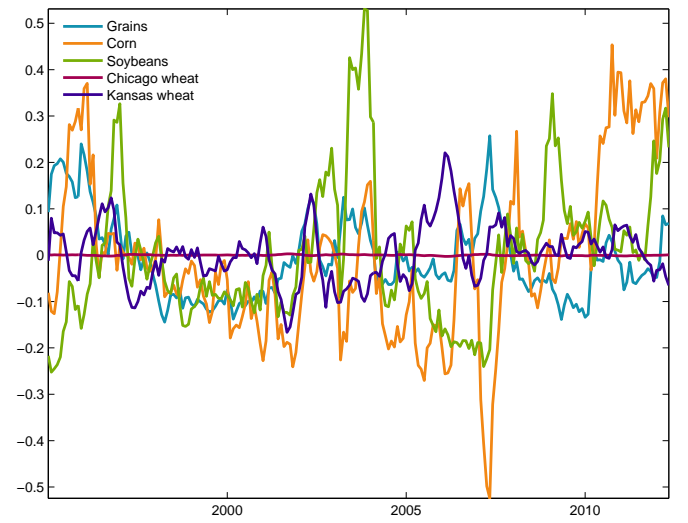

(b) Slope - energy

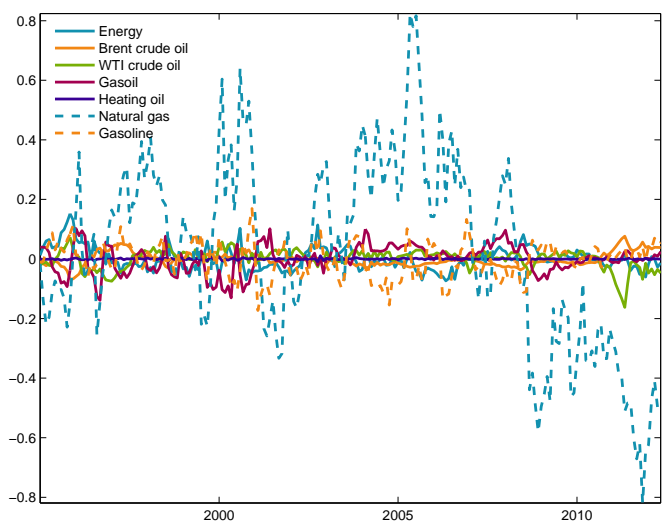

(d) Slope - softs

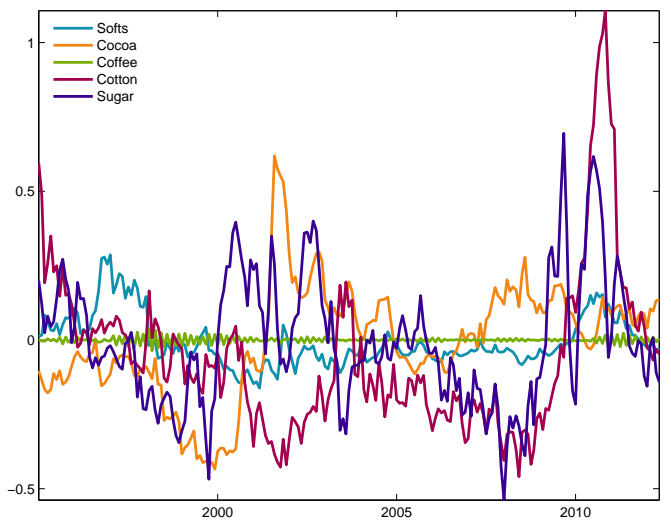

(f) Slope - meats

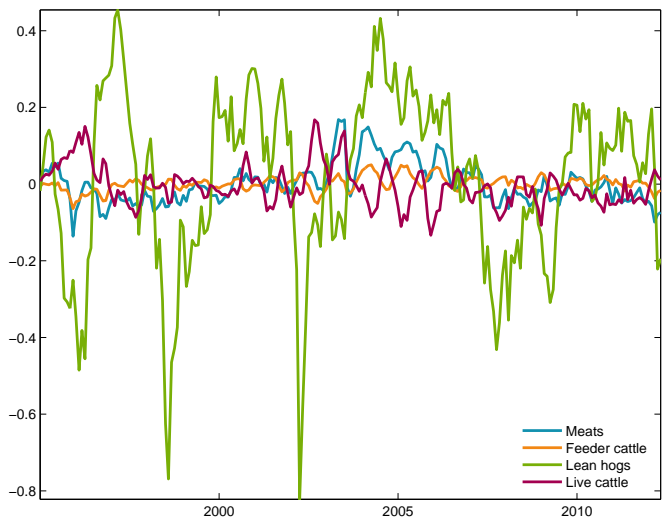


Figure 10 Joint model - extracted commodity curvature factors

These figures show the extracted curvature factors of our joint model estimated using all 24 commodities. Subfigure A shows the market-wide and sector components. Subfigures B-E show the estimated idiosyncratic curvature factors for the commodities of a specific sector. Note that the metal commodities subfigure is missing because we use a two factor model for the metal commodities.

(a) Curvature - market-wide

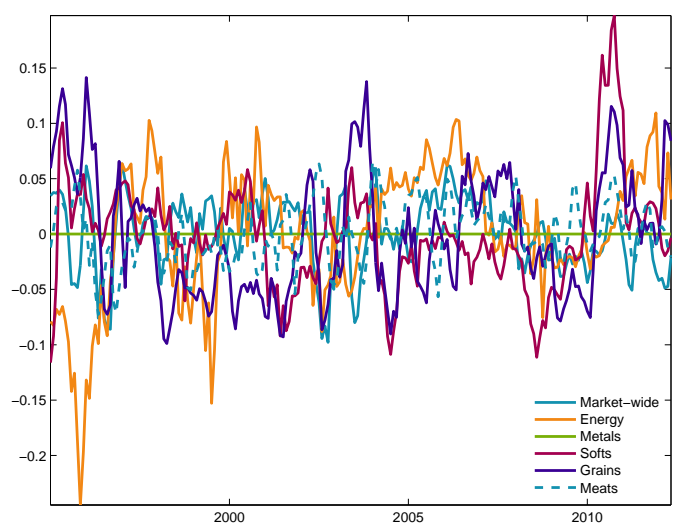

(c) Curvature - softs

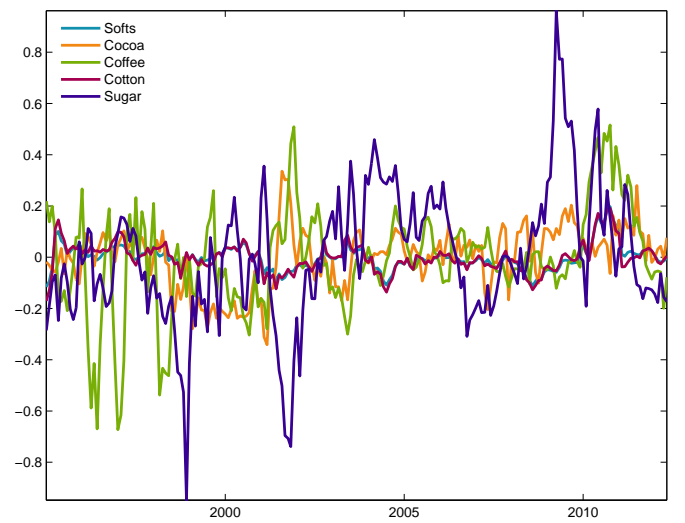

(b) Curvature - energy

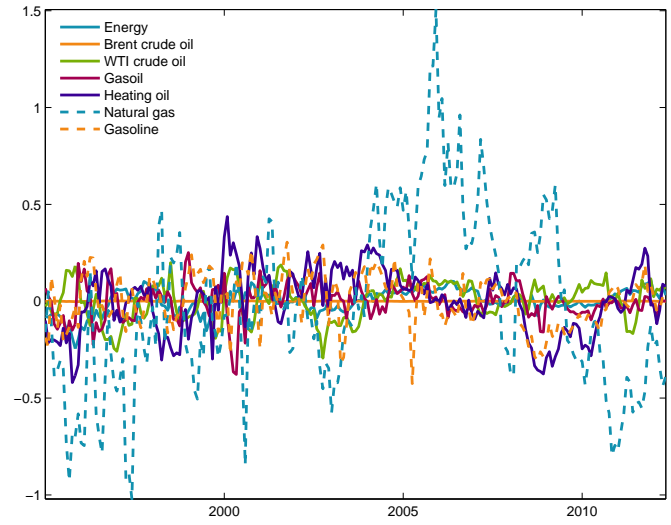

(d) Curvature - grains

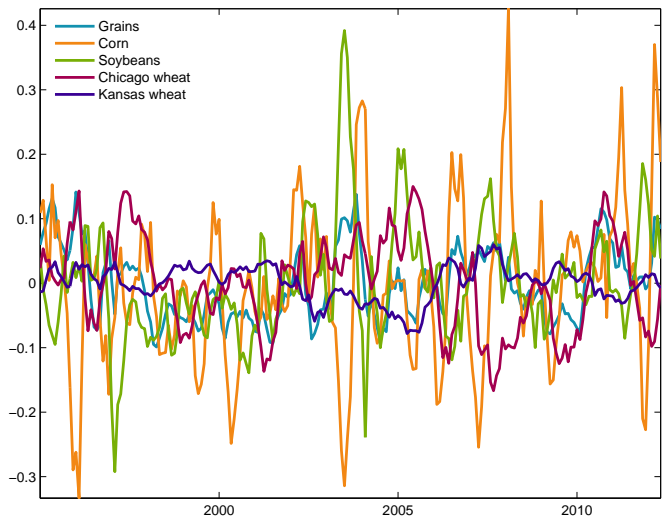

(e) Curvature - meats

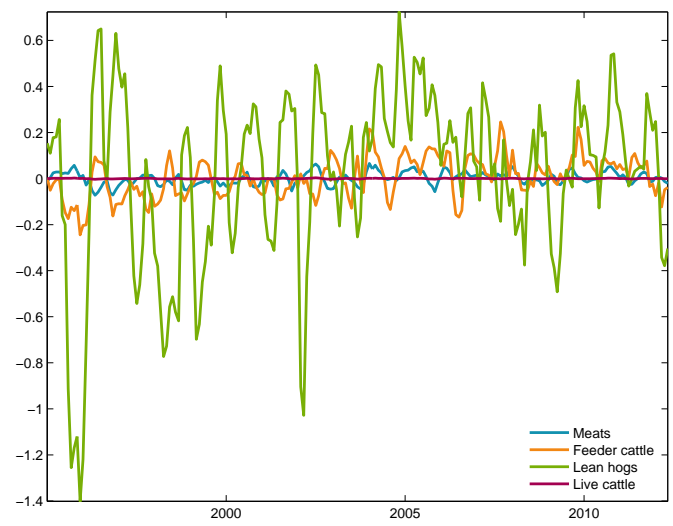




\subsection{Economic interpretation of unobserved states}

We have established that there are common factors in commodities futures curves and these factors explain a substantial part of the variation in level, slope and curvature factors that drive observed futures prices. As these common components are unobserved, it is not straightforward which economic mechanism is underlying this. In this section we link our unobserved common factors to observed macroeconomic variables.

Existing literature provides us with a range of variables that could be related to our level, slope or curvature factors. The theory of normal backwardation (Keynes, 1930) argues that commodity producers and inventory holders hedge their risk by shorting futures. To induce risk-averse speculators into taking the opposite long positions, current futures prices are set at a discount (i.e., are "backwardated") to expected future spot prices at maturity. Therefore the ratio of hedgers versus speculators could be related to the shape of the futures curve and hence to our factors. Alternatively, the theory of storage (Kaldor, 1939; Working, 1949) argues that convenience yield, basis, and inventories are closely related. In our set-up we capture the convenience yield in our slope (see Section 4.2) factors. Besides commodity specific variables, we also use macroeconomic variables to interpret our factors.

We collect a large database of macroeconomic and commodity specific variables. We consider the same set of 108 macroeconomic variables as in Stock and Watson (2012). Following Stock and Watson (2012) we transform the variables to ensure stationarity and assign them to 12 categories: GDP components, industrial production, employment, unemployment rate, housing, business inventories, wages, interest rates, money, exchange rates, stock prices, and consumer expectations. ${ }^{18}$ For each category we apply a Principal Components Analysis (PCA) to summarize the variables within that group and proceed with the principal component that explains most of their variation. In this way we reduce the dimension to 12 series that all correspond to a particular macroeconomic category. Besides the Stock and Watson (2012) dataset, we add a "financial conditions" group to capture investor expectations and market conditions. This category consists

\footnotetext{
${ }^{18}$ We leave out the Prices category due to endogeneity issues.
} 
of the Aruoba, Diebold, and Scotti (2009) (ADS) business conditions index, the Baker and Wurgler (2006) sentiment index (Lutzenberger, 2014), and the Baltic dry shipping index (Bakshi et al., 2011). ${ }^{19}$ Even though our financial conditions variable is based on macroeconomic series that are already included in other categories, it is not highly correlated with these other explanatory variables. We collect commodity inventory and hedging pressure data following the methodology of Gorton, Hayashi, and Rouwenhorst (2013). Last, we add volatility of the Commodity Research Bureau (CRB) spot market price index (Pindyck, 2004) as possible candidate. The in total 209 collected individual series result in 17 stationary variables. A complete overview of the individual series, their sources, categories and transformations is given in Appendix E.

To determine which variables are most related to which common component we use a multivariate regression. Table 6 shows the variables that have a statistically significant coefficient. Up to one third of the variation of the differenced level components can be explained by our explanatory variables. These percentages are higher for our slope and curvature components.

Focusing on Panel A, the results for the common market-wide components are in line with our expectations. Changes in the level component, i.e. returns, are related to returns in foreign exchange and equity markets. As all commodity futures contracts we examine are denominated in dollars, a stronger dollar leads to lower commodity prices, which is reflected by the negative coefficient. The positive relation between equity and commodity prices is surprising as commodities are often used for diversification purposes (see e.g. Erb and Harvey, 2006; Gorton and Rouwenhorst, 2006). However it is in line with more recent findings of Singleton (2014) and Tang and Xiong (2012). The (almost significant) positive relation with hedging pressure is in line with the theory of normal backwardation Keynes (1930) and the results in Gorton, Hayashi, and Rouwenhorst (2013); Hamilton and $\mathrm{Wu}(2014) \cdot{ }^{20}$

\footnotetext{
${ }^{19}$ The ADS index is designed to track real business conditions at high frequency. Baker and Wurgler (2006) define sentiment as investor propensity to speculate. The Baltic Dry Index is an indicator of transportation costs for raw materials shipped by sea.

${ }^{20}$ Note that Gorton et al. (2013) Table XI reports significant negative slope coefficients. However, they define hedging pressure as net long positions of hedgers while we look at net short positions.
} 


\section{Table 6 Interpretation common components}

The table presents observed macroeconomic and commodity specific variables that are related to our unobserved states. Each component is regressed on a set of 17 explanatory variables. The table presents the statistically significant coefficients with their corresponding $t$-stat. The macroeconomic variables are taken from Stock and Watson (2012), while the commodity specific variables are collected as described by Gorton et al. (2013). Full details on the data series are given in Appendix E.

\begin{tabular}{|c|c|c|c|c|c|}
\hline \multicolumn{2}{|l|}{$\Delta$ Level } & \multicolumn{2}{|l|}{ Slope } & \multicolumn{2}{|l|}{ Curvature } \\
\hline Variable & $t$-stat & Variable & $t$-stat & Variable & $t$-stat \\
\hline \multicolumn{6}{|c|}{ Panel A Market-wide components } \\
\hline $\begin{array}{l}R^{2}=16.5 \% \\
\text { Equity } \\
\text { Exchange rates } \\
\text { Hedging pressure }\end{array}$ & $\begin{array}{r}3.29 \\
-2.48 \\
1.93\end{array}$ & $\begin{array}{l}R^{2}=60.1 \% \\
\text { Business inventories } \\
\text { Employment } \\
\text { Financial conditions } \\
\text { Hedging pressure } \\
\text { Housing } \\
\text { Industrial production }\end{array}$ & $\begin{array}{r}4.43 \\
-2.74 \\
8.29 \\
10.04 \\
8.54 \\
-2.78\end{array}$ & $\begin{array}{l}R^{2}=22.6 \% \\
\text { Business inventories } \\
\text { Hedging pressure } \\
\text { Interest rates }\end{array}$ & $\begin{array}{r}2.53 \\
-3.39 \\
3.76\end{array}$ \\
\hline \multicolumn{6}{|c|}{ Panel B Energy sector components } \\
\hline $\begin{array}{l}R^{2}=31.0 \% \\
\text { Employment } \\
\text { Equity } \\
\text { Exchange rates } \\
\text { Financial conditions } \\
\text { Hedging pressure } \\
\text { Housing } \\
\text { Interest rates }\end{array}$ & $\begin{array}{r}-2.49 \\
2.09 \\
-2.05 \\
2.80 \\
6.92 \\
3.69 \\
2.34\end{array}$ & $\begin{array}{l}R^{2}=24.3 \% \\
\text { Business inventories } \\
\text { Commodity inventories } \\
\text { Financial conditions }\end{array}$ & $\begin{array}{l}-4.63 \\
-3.02 \\
-5.10\end{array}$ & $\begin{array}{l}R^{2}=31.1 \% \\
\text { Business inventories } \\
\text { Financial conditions } \\
\text { Hedging pressure } \\
\text { Industrial production } \\
\text { Interest rates } \\
\text { Unemployment }\end{array}$ & $\begin{array}{r}3.74 \\
4.90 \\
-4.75 \\
-3.55 \\
1.99 \\
-2.23\end{array}$ \\
\hline \multicolumn{6}{|c|}{ Panel C Metals sector components } \\
\hline $\begin{array}{l}R^{2}=29.9 \% \\
\text { Employment } \\
\text { Equity } \\
\text { Exchange rates } \\
\text { Industrial production } \\
\text { Interest rates } \\
\text { Wages }\end{array}$ & $\begin{array}{r}-3.64 \\
4.72 \\
-3.36 \\
2.40 \\
2.43 \\
-2.68\end{array}$ & $\begin{array}{l}R^{2}=49.1 \% \\
\text { Business inventories } \\
\text { Commodity inventories } \\
\text { Hedging pressure } \\
\text { Housing }\end{array}$ & $\begin{array}{r}7.93 \\
-2.09 \\
-7.53 \\
8.41\end{array}$ & & \\
\hline \multicolumn{6}{|c|}{ Panel D Softs sector components } \\
\hline $\begin{array}{l}R^{2}=36.9 \% \\
\text { Employment } \\
\text { Equity } \\
\text { Hedging pressure } \\
\text { Housing }\end{array}$ & $\begin{array}{r}-4.00 \\
2.00 \\
8.02 \\
3.09\end{array}$ & $\begin{array}{l}R^{2}=47.0 \% \\
\text { Employment } \\
\text { Hedging pressure } \\
\text { Housing }\end{array}$ & $\begin{array}{r}6.84 \\
5.10 \\
-4.83\end{array}$ & $\begin{array}{l}R^{2}=41.7 \% \\
\text { Business inventories } \\
\text { Commodity volatility } \\
\text { Employment } \\
\text { Housing } \\
\text { Industrial production }\end{array}$ & $\begin{array}{r}2.53 \\
-2.06 \\
4.99 \\
-5.12 \\
-2.28\end{array}$ \\
\hline \multicolumn{6}{|c|}{ Panel E Grains sector components } \\
\hline$R^{2}=7.1 \%$ & & $\begin{array}{l}R^{2}=56.1 \% \\
\text { Business inventories } \\
\text { Commodity volatility } \\
\text { Employment } \\
\text { Financial conditions } \\
\text { Hedging pressure } \\
\text { Housing } \\
\text { Interest rates }\end{array}$ & $\begin{array}{r}-2.90 \\
-2.67 \\
2.23 \\
-7.82 \\
10.62 \\
3.74 \\
-3.20\end{array}$ & $\begin{array}{l}R^{2}=60.8 \% \\
\text { Employment } \\
\text { Financial conditions } \\
\text { Hedging pressure } \\
\text { Industrial production }\end{array}$ & $\begin{array}{r}4.36 \\
-5.20 \\
13.26 \\
-2.32\end{array}$ \\
\hline \multicolumn{6}{|c|}{ Panel F Meats sector components } \\
\hline $\begin{array}{l}R^{2}=19.0 \% \\
\text { Hedging pressure }\end{array}$ & 4.82 & $\begin{array}{l}R^{2}=39.8 \% \\
\text { Business inventories } \\
\text { Employment } \\
\text { Hedging pressure } \\
\text { Housing } \\
\text { Wages }\end{array}$ & $\begin{array}{r}4.66 \\
-4.44 \\
3.27 \\
8.43 \\
-2.88\end{array}$ & $\begin{array}{l}R^{2}=10.9 \% \\
\text { Hedging pressure }\end{array}$ & 2.14 \\
\hline
\end{tabular}


Business inventories (new orders growth), housing (construction growth) and financial conditions are all considered leading economic indicators. Their positive relation with our market-wide slope factor implies a shift to more backwardated commodities curves when economic future perspectives are positive. ${ }^{21}$ The same holds for hedging pressure. When it goes up (more net short positions by hedgers), our slope component goes up, which results in a backwardated futures curve. The relations between the market-wide slope and industrial production growth and changes in employment are negative, hence the commodity curves are more backwardated at times when the economy slows down. This is not in line with our expectations, e.g. Fama and French (1988) find that when metal inventories are high, convenience yields are lower and the curve will be in contango.

The curvature component is related to business inventories, hedging pressure and interest rates. An increase in the curvature component leads to an increase in the price of mid-term contracts, while the contracts with very short or very long time to maturities are less affected. This seems to be coinciding with higher Treasury yields and lower hedging pressures.

Panels B to $\mathrm{F}$ show for each sector to which variables the components are linked. For the commodity specific variables we use only data of the commodities included in the sector of interest. In general, all level components are related to exchange rates, equity and hedging pressure. The grains level component is an exception as it hardly explained by any of our explanatory variables, shown by the $R^{2}$ of $7.1 \%$. The sector slope components relate positively to hedging pressure, just as the market-wide slope component. Only for the metals sector the coefficient for hedging pressure is negative, which is opposite of what we would expect. It is also interesting to see that two sector slope components have a negative coefficient for commodity inventories. This is in line with the theory of storage as shown by, e.g., Gorton et al. (2013); Geman and Nhuyen (2005). Last, the sector curvature components show similar results as the market-wide curvature component. Business inventories, hedging pressure and yield curve variables have signifi-

\footnotetext{
${ }^{21}$ Recall that the loadings on our slope factors are convex, hence a positive (negative) slope factor implies a backwardated (contangoed) futures curve.
} 
cant explanatory power. Furthermore, industrial production is negatively related to most sector curvature components, while employment variables are positively related.

Concluding, our unobserved common components relate to observed macroeconomic and commodity specific variables. In general, changes in the level components are related to equity, exchange rates and hedging pressure which is in line with results of existing literature. Also the slope components show significant coefficients for hedging pressure, housing, and commodity inventories that are in line with our expectations. Last, our curvature factor, which to the best of our knowledge has not yet been investigated in existing research, is positively related to interest rates and business inventories and negatively to industrial production.

\subsection{Time variation}

According to the ongoing debate on the financialization of commodities markets, the entrance of financial investors (around 2004-2005) has changed the commodities market dynamics (Cheng and Xiong, 2014). All our analyses so far are based on the full sample period from 1995 to 2012. It would be interesting to see if the amount of commonality varies over time during this period.

To investigate variation over time, we re-estimate the model attaching weights to the likelihood contributions of different observations in such a way that we emphasize specific data periods. The likelihood contribution of the observation at time $\Theta+k$ is given weight $\delta^{|k|}$, for $k=\ldots,-2,-1,0,1,2, \ldots$, with $0<\delta<1$, resulting in estimates centered at $t=\Theta$. Repeating this for $\Theta=1,2, \ldots, T$ yields a sequence of smoothly time-varying parameter estimates. Although by design, this weighting will not produce any abrupt change, it nevertheless provides information about the presence, or otherwise, of temporal variation. We favor this approach to the use of subsamples because our data covers a limited time period and we do not want to impose breakdates ourselves. We use $\delta=0.99$ to ensure that each estimate reflects information in a sample of reasonable effective size. 


\section{Figure 11 Moving window variance decompositions}

These figures show the percentage of explained variation per component. Time-variation is introduced by estimating the model using a rolling window and applying a variance decomposition analysis at each point in time. The time-varying specification is estimated by attaching lower weights to more distant observations. The observation at time $\Theta+k$ is given weight $\delta^{|k|}$, for $k=\ldots,-2,-1,0,1,2, \ldots$, with $0<\delta<1$, resulting in estimates centered at $t=\Theta$.

(a) $\Delta$ Level

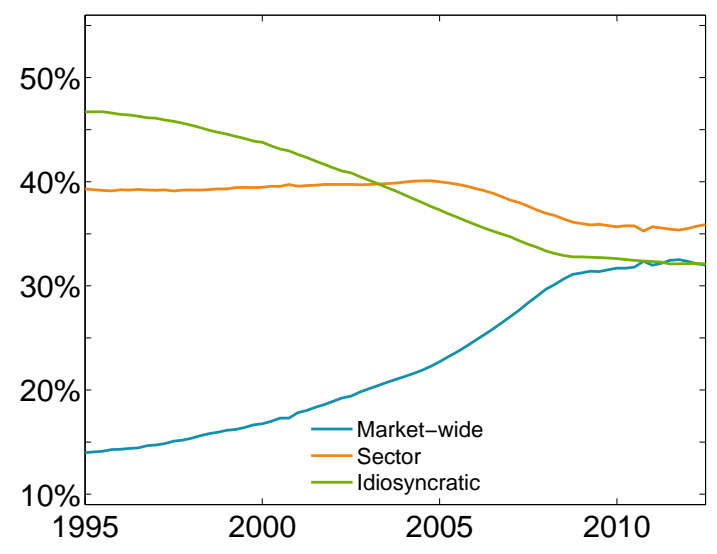

(b) Slope

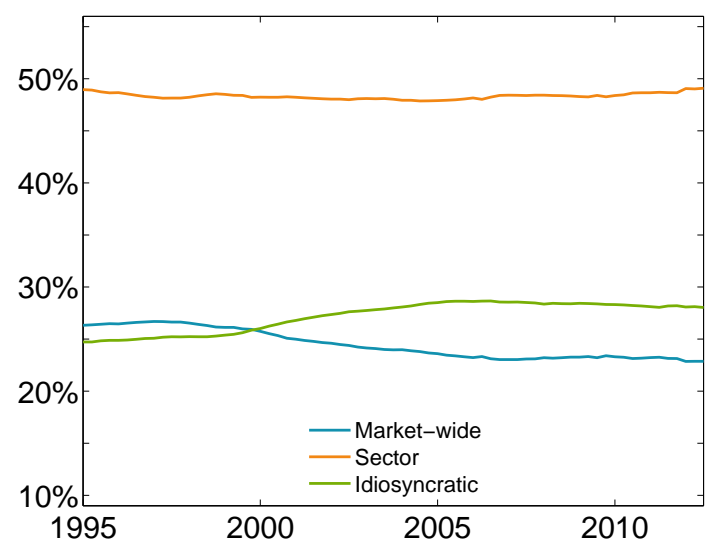

(c) Curvature

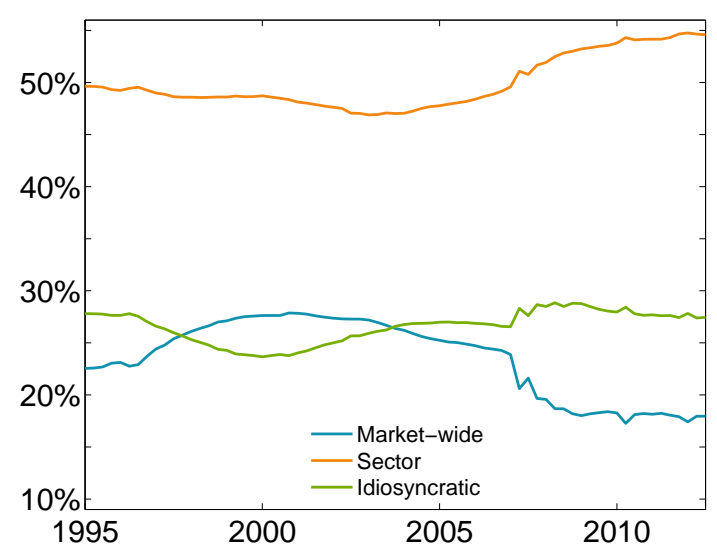


Of particular interest is the relative importance over time of the common, market-wide and sector components. Figure 11 shows results of time-varying variance decompositions, which are at each point in time based on estimation results of the above described methodology. Both the lines corresponding to sector and idiosyncratic explained variation are based on averages across all sectors or commodities, respectively. Subfigure A shows that the market-wide component becomes increasingly important over time. In 1995 this component common to all commodities explained just $14 \%$ of total variance, while this percentage steadily increases to $32 \%$ in 2008 after which it stays constant. Most of the increase happened at the expense of the idiosyncratic components. Subfigure B shows the results for the slope factors. All three lines are pretty constant over time. Subfigure C shows slightly more variation over time for the curvature components. From 2007 onward, the sector components explain a larger part of total curvature variation, while the market-wide component explains less variation. Still, the total amount of curvature variation explained by common components remains quite constant over time.

Our findings show that only the level factors show an increase in commonality over time. These findings are in line with Tang and Xiong (2012).

\subsection{Importance curve data}

In all our analysis we use term-structure information while investigating commonality. An obvious advantage of this additional data is that it allows us to investigate commonality in curve shapes, besides the often investigated commonality in levels. We argue that the inclusion of more distant futures data not only gains additional insight but also affects the common level component analysis. To quantify potential differences due to the inclusion of term structure information, we redo some of our analysis with only first nearby contract information. This allows us to compare the market-wide level factors that we obtained using our full model and dataset with the market-wide level factor that we obtain from a restricted version of our model and a limited dataset.

Our one factor model based on only first nearby contracts is obtained by restricting 
(2)-(4) into

$$
f_{i, t}=l_{i, t}+\nu_{i, t}=\alpha_{i}^{L}+\beta_{i}^{L} L_{\text {market }, t}+\gamma_{i}^{L} L_{\text {sector }, t}+L_{i, t}+\nu_{i, t}
$$

where

$$
\Delta L_{x, t}=\phi^{x} \Delta L_{x, t-1}+\eta_{x, t}^{L}
$$

We estimate this model using the same Kalman filter methodology but use only data on first nearby contracts. Figure 12 shows a comparison of the extracted market-wide factors. The results from both methodologies are in line but there are some notable differences. First, the factor from the full model is pretty constant in the period 20042006 and 2009-2010, while the factor from the one-factor model rises sharply. However, after both subperiods, the full model factor quickly picks up and rises to the same level as the one-factor model. The differences in behavior are also reflected by the correlation of 0.53 between the first differenced series of both factors.

\section{Figure 12 Comparison market-wide level components}

Each line shows the market-wide level component of a particular model. The blue line corresponds to the full joint model with slope and curvature factors and curve information. The orange line is a restricted version of the full model with only level factors and first nearby contract information.

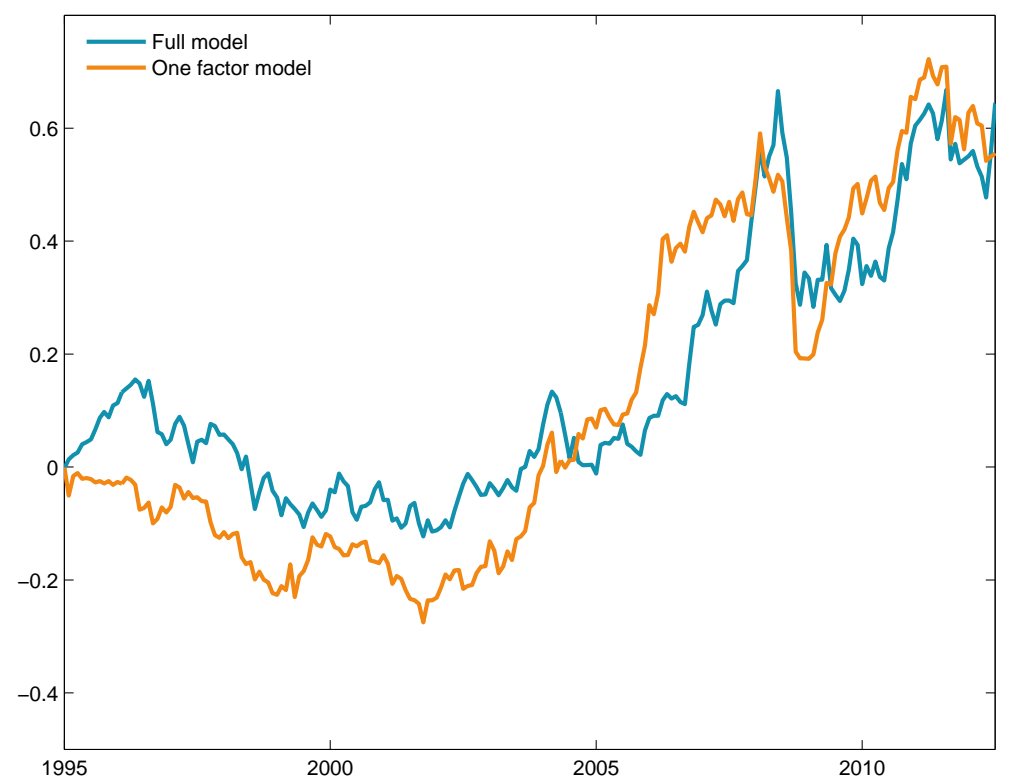

The extracted market-wide factors are just one side of the story. It is also interesting 
to investigate the other side, namely the loadings on these factors. Of most interest is the amount of commonality, i.e. the interplay of loadings and common factors. When we redo the variance decompositions we find that the market-wide factor explains a larger part of the variance in the one-factor model, $30.3 \%$ versus $23.3 \%$ for the full model. However, the seasonal commodities are less well explained compared to including the full dataset. The market-wide component explains $15.2 \%$ of their variation in the one-factor case, while this is $27.2 \%$ in our main results.

To see whether it is a coincidence that the seasonal commodities are better explained by our full curve model, we correct the first nearby contract data for seasonal effects. We do this by applying the same seasonal correction (based on our individual model estimates from Section 4.1). Note that in this way we favor the one-factor model as this correction is based on full curve data. Unreported results show that all previous reported findings hardly change. In other words, the seasonal correction has only a small effect on the difference between full curve and first contract results. This implies that there is a large difference between quantifying the commodity price levels based on only the first nearby contract data versus the levels based on the full commodities curve. Furthermore, commonality seems to be larger when only the front contracts are used. This was not expected as front contracts are more volatile than contracts further down the curve (see Table 1 and Samuelson 1965). A possible explanation is the effect of commodity indices. These indices (or funds that track them) are mostly invested in front contracts, which could lead to increased commonality (Tang and Xiong, 2012).

\section{Conclusion}

We investigate comovement across commodities by examining the commonality in the price levels and shapes of their futures curves. We use an enhanced version of the Nelson and Siegel (1987) model and extend the framework of Diebold, Li, and Yue (2008) to extract the factors that drive the individual commodity futures curves. Comovement across commodities is investigated by decomposing each individual factor in a market- 
wide, sector, and idiosyncratic component.

Using a monthly dataset of 24 commodities that are part of the S\&P Goldman Sachs Commodity Index (GSCI) we show that there is comovement across commodity futures curves, either due to a market-wide or due to a sector component. Sector components explain close to $50 \%$ of the variation of our shape factors (slope and curvature), while a market-wide component explains $24 \%$ of their variations. For the individual commodity level factors, the percentage of explained variation by common (market-wide and sector) components is lower and on average $62 \%$. Concluding, common components explain between $62 \%$ and $74 \%$ of the variation of individual commodities. In all cases the commonality is mostly driven by the sector components. For the shape related factors we find almost no variation in results over time. In contrast to the level factors where the market-wide component explains more variation over time. The percentage of explained variation starts at $14 \%$ in 1995 and increases to $32 \%$ in 2012.

The unobserved common components relate to macroeconomic and commodity specific variables in ways which are consistent with existing literature. Our level components relate to equity markets, exchange rates and hedging pressure. The slope components are linked to hedging pressure (theory of normal backwardation) and commodity inventories (theory of storage). Last, the newly introduced curvature components related to the yield curve, business inventories and industrial production.

The presented framework provides a way to include more futures data to investigate commonality across commodities. Using this framework we show that it is important to include the term-structure dimension in the analysis of comovement as it alters the findings on the extent of comovement. The current findings are insightful for portfolio construction, risk management and hedging purposes using commodity futures. 


\section{References}

Ai, C., A. Chatrath, and F. Song (2006). "On the comovement of commodity prices." American Journal of Agricultural Economics, 88(3), 574-588.

Aruoba, S., F. Diebold, and C. Scotti (2009). "Real-time measurement of business conditions." Journal of Business and Economic Statistics, 27(4), 417-427.

Baker, M. and J. Wurgler (2006). "Investor sentiment and the cross-section of stock returns." Journal of Finance, 61(4), 1645-1680.

Bakshi, G., G. Panayotov, and G. Skoulakis (2011). "The baltic dry index as a predictor of global stock returns, commodity returns, and global economic activity." Working paper.

Bessembinder, H. (1992). "Systematic risk, hedging pressure, and risk premiums in futures markets." The Review of Financial Studies, 5(4), 637-667.

Brennan, M. (1991). "The price of convenience and the valuation of commodity contingent claims." In D. Lund and B. Oksendal (Eds.), "Stochastic Models and Option Values: Applications to Resources, Environment and Investment Problems," North-Holland, New York.

Brooks, C. and M. Prokopczuk (2013). "The dynamics of commodity prices." Quantitative Finance, 13(4), 527-542.

Byrne, J. P., G. Fazio, and N. Fiess (2012). "Primary commodity prices: Co-movements, common factors and fundamentals." Journal of Development Economics, 101, 16-26.

Carter, C. A., G. C. Rausser, and A. Schmitz (1983). "Efficient asset portfolios and the theory of normal backwardation." Journal of Political Economy, 91(2), 319-331.

Casassus, J. and P. Collin-Dufresne (2005). "Stochastic convenience yield implied from commodity futures and interest rates." Journal of Finance, 60(5), 2283-2331.

Casassus, J., P. Liu, and K. Tang (2013). "Economic linkages, relative scarcity, and commodity futures returns." Review of Financial Studies, 26(5), 1324-1362.

Chang, E. C. (1985). "Returns to speculators and the theory of normal backwardation." Journal of Finance, 40(1), 193-208.

Chen, Y.-C., K. S. Rogoff, and B. Rossi (2010). "Can exchange rates forecast commodity prices?" The Quarterly Journal of Economics, 125(3), 1145-1194.

Cheng, I.-H. and W. Xiong (2014). "The financialization of commodities markets." Annual Review of Financial Economics, 6(1), 1-23.

Christoffersen, P., A. Lunde, and K. V. Olesen (2014). "Factor structure in commodity futures return and volatility." Working paper.

Cortazar, G., C. Milla, and F. Severino (2008). "A multicommodity model of futures prices: Using futures prices of one commodity to estimate the stochastic process of another." Journal of Futures Markets, 28(6), 537-560. 
Cortazar, G. and L. Naranjo (2006). "An N-factor gaussian model of oil futures." The Journal of Futures Markets, 26, 243-268.

Daskalaki, C., A. Kostakis, and G. S. Skiadopoulos (2014). "Are there common factors in individual commodity futures returns?" Journal of Banking and Finance, 40(3), 346-363.

de Roon, F. A., T. E. Nijman, and C. Veld (2000). "Hedging pressure effects in futures markets." Journal of Finance, 55(3), 1437-1456.

Deaton, A. and G. Laroque (1992). "On the behaviour of commodity prices." Review of Economic Studies, 59, 1-23.

Deb, P., P. Trivedi, and P. Varangis (1996). "The excess comovement of commodity prices reconsidered." Journal of Applied Econometrics, 11, 275-291.

Diebold, F. X. and C. Li (2006). "Forecasting the Term Structure of Government Bond Yields." Journal of Econometrics, 130, 337-364.

Diebold, F. X., C. Li, and V. Z. Yue (2008). "Global yield curve dynamics and interactions: A dynamic Nelson-Siegel approach." Journal of Econometrics, 146, 351-363.

Diebold, F. X., G. D. Rudebusch, and S. B. Aruoba (2006). "The macroeconomy and the yield curve: A dynamic latent factor approach." Journal of Econometrics, 131(1-2), 309-338.

Duffee, G. (2011). "Forecasting with the term structure: The role of no- arbitrage restrictions." working paper.

Erb, C. and C. Harvey (2006). "The tactical and strategic value of commodity futures." Financial Analysts Journal, 62(2), 69-97.

Fama, E. and K. French (1987). "Commodity futures prices: Some evidence on forecast power, premiums and the theory of storage." Journal of Business, 60, 55-73.

Fama, E. and K. French (1988). "Business cycles and the behavior of metals prices." The Journal of Finance, 43(5), 1075-1093.

Geman, H. (2005). Commodities and Commodity Derivatives: Modeling and Pricing for Agriculturals, Metals, and Energy. Wiley Finance, London, UK.

Geman, H. and V.-N. Nhuyen (2005). "Soybean inventory and forward curve dynamics." Management Science, 51(7), 1076-1091.

Gibson, R. and E. S. Schwartz (1990). "Stochastic convenience yield and the pricing of oil contingent claims." Journal of Finance, 45(3), 959-976.

Gorton, G., F. Hayashi, and K. G. Rouwenhorst (2013). "The fundamentals of commodity futures returns." Review of Finance, 17(1), 1-71.

Gorton, G. and K. G. Rouwenhorst (2006). "Facts and fantasies about commodity futures." Financial Analysts Journal, 62(2), 47-68. 
Hamilton, J. D. and J. C. Wu (2014). "Risk premia in crude oil futures." Journal of International Money and Finance, 42(4), 9-37.

Hansen, N. S. and A. Lunde (2013). "Analyzing oil futures with a dynamic Nelson-Siegel model." CREATES research paper 2013-36.

Kaldor, N. (1939). "Speculation and economic stability." The Review of Economic Studies, $7,1-27$.

Keynes, J. (1930). A Treatise on Money, vol. 2. Macmillan, London.

Koopman, S. and J. Durbin (2000). "Fast filtering and smoothing for multivariate state space models." Time Series Analysis, 21, 281-296.

Koopman, S. J., M. I. P. Mallee, and M. Van der Wel (2010). "Analyzing the term structure of interest rates using the dynamic Nelson-Siegel model with time-varying parameters." Journal of Business and Economic Statistics, 28(3), 329-343.

Kose, M. A., C. Otrok, and C. H. Whiteman (2003). "International business cycles: World, region, and country-specific factors." The American Economic Review, 93(4), 1216-1239.

Lutzenberger, F. (2014). "The predictability of aggregate returns on commodity futures." Review of Financial Economics, 23(3), 120-130.

Milonas, N. T. (1991). "Measuring seasonalities in commodity markets and the half-month effect." Journal of Futures Markets, 11(3), 331-345.

Nelson, C. and A. Siegel (1987). "Parsimonious modeling of yield curves." Journal of Business, 60, 473-489.

Ohana, S. (2010). "Modeling global and local dependence in a pair of commodity forward curves with an application to the US natural gas and heating oil markets." Energy Economics, 32, 373-388.

Pindyck, R. and J. Rotemberg (1990). "The excess co-movement of commodity prices." Economic Journal, 100, 1173-1189.

Pindyck, R. S. (2004). "Volatility and commodity price dynamics." Journal of Futures Markets, 24(11), 1029-1047.

Samuelson, P. (1965). "Proof that properly anticipated prices fluctuate randomly." Industrial Management Review, 2, 41-49.

Sargent, T. J. and C. A. Sims (1977). "Business cycle modeling without pretending to have too much a priori economic theory." Working paper.

Schwartz, E. S. (1997). "The stochastic behavior of commodity prices: Implications for valuation and hedging." Journal of Finance, 52(3), 923-973.

Schwartz, E. S. and J. E. Smith (2000). "Short-term variations and long-term dynamics in commodity prices." Management Science, 46(7), 893-911. 
Singleton, K. J. (2014). "Investor flows and the 2008 boom/bust in oil prices." Management Science, 60(2), 300-318.

Sorensen, C. (2002). "Modeling seasonality in agricultural commodity futures." Journal of Futures Markets, 22(5), 393-426.

Stock, J. H. and M. W. Watson (1989). "New indexes of coincident and leading economic indicators." In "NBER Macroeconomics Annual 1989, Volume 4," 351-409. MIT Press.

Stock, J. H. and M. W. Watson (2012). "Generalized shrinkage methods for forecasting using many predictors." Journal of Business and Economic Statistics, 30(4), 481-493.

Stoll, H. R. and R. E. Whaley (2010). "Commodity index investing and commodity futures prices." Journal of Applied Finance, 20(1), 7-46.

Szymanowska, M., F. de Roon, T. Nijman, and R. van den Goorbergh (2014). "An anatomy of commodity futures risk premia." Journal of Finance, 69(1), 453-482.

Tang, K. and W. Xiong (2012). "Index investment and financialization of commodities." Financial Analysts Journal, 68(6), 54-74.

Vansteenkiste, I. (2009). "How important are common factors in driving non-fuel commodity prices? A dynamic factor analysis." Working paper, European Central Bank.

Vasicek, O. (1977). "An equilibrium characterization of the term structure." Journal of Financial Economics, 5, 177-188.

West, J. (2012). "Long-dated agricultural futures price estimates using the seasonal Nelson-Siegel model." International Journal of Business and Management, 7(3), 78-93.

Working, H. (1949). "The theory of price storage." American Economic Review, 39, 1254-1262. 


\section{Appendix}

\section{A State space representation}

The state space representation follows naturally from the model given by (2)-(4). The measurement equation in (A.1) is a combination of (2) and (3). Note that the individual latent level $l_{i, t}$, slope $s_{i, t}$, and curvature $c_{i, t}$ factors do not appear in the measurement equation, as we can link the observed futures prices $f_{i, t}(\tau)$ directly to the unobserved market-wide, sector and idiosyncratic components.

$$
\left(\begin{array}{c}
f_{1, t}\left(\tau_{1}\right) \\
f_{1, t}\left(\tau_{2}\right) \\
\vdots \\
f_{1, t}\left(\tau_{J_{1}}\right) \\
\vdots \\
f_{N, t}\left(\tau_{J_{N}}\right)
\end{array}\right)=A\left(\begin{array}{c}
\alpha_{1}^{L} \\
\alpha_{1}^{S} \\
\alpha_{1}^{C} \\
\vdots \\
\alpha_{N}^{C}
\end{array}\right)+B\left(\begin{array}{c}
L_{\text {market }, t} \\
S_{\text {market }, t} \\
C_{\text {market }, t}
\end{array}\right)+C\left(\begin{array}{c}
L_{\text {Energy }, t} \\
S_{\text {Energy,t }} \\
C_{\text {Energy, },} \\
\vdots \\
L_{\text {Meats }, t} \\
S_{\text {Meats }, t} \\
C_{\text {Meats }, t}
\end{array}\right)+A\left(\begin{array}{c}
L_{1, t} \\
S_{1, t} \\
C_{1, t} \\
\vdots \\
C_{N, t}
\end{array}\right)+D\left(\begin{array}{c}
\kappa_{1} \\
\kappa_{2} \\
\vdots \\
\kappa_{N}
\end{array}\right)+\left(\begin{array}{c}
\nu_{1, t}\left(\tau_{1}\right) \\
\nu_{1, t}\left(\tau_{2}\right) \\
\vdots \\
\nu_{1, t}\left(\tau_{J_{1}}\right) \\
\vdots \\
\nu_{N, t}\left(\tau_{J_{N}}\right)
\end{array}\right)
$$

where $J_{i}$ is the number of available contracts of commodity $i$. As discussed in Section $2 J_{i}$ varies over time, yet for readability reasons we keep writing $J_{i}$ instead of $J_{i_{t}}$.

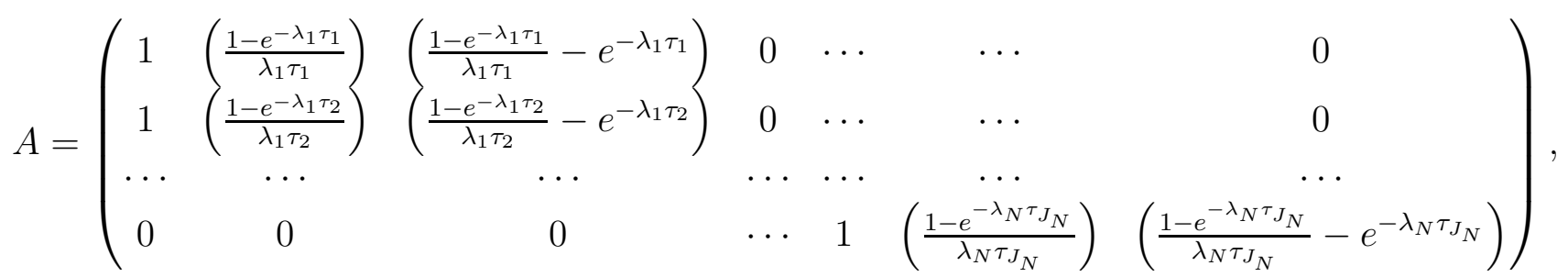

$$
\begin{aligned}
& B=\left(\begin{array}{ccc}
\beta_{1}^{l} & \beta_{1}^{s}\left(\frac{1-e^{-\lambda_{1} \tau_{1}}}{\lambda_{1} \tau_{1}}\right) & \beta_{1}^{c}\left(\frac{1-e^{-\lambda_{1} \tau_{1}}}{\lambda_{1} \tau_{1}}-e^{-\lambda_{1} \tau_{1}}\right) \\
\beta_{1}^{l} & \beta_{1}^{s}\left(\frac{1-e^{-\lambda_{1} \tau_{2}}}{\lambda_{1} \tau_{2}}\right) & \beta_{1}^{c}\left(\frac{1-e^{-\lambda_{1} \tau_{2}}}{\lambda_{1} \tau_{2}}-e^{-\lambda_{1} \tau_{2}}\right) \\
\vdots & \vdots & \vdots \\
\beta_{N}^{l} & \beta_{N}^{s}\left(\frac{1-e^{-\lambda_{N} \tau_{N}}}{\lambda_{N} \tau_{J_{N}}}\right) & \beta_{N}^{c}\left(\frac{1-e^{-\lambda_{N} \tau_{N}}}{\lambda_{N} \tau_{J_{N}}}-e^{-\lambda_{N} \tau_{J_{N}}}\right)
\end{array}\right)
\end{aligned}
$$




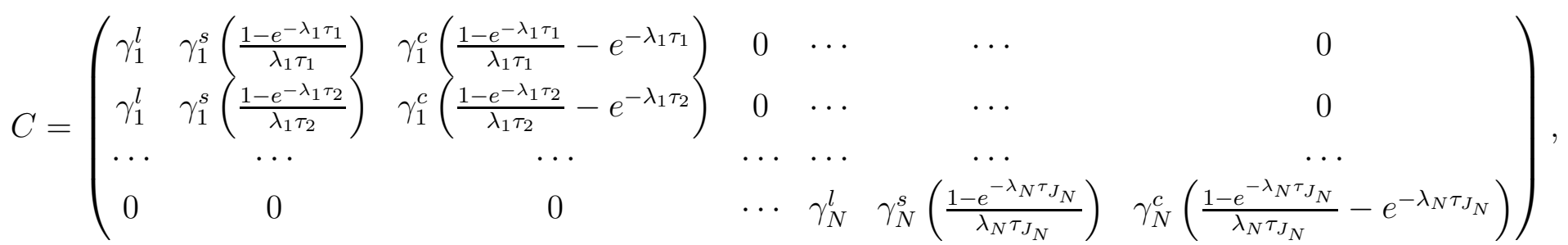

$$
\begin{aligned}
& D=\left(\begin{array}{cccc}
\cos \left(\omega g_{1}\left(t, \tau_{1}\right)-\omega \theta_{1}\right) & 0 & \cdots & 0 \\
\cos \left(\omega g_{1}\left(t, \tau_{2}\right)-\omega \theta_{1}\right) & 0 & \cdots & 0 \\
\cdots & \cdots & \cdots & \cdots \\
\cos \left(\omega g_{1}\left(t, \tau_{J_{1}}\right)-\omega \theta_{1}\right) & 0 & \cdots & 0 \\
\cdots & \cdots & \cdots & \cdots \\
0 & 0 & \cdots & \cos \left(\omega g_{N}\left(t, \tau_{J_{N}}\right)-\omega \theta_{N}\right)
\end{array}\right)
\end{aligned}
$$

The transition equations of the latent states are given by (4). The market-wide, sector, and idiosyncratic components are assumed to have first-order autoregressive dynamics. For completeness, we also present them here:

$$
\left(\begin{array}{c}
\Delta L_{y, t} \\
S_{y, t} \\
C_{y, t}
\end{array}\right)=\left(\begin{array}{lll}
\phi_{11}^{y} & \phi_{12}^{y} & \phi_{13}^{y} \\
\phi_{21}^{y} & \phi_{22}^{y} & \phi_{23}^{y} \\
\phi_{31}^{y} & \phi_{32}^{y} & \phi_{33}^{y}
\end{array}\right)\left(\begin{array}{c}
\Delta L_{y, t-1} \\
S_{y, t-1} \\
C_{y, t-1}
\end{array}\right)+\left(\begin{array}{c}
\eta_{y, t}^{L} \\
\eta_{y, t}^{S} \\
\eta_{y, t}^{C}
\end{array}\right)
$$

where $y=\{$ market, sector, idiosyncratic $\}$, and the disturbances $\eta_{y, t}=\left(\eta_{y, t}^{L}, \eta_{y, t}^{S}, \eta_{y, t}^{C}\right)$ are normally distributed with covariance matrix $\Sigma_{\eta_{y}}$.

\section{B Maturity bound}

We choose to introduce a maturity bound to exclude long-dated contracts. By limiting the term-structure dimension variation within a commodity, we can keep using a fixed $\lambda$ value. Furthermore, these long-dated contracts are possibly less liquid and hence have more noisy price information, which could otherwise affect our results. The introduced maturity bound excludes on average $10 \%$ of our observations. Figure B.1 gives more details on individual commodities. Note that the longest available maturity varies substantially over time. 


\section{Figure B.1 Maturity bounds}

These figures show for each commodity the maturity bound and the longest available maturity (in years).
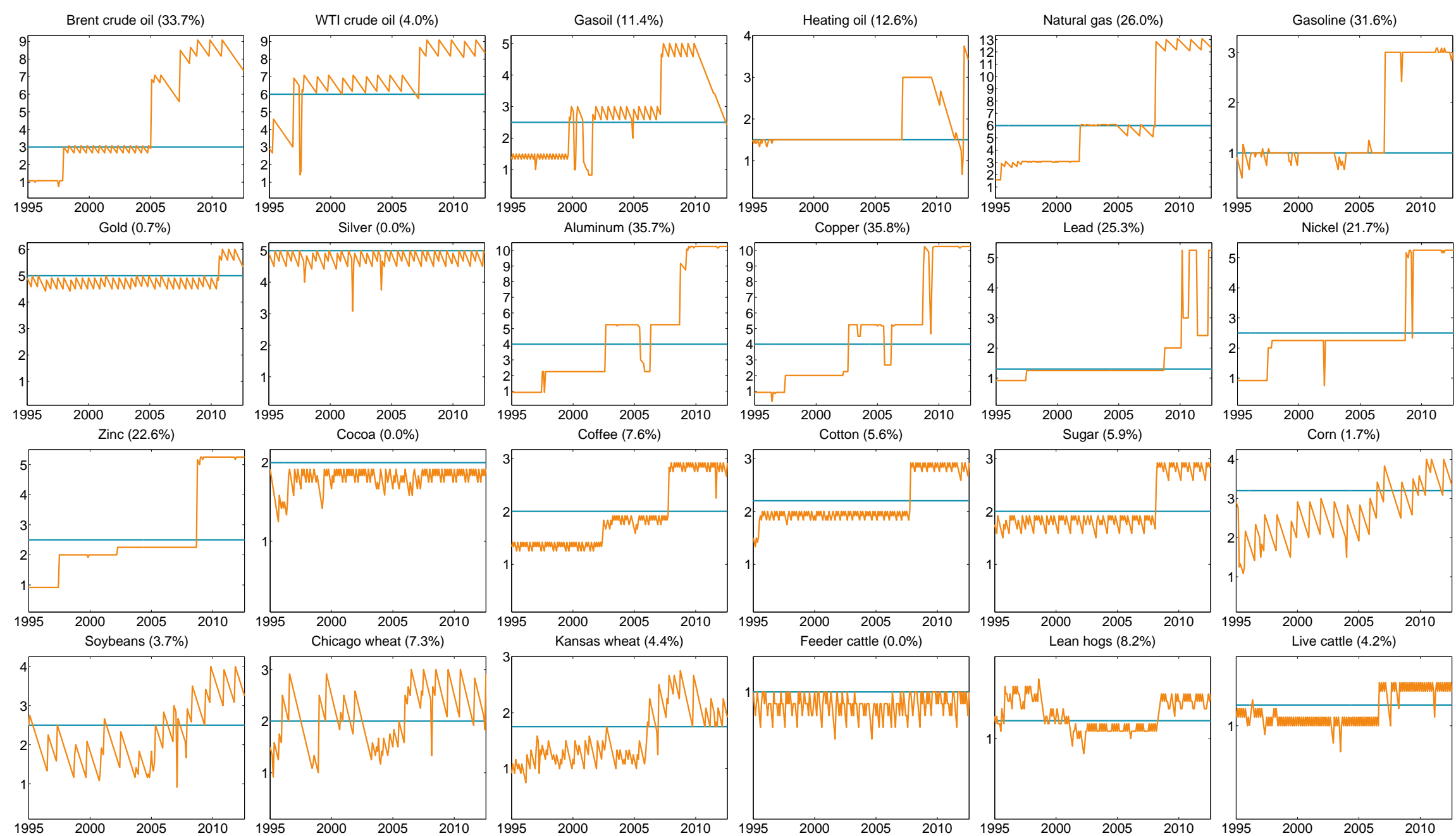


\section{Additional individual commodity results}

\section{Detailed individual model results}

This section provides the estimation results for all individual model specifications. Based on these results we decide on the final model specification for every commodity. The final model choice is based on several criteria. First, we compare the results of three factor models with and without seasonal term, to see if the exposure $\kappa$ to the seasonal correction is significantly different from zero. There are 13 commodities in Table C.1 that have highly significant $\kappa$ parameters, ranging between 0.73 and 7.78 . There is a big gap between the 11 commodities which have a $t$-stat below 5 , and the remaining 13 commodities which have a $t$-stat above 400. Therefore we decide to not include a seasonal correction when $\kappa$ is below 0.1. Second, for the non-seasonal commodities, we need to decide if we include a third curvature factor or not. Non-reported AIC or BIC values indicate that we should always choose for the larger models. However, the $\lambda$ values for some metal commodities in Table C. 1 are below 0.5 which leads to slope and curvature loadings that are close to opposite with a correlation below -0.80 . Therefore we decide to exclude the curvature factor for all metal commodities.

\section{Principal component analysis on raw prices}

To provide additional evidence that the Nelson and Siegel (1987) model is suited for commodity futures, we apply PCA to raw price data. In order to apply PCA, we need a balaced data panel. Therefore we exclude contract data if they have missing price data for more than $10 \%$ of the time periods. Then, for this selection, we exclude months where one of the contracts has missing price data. In the end we are left with a balanced sample with no missing observations.

Figure C.2 shows the loadings of the first three principal components (based on the covariance matrix). For most commodities these loadings resemble the level, slope and curvature factor loadings. The only exceptions are some commodities with a pronounced seasonal pattern, namely heating oil, natural gas, gasoline, cotton and lean hogs. Due to the Samuelson (1965) effect, results based on the correlation matrix are even more similar to level, slope and curvature loadings. 


\section{Table C.1 All individual model results}

The table presents the estimation results and the fit of the individual commodity state space models. We show the results of three different specification applied to all individual commodities. The two factor $(2 \mathrm{~F})$ model contains only a level and slope factor; the three factor (3F) model includes a curvature factor; and the 3FS model adds a seasonal correction term. For each model we present the estimated parameter values for the decay parameter $\lambda$, and (if relevant) the exposure $\kappa$ to the seasonal term and the most expensive contract expiry month $\theta$, where $\theta=0$ corresponds to January. The last column presents the volatility of errors $\sigma(\nu)$. Standard errors of all estimates are provided between brackets.

\begin{tabular}{|c|c|c|c|c|c|c|c|c|c|c|c|c|c|c|c|c|c|}
\hline \multirow{8}{*}{$\begin{array}{l}\text { Sector } \\
\text { Energy }\end{array}$} & \multirow{8}{*}{$\begin{array}{c}\text { Commodity } \\
\text { Brent crude oil } \\
\text { WTI crude oil } \\
\text { Gasoil } \\
\text { Heating oil } \\
\text { Natural gas } \\
\text { Gasoline }\end{array}$} & \multicolumn{4}{|c|}{ two factor $(2 \mathrm{~F})$} & \multicolumn{4}{|c|}{ three factor $(3 \mathrm{~F})$} & \multicolumn{8}{|c|}{ three factor and seasonal $(3 \mathrm{~F})$} \\
\hline & & \multicolumn{2}{|c|}{$\lambda$} & \multirow{2}{*}{$\begin{array}{l}\sigma(\nu) \\
1.28 \%\end{array}$} & \multirow{2}{*}{$\begin{array}{c}R^{2} \\
99.96 \%\end{array}$} & \multicolumn{2}{|c|}{$\lambda$} & \multirow{2}{*}{$\begin{array}{l}\sigma(\nu) \\
0.65 \%\end{array}$} & \multirow{2}{*}{$\begin{array}{c}R^{2} \\
99.99 \%\end{array}$} & \multicolumn{2}{|c|}{$\lambda$} & \multicolumn{2}{|r|}{$\kappa$} & \multicolumn{2}{|r|}{$\theta$} & \multirow{2}{*}{$\begin{array}{l}\sigma(\nu) \\
0.65 \%\end{array}$} & \multirow{2}{*}{$\begin{array}{c}R^{2} \\
99.99 \%\end{array}$} \\
\hline & & 0.884 & $(0.01)$ & & & 1.144 & $(0.01)$ & & & 1.143 & $(0.01)$ & 0.04 & (0.99) & 1.1 & $(0.02)$ & & \\
\hline & & 1.262 & $(0.01)$ & $1.49 \%$ & $99.95 \%$ & 1.272 & $(0.01)$ & $0.79 \%$ & $99.99 \%$ & 1.273 & $(0.01)$ & 0.03 & (1.24) & 0.1 & $(0.03)$ & $0.79 \%$ & $99.99 \%$ \\
\hline & & 1.644 & $(0.02)$ & $1.41 \%$ & $99.96 \%$ & 1.991 & $(0.04)$ & $1.17 \%$ & $99.97 \%$ & 1.688 & $(0.04)$ & 0.92 & $(0.02)$ & 0.4 & $(0.00)$ & $1.03 \%$ & $99.98 \%$ \\
\hline & & 1.956 & $(0.04)$ & $2.40 \%$ & $99.88 \%$ & 3.392 & $(0.06)$ & $2.17 \%$ & $99.90 \%$ & 3.600 & $(0.03)$ & 2.80 & $(0.01)$ & 0.8 & $(0.00)$ & $1.21 \%$ & $99.97 \%$ \\
\hline & & 0.822 & $(0.03)$ & $6.39 \%$ & $98.07 \%$ & 1.171 & $(0.03)$ & $5.72 \%$ & $98.45 \%$ & 1.137 & $(0.02)$ & 6.38 & $(0.01)$ & 0.9 & $(0.00)$ & $3.56 \%$ & $99.40 \%$ \\
\hline & & 2.298 & $(0.07)$ & $3.59 \%$ & $99.67 \%$ & 4.346 & $(0.04)$ & $3.11 \%$ & $99.75 \%$ & 3.285 & $(0.04)$ & 4.78 & $(0.01)$ & 6.2 & $(0.00)$ & $1.52 \%$ & $99.94 \%$ \\
\hline \multirow[t]{7}{*}{ Metals } & Gold & 0.011 & $(6.36)$ & $0.44 \%$ & $99.99 \%$ & 0.129 & $(0.08)$ & $0.19 \%$ & $100.00 \%$ & 0.129 & $(0.08)$ & 0.00 & $(22.65)$ & 0.1 & $(0.79)$ & $0.19 \%$ & $100.00 \%$ \\
\hline & Silver & 0.026 & $(1.79)$ & $0.54 \%$ & $99.99 \%$ & 0.278 & $(0.05)$ & $0.35 \%$ & $100.00 \%$ & 0.278 & $(0.05)$ & 0.02 & $(2.08)$ & 2.6 & $(0.04)$ & $0.35 \%$ & $100.00 \%$ \\
\hline & Aluminum & 0.187 & $(0.04)$ & $0.77 \%$ & $99.91 \%$ & 0.574 & $(0.01)$ & $0.32 \%$ & $99.98 \%$ & 0.574 & $(0.01)$ & 0.01 & $(2.81)$ & 9.6 & $(0.03)$ & $0.32 \%$ & $99.98 \%$ \\
\hline & Copper & 0.111 & $(0.10)$ & $1.13 \%$ & $99.97 \%$ & 0.489 & $(0.01)$ & $0.41 \%$ & $100.00 \%$ & 0.489 & $(0.01)$ & 0.02 & (1.35) & 7.3 & $(0.02)$ & $0.41 \%$ & $100.00 \%$ \\
\hline & Lead & 0.324 & $(0.13)$ & $0.57 \%$ & $99.99 \%$ & 1.771 & $(0.02)$ & $0.36 \%$ & $100.00 \%$ & 1.767 & $(0.02)$ & 0.04 & $(0.72)$ & 9.2 & $(0.02)$ & $0.36 \%$ & $100.00 \%$ \\
\hline & Nickel & 0.095 & $(0.28)$ & $0.91 \%$ & $99.98 \%$ & 1.250 & $(0.01)$ & $0.71 \%$ & $99.99 \%$ & 1.250 & $(0.01)$ & 0.00 & $(30.31)$ & 4.5 & $(0.17)$ & $0.71 \%$ & $99.99 \%$ \\
\hline & Zinc & 0.059 & $(0.19)$ & $0.69 \%$ & $99.97 \%$ & 1.132 & $(0.01)$ & $0.32 \%$ & $99.99 \%$ & 1.131 & $(0.01)$ & 0.03 & $(0.79)$ & 9.6 & $(0.02)$ & $0.32 \%$ & $99.99 \%$ \\
\hline \multirow[t]{4}{*}{ Softs } & Cocoa & 0.360 & $(0.10)$ & $0.74 \%$ & $99.96 \%$ & 1.413 & $(0.03)$ & $0.58 \%$ & $99.97 \%$ & 1.415 & $(0.03)$ & 0.08 & $(0.71)$ & 8.8 & $(0.02)$ & $0.58 \%$ & $99.97 \%$ \\
\hline & Coffee & 0.954 & $(0.03)$ & $0.80 \%$ & $99.96 \%$ & 1.468 & $(0.03)$ & $0.57 \%$ & $99.98 \%$ & 1.468 & $(0.03)$ & 0.00 & (56.48) & 0.1 & $(1.61)$ & $0.57 \%$ & $99.98 \%$ \\
\hline & Cotton & 1.484 & $(0.03)$ & $1.76 \%$ & $99.45 \%$ & 3.566 & $(0.03)$ & $1.37 \%$ & $99.67 \%$ & 3.482 & $(0.03)$ & 0.91 & $(0.06)$ & 5.9 & $(0.01)$ & $1.21 \%$ & $99.74 \%$ \\
\hline & Sugar & 1.610 & $(0.05)$ & $2.13 \%$ & $99.76 \%$ & 3.585 & $(0.04)$ & $1.53 \%$ & $99.88 \%$ & 3.272 & $(0.04)$ & 1.13 & $(0.05)$ & 2.5 & $(0.01)$ & $1.32 \%$ & $99.91 \%$ \\
\hline \multirow[t]{4}{*}{ Grains } & Corn & 1.603 & $(0.03)$ & $2.37 \%$ & $99.57 \%$ & 0.696 & $(0.18)$ & $2.10 \%$ & $99.67 \%$ & 2.743 & $(0.04)$ & 1.80 & $(0.03)$ & 5.7 & $(0.00)$ & $1.56 \%$ & $99.81 \%$ \\
\hline & Soybeans & 1.284 & $(0.05)$ & $1.82 \%$ & $99.73 \%$ & 3.536 & $(0.03)$ & $1.46 \%$ & $99.83 \%$ & 3.350 & $(0.03)$ & 1.30 & $(0.03)$ & 5.7 & $(0.00)$ & $1.19 \%$ & $99.89 \%$ \\
\hline & Chicago wheat & 1.345 & $(0.05)$ & $2.09 \%$ & $99.70 \%$ & 1.143 & $(0.15)$ & $1.86 \%$ & $99.76 \%$ & 1.496 & $(0.17)$ & 1.53 & $(0.04)$ & 2.0 & $(0.00)$ & $1.51 \%$ & $99.84 \%$ \\
\hline & Kansas wheat & 1.027 & $(0.11)$ & $1.94 \%$ & $99.72 \%$ & 3.318 & $(0.07)$ & $1.64 \%$ & $99.80 \%$ & 2.461 & $(0.08)$ & 1.44 & $(0.05)$ & 2.2 & $(0.01)$ & $1.35 \%$ & $99.86 \%$ \\
\hline \multirow[t]{3}{*}{ Meats } & Feeder cattle & 2.532 & $(0.07)$ & $0.96 \%$ & $99.83 \%$ & 4.522 & $(0.05)$ & $0.78 \%$ & $99.89 \%$ & 5.221 & $(0.07)$ & 0.73 & $(0.07)$ & 10.0 & $(0.01)$ & $0.71 \%$ & $99.91 \%$ \\
\hline & Lean hogs & 1.701 & $(0.18)$ & $6.66 \%$ & $89.78 \%$ & 4.022 & $(0.04)$ & $5.12 \%$ & $93.95 \%$ & 4.109 & $(0.07)$ & 7.78 & $(0.02)$ & 6.1 & $(0.00)$ & $3.09 \%$ & $97.80 \%$ \\
\hline & Live cattle & 3.200 & $(0.10)$ & $2.19 \%$ & $98.85 \%$ & 4.099 & $(0.05)$ & $1.77 \%$ & $99.25 \%$ & 4.487 & $(0.10)$ & 2.32 & $(0.03)$ & 1.9 & $(0.00)$ & $1.29 \%$ & $99.60 \%$ \\
\hline
\end{tabular}




\section{Figure C.2 Principal components}

These figures show for each commodity the first three principal component loadings extracted from the covariance matrix of raw prices. Contracts are included when they have valid observations for at least $90 \%$ of the months in our sample.

Brent crude oil $100.0 \%$

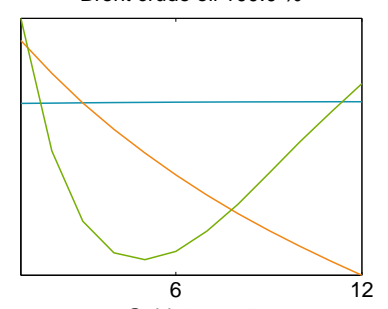

Gold $100.0 \%$

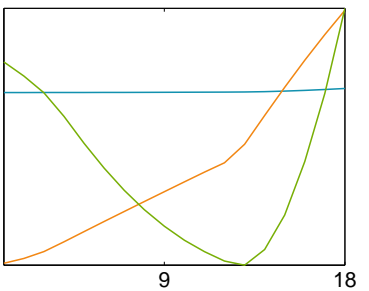

Zinc $100.0 \%$

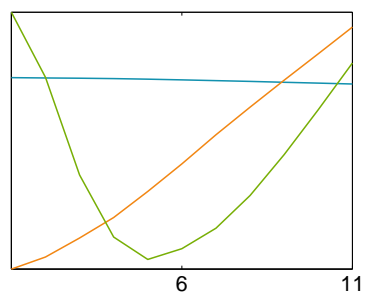

Soybeans $99.9 \%$

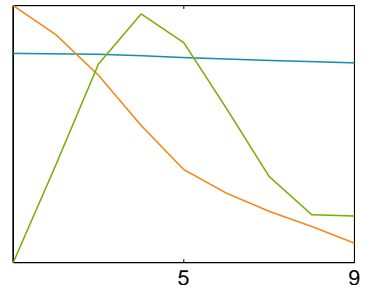

WTI crude oil $100.0 \%$

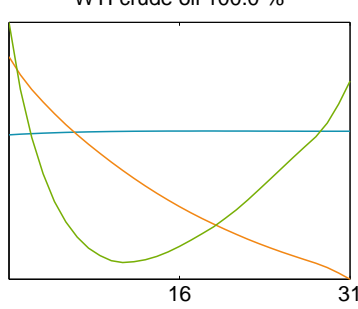

Silver $100.0 \%$

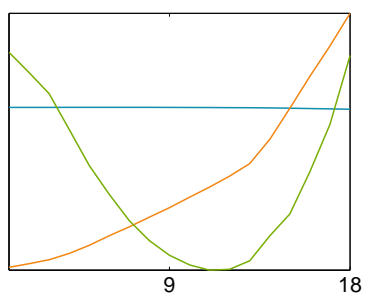

Cocoa $100.0 \%$

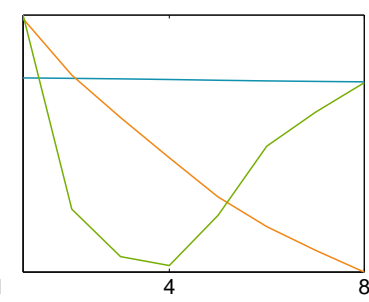

Chicago wheat $99.9 \%$

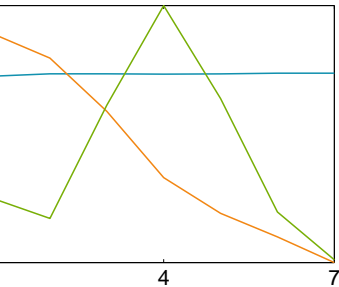

Gasoil $100.0 \%$

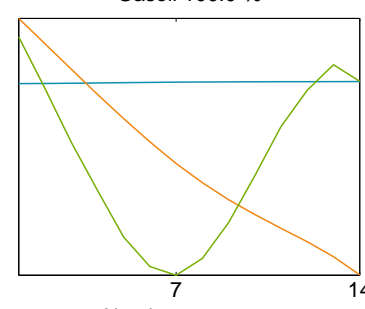

Aluminum $100.0 \%$

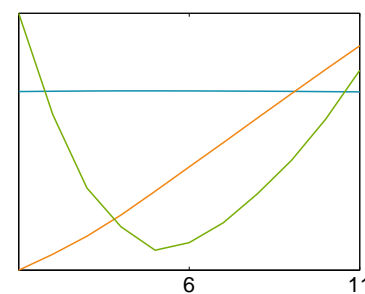

Coffee $100.0 \%$

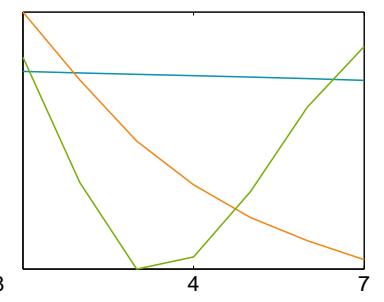

Kansas whet $100.0 \%$

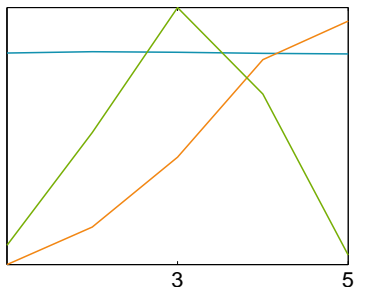

Heating oil $100.0 \%$

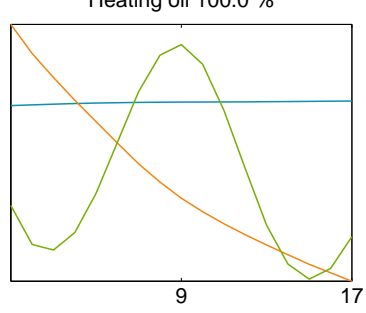

Copper $100.0 \%$

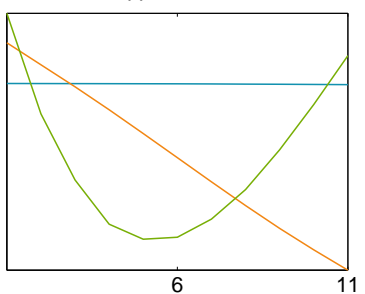

Cotton $99.7 \%$

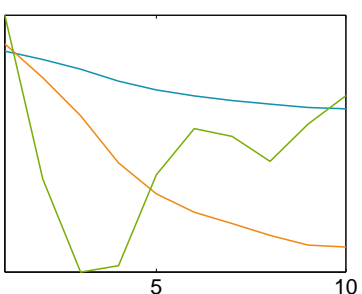

Feeder cattle $100.0 \%$

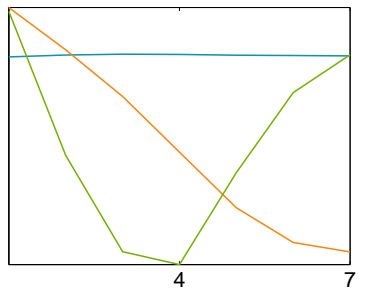

Natural gas $98.6 \%$

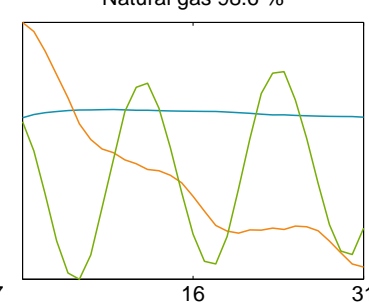

Lead $100.0 \%$

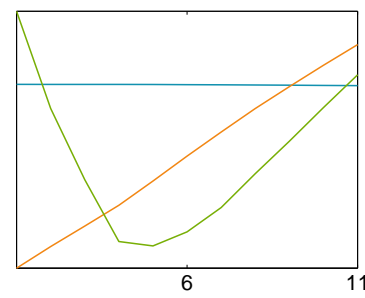

Sugar $100.0 \%$

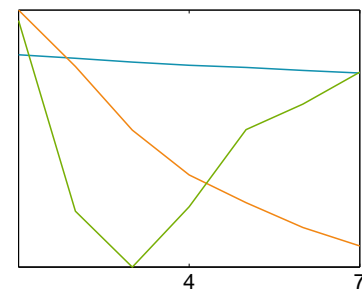

\begin{tabular}{c}
4 \\
Lean hogs $96.7 \%$ \\
\hline
\end{tabular}

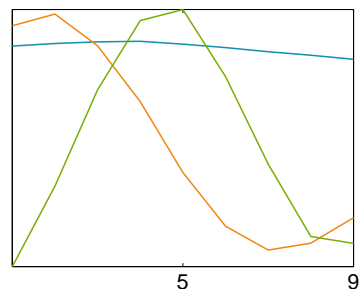

Gasoline $99.9 \%$

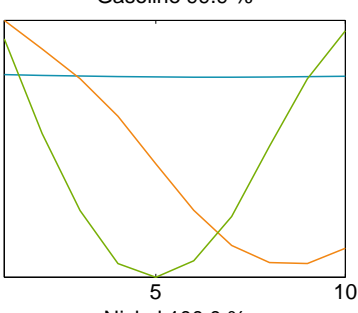

Nickel $100.0 \%$

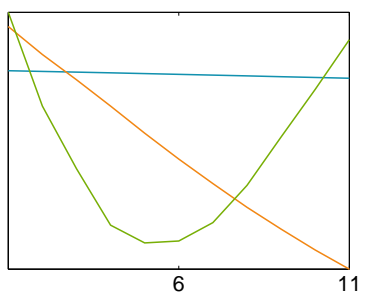

Corn $99.8 \%$

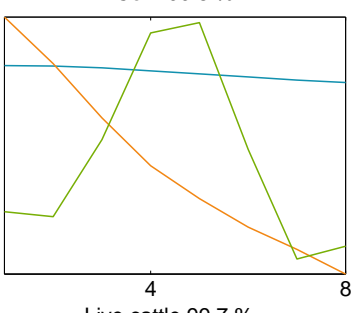

Live cattle $99.7 \%$

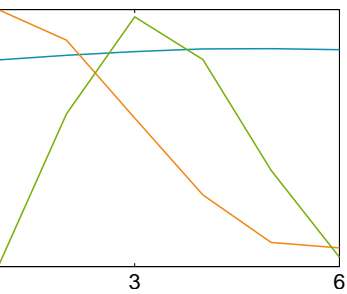




\section{Preliminary commonality results}

A preliminary check for commonality is obtained by comparing the unobserved level, slope and curvature factors from the individual models. Using PCA, we check to what extent the factors can be explained by the first principal component. The market-wide level component is approximated by the first principal component when PCA is applied to all 24 extracted level factors. For each commodity we can compute the fraction of "individual" variance that is explained by this first principal component. We then take the average over all commodities in a particular sector. The same analysis is also applied on all slope factors and on all curvature factors. If the first principal explains a large part of the factors variations, it is an indication for commonality.

Panel A in Table C.2 shows that there seems to be a market-wide component that drives the level factors as the first principal component explains $78.7 \%$ of the variation in individual level factors. Especially, the energy, metals, and grains level factors comove with the market-wide level component, as more than $80 \%$ of their variation is explained. For the other two commodity sectors we observe that $56.1 \%$ and $77.3 \%$ of their variation is explained by the market-wide level component. Investigating the market-wide slope component shows that there is less comovement on average indicated by the explained variation of $26.6 \%$. The decomposition in sectors shows that the market-wide slope component still explains half of the variation in the energy slope factors, while it hardly explains variation for the softs and grains sectors. The market-wide curvature component shows similar results as the market-wide slope component. In general, the market-wide curvature component explains $19.9 \%$ of the variation in the individual commodity curvature factors. For energy the percentage of explained variation is much higher $(38.2 \%)$, while for the softs sector it explains none of the variation at all.

\section{Table C.2 PCA commonality results}

The table presents the percentage of explained variation of the extracted level, slope and curvature factors for the first three principal components. Panel A shows how much variation is explained by the marketwide level, slope and curvature components. In Panel B the percentages refer to the explained variation when PCA is applied to a particular sector, i.e. this variation can be due to both the market-wide and sector specific component. The differences in percentages explained variation between Panel A and B, indicate the comovement due to the sector specific component.

\begin{tabular}{|c|c|c|c|c|c|c|c|c|c|}
\hline & \multicolumn{3}{|c|}{ level factor } & \multicolumn{3}{|c|}{ slope factor } & \multicolumn{3}{|c|}{ curvature factor } \\
\hline & $1 \mathrm{st}$ & 2 nd & $3 \mathrm{rd}$ & $1 \mathrm{st}$ & 2 nd & $3 \mathrm{rd}$ & 1 st & 2 nd & $3 \mathrm{rd}$ \\
\hline \multicolumn{10}{|c|}{ Panel A Market-wide component } \\
\hline 1) all commodities & $78.7 \%$ & $9.8 \%$ & $3.5 \%$ & $26.5 \%$ & $17.0 \%$ & $14.9 \%$ & $19.9 \%$ & $16.7 \%$ & $9.4 \%$ \\
\hline 2) energy & $80.9 \%$ & $16.3 \%$ & $0.3 \%$ & $58.6 \%$ & $2.4 \%$ & $22.8 \%$ & $38.2 \%$ & $5.9 \%$ & $12.4 \%$ \\
\hline 3) metals & $86.5 \%$ & $1.4 \%$ & $6.7 \%$ & $23.9 \%$ & $12.5 \%$ & $25.8 \%$ & - & - & - \\
\hline 4) softs & $56.1 \%$ & $22.4 \%$ & $2.7 \%$ & $6.5 \%$ & $13.2 \%$ & $1.4 \%$ & $0.0 \%$ & $0.0 \%$ & $0.0 \%$ \\
\hline 5) grains & $85.5 \%$ & $7.0 \%$ & $1.1 \%$ & $1.9 \%$ & $61.5 \%$ & $4.0 \%$ & $0.1 \%$ & $1.1 \%$ & $7.9 \%$ \\
\hline 6) meats & $77.3 \%$ & $3.4 \%$ & $6.7 \%$ & $27.9 \%$ & $2.6 \%$ & $6.1 \%$ & $6.5 \%$ & $11.5 \%$ & $12.1 \%$ \\
\hline \multicolumn{10}{|c|}{ Panel B Market-wide and Sector component } \\
\hline 1) energy & $93.5 \%$ & $6.4 \%$ & $0.0 \%$ & $79.1 \%$ & $11.7 \%$ & $4.9 \%$ & $46.0 \%$ & $21.4 \%$ & $12.4 \%$ \\
\hline 2) metals & $90.3 \%$ & $5.8 \%$ & $1.7 \%$ & $49.9 \%$ & $24.4 \%$ & $12.2 \%$ & - & - & - \\
\hline 3) softs & $77.3 \%$ & $12.8 \%$ & $6.9 \%$ & $43.4 \%$ & $26.3 \%$ & $20.3 \%$ & $33.6 \%$ & $28.3 \%$ & $24.1 \%$ \\
\hline 4) grains & $97.8 \%$ & $1.3 \%$ & $0.8 \%$ & $69.2 \%$ & $19.3 \%$ & $9.4 \%$ & $60.4 \%$ & $20.1 \%$ & $11.0 \%$ \\
\hline 5) meats & $90.4 \%$ & $9.0 \%$ & $0.6 \%$ & $62.6 \%$ & $26.2 \%$ & $11.2 \%$ & $47.6 \%$ & $35.3 \%$ & $17.1 \%$ \\
\hline
\end{tabular}




\section{Additional Schwartz comparison results}

This section presents results on the differences in model fit between our Nelson-Siegel framework and the Schwartz (1997) model. In Section 4.1 Table 2 we present the fit of our individual models. In Table D.1 we present these same numbers together with the $R^{2}$ of the corresponding Schwartz (1997) model. For all commodities our model has a better fit. The minimum fit increase is $1.6 \%$, the average increase is $5.6 \%$ and the maximum increase is $29.2 \%$.

\section{Table D.1 Model fit comparison}

This table compares the differences in fit $\left(R^{2}\right)$ between the Schwartz (1997) model and our Nelson-Siegel type model. The difference is computed as $\left(R_{\text {Nelson-Siegel }}^{2}-R_{\text {Schwartz }}^{2}\right) / R_{\text {Nelson-Siegel }}^{2}$.

\begin{tabular}{|c|c|c|c|c|c|c|c|}
\hline Commodity & Schwartz & Nelson-Siegel & diff. & Commodity & Schwartz & Nelson-Siegel & diff \\
\hline Brent crude oil & $97.06 \%$ & $99.99 \%$ & $3.0 \%$ & Cocoa & $93.22 \%$ & $99.97 \%$ & $7.2 \%$ \\
\hline WTI crude oil & $97.28 \%$ & $99.99 \%$ & $2.8 \%$ & Coffee & $94.76 \%$ & $99.98 \%$ & $5.5 \%$ \\
\hline Gasoil & $98.40 \%$ & $99.98 \%$ & $1.6 \%$ & Cotton & $88.66 \%$ & $99.74 \%$ & $12.5 \%$ \\
\hline Heating oil & $98.41 \%$ & $99.97 \%$ & $1.6 \%$ & Sugar & $96.51 \%$ & $99.91 \%$ & $3.5 \%$ \\
\hline Natural gas & $92.14 \%$ & $99.40 \%$ & $7.9 \%$ & & & & \\
\hline \multirow[t]{2}{*}{ Gasoline } & $97.43 \%$ & $99.94 \%$ & $2.6 \%$ & Corn & $95.72 \%$ & $99.81 \%$ & $4.3 \%$ \\
\hline & & & & Soybeans & $95.32 \%$ & $99.89 \%$ & $4.8 \%$ \\
\hline Gold & $96.73 \%$ & $99.99 \%$ & $3.4 \%$ & Chicago wheat & $95.47 \%$ & $99.84 \%$ & $4.6 \%$ \\
\hline Silver & $96.13 \%$ & $99.99 \%$ & $4.0 \%$ & Kansas wheat & $95.15 \%$ & $99.86 \%$ & $5.0 \%$ \\
\hline Aluminum & $90.29 \%$ & $99.91 \%$ & $10.7 \%$ & & & & \\
\hline Copper & $96.99 \%$ & $99.97 \%$ & $3.1 \%$ & Feeder cattle & $97.51 \%$ & $99.91 \%$ & $2.5 \%$ \\
\hline Lead & $98.05 \%$ & $99.99 \%$ & $2.0 \%$ & Lean hogs & $75.68 \%$ & $97.80 \%$ & $29.2 \%$ \\
\hline Nickel & $96.45 \%$ & $99.98 \%$ & $3.7 \%$ & Live cattle & $95.77 \%$ & $99.60 \%$ & $4.0 \%$ \\
\hline Zinc & $94.80 \%$ & $99.97 \%$ & $5.5 \%$ & & & & \\
\hline
\end{tabular}




\section{E Macroeconomic data}

Table E.1 lists all macroeconomic and commodity specific data series. For each series we provide their name, code, transformation, category, source, and description. An overview of the categories is shown in Table E. 2 while the transformation codes are explained in Table E.3.

\section{Table E.1 Data series}

The table presents all macroeconomic and commodity specific data series (in line with Stock and Watson, 2012 and Gorton, Hayashi, and Rouwenhorst, 2013). For each series we provide their name, code, transformation, category, source, and description. An overview of the categories is shown in Table E.2 while the transformation codes are explained in Table E.3. The codes correspond to the database identifiers of the source.

Used abbreviations: St. Louis, Federal Reserve Economic Data (FRED); Commodity Futures Trading Commission (CFTC); Department of Energy (DOE);

Intercontinental Exchange (ICE); U.S. Department of Agriculture (USDA).

${ }^{a}$ Author's website:

${ }^{b}$ We follow the details given in Appendix B of Gorton, Hayashi, and Rouwenhorst (2013)

\begin{tabular}{|c|c|c|c|c|c|}
\hline Name & Code & $\mathrm{T}$ & Cat & Source & Description \\
\hline Cons-Dur & DNDGRG3M086SBEA & 5 & 1 & FRED & Personal consumption expenditures: Nondurable goods, Price index $(2009=100)$, SA \\
\hline Cons-NonDur & DPCERA3M086SBEA & 5 & 1 & FRED & Real personal consumption expenditures, Quantity index $(2009=100)$, SA \\
\hline Cons-Serv & DSERRG3M086SBEA & 5 & 1 & FRED & Personal consumption expenditures: Services, Price index $(2009=100)$, SA \\
\hline Exports & USEXNGS.B & 5 & 1 & Datastream & Real exports \\
\hline Imports & USIMNGS.B & 5 & 1 & Datastream & Real imports \\
\hline IP: cons dble & IPDCONGD & 5 & 2 & FRED & Industrial Production: Durable Consumer Goods Index $(2007=100)$, SA \\
\hline IP: cons nondble & IPNCONGD & 5 & 2 & FRED & Industrial Production: Nondurable Consumer Goods Index $(2007=100)$, SA \\
\hline IP: bus eqpt & IPBUSEQ & 5 & 2 & FRED & Industrial Production: Business Equipment Index $(2007=100)$, SA \\
\hline IP: dble mats & IPDMAT & 5 & 2 & FRED & Industrial Production: Durable Materials Index $(2007=100)$, SA \\
\hline IP: nondble mats & IPNMAT & 5 & 2 & FRED & Industrial Production: nondurable Materials Index $(2007=100)$, SA \\
\hline IP: $\mathrm{mfg}$ & IPMANSICS & 5 & 2 & FRED & Industrial Production: Manufacturing (SIC) Index $(2007=100)$, SA \\
\hline IP: fuels & IPUTIL & 5 & 2 & FRED & Industrial Production: Electric and Gas Utilities Index $(2007=100)$, SA \\
\hline NAPM prodn & NAPMPI & 1 & 2 & FRED & ISM Manufacturing: Production Index, SA \\
\hline Capacity Util & TCU & 1 & 2 & FRED & Capacity Utilization: Total Industry \% of Capacity, SA \\
\hline Emp: mining & CES1021000001 & 5 & 3 & FRED & All Employees: Mining and Logging: Mining, Thous. of Persons, SA \\
\hline Emp: const & USCONS & 5 & 3 & FRED & All Employees: Construction, Thous. of Persons, SA \\
\hline Emp: dble gds & DMANEMP & 5 & 3 & FRED & All Employees: Durable goods, Thous. of Persons, SA \\
\hline Emp: nondbles & NDMANEMP & 5 & 3 & FRED & All Employees: Nondurable goods, Thous. of Persons, SA \\
\hline Emp: services & SRVPRD & 5 & 3 & FRED & All Employees: Service-Providing Industries, Thous. of Persons, SA \\
\hline Emp: TTU & USTPU & 5 & 3 & FRED & All Employees: Trade, Transportation \& Utilities, Thous. of Persons, SA \\
\hline Emp: wholesale & USWTRADE & 5 & 3 & FRED & All Employees: Wholesale Trade, Thous. of Persons, SA \\
\hline Emp: retail & USTRADE & 5 & 3 & FRED & All Employees: Retail Trade, Thous. of Persons, SA \\
\hline Emp: FIRE & USFIRE & 5 & 3 & FRED & All Employees: Financial Activities, Thous. of Persons, SA \\
\hline
\end{tabular}




\begin{tabular}{|c|c|c|c|c|c|}
\hline Name & Code & $\mathrm{T}$ & Cat & Source & Description \\
\hline Emp: Govt & USGOVT & 5 & 3 & FRED & All Employees: Government, Thous. of Persons, SA \\
\hline Emp. Hours & AWHI & 5 & 3 & FRED & Aggr. Wkly Hours: Prod. and Nonsuperv. Employ.: Total Private Industries $(2002=100)$, SA \\
\hline Avg hrs & CES0600000007 & 1 & 3 & FRED & Avg. Wkly Hours of Prod. and Nonsuperv. Employ.: Goods-Producing Hours, SA \\
\hline Overtime: $\mathrm{mfg}$ & AWOTMAN & 2 & 3 & FRED & Avg. Wkly Overtime Hours of Prod. and Nonsuperv. Employees: Manufacturing Hours, SA \\
\hline U: all & UNRATE & 2 & 4 & FRED & Unemployment rate: all workers, 16 years and over, Percentage, SA \\
\hline U: mean duration & UEMPMEAN & 2 & 4 & FRED & Average (Mean) Duration of Unemployment, Weeks, SA \\
\hline $\mathrm{U}:<5 \mathrm{wks}$ & UEMPLT5 & 5 & 4 & FRED & Number of Civilians Unemployed - Less Than 5 Weeks, Thous. of Persons, SA \\
\hline $\mathrm{U}: 5-14 \mathrm{wks}$ & UEMP5TO14 & 5 & 4 & FRED & Number of Civilians Unemployed for 5 to 14 Weeks, Thous. of Persons, SA \\
\hline $\mathrm{U}: 15+\mathrm{wks}$ & UEMP15OV & 5 & 4 & FRED & Number of Civilians Unemployed for 15 Weeks and Over, Thous. of Persons, SA \\
\hline $\mathrm{U}: 15-26$ wks & UEMP15T26 & 5 & 4 & FRED & Number of Civilians Unemployed for 15 to 26 Weeks, Thous. of Persons, SA \\
\hline $\mathrm{U}: 27+$ wks & UEMP27OV & 5 & 4 & FRED & Number of Civilians Unemployed for 27 Weeks and Over, Thous. of Persons, SA \\
\hline HStarts: NE & HOUSTNE & 4 & 5 & FRED & Housing Starts in Northeast Census Region, Thous. of Units, SAAR \\
\hline HStarts: MW & HOUSTMW & 4 & 5 & FRED & Housing Starts in Midwest Census Region, Thous. of Units, SAAR \\
\hline HStarts: S & HOUSTS & 4 & 5 & FRED & Housing Starts in South Census Region, Thous. of Units, SAAR \\
\hline HStarts: W & HOUSTW & 4 & 5 & FRED & Housing Starts in West Census Region, Thous. of Units, SAAR \\
\hline PMI & NAPM & 1 & 6 & FRED & ISM Manufacturing: PMI Composite Index, SA \\
\hline NAPM new orders & NAPMNOI & 1 & 6 & FRED & ISM Manufacturing: New Orders Index, SA \\
\hline NAPM vendor del & NAPMSDI & 1 & 6 & FRED & ISM Manufacturing: Supplier Deliveries Index, SA \\
\hline NAPM Invent & NAPMII & 1 & 6 & FRED & ISM Manufacturing: Inventories Index, NSA \\
\hline Orders (ConsGoods) & ACOGNO & 5 & 6 & FRED & Manufacturers New Orders for Cons. Goods Indus., Mil. of $\$$, SA \\
\hline Orders (NDCapGoods) & ANDENO & 5 & 6 & FRED & Manufacturers New Orders for Capital Goods: Nondef. Capital Goods Indus., Mil. of $\$$, SA \\
\hline CPI-core & CPIULFSL & 6 & 7 & FRED & Consumer Price Index for All Urban Cons.: All Items Less Food, Index (1982-84=100), SA \\
\hline PCED & PCEPI & 6 & 7 & FRED & Personal Consumption Expenditures, Price Index $(2009=100)$, SA \\
\hline AHE: const & CES2000000008 & 5 & 8 & FRED & Avg. Hourly Earnings of Prod. and Nonsuperv. Employees: Construction, $\$$ per Hour, SA \\
\hline AHE: $\mathrm{mfg}$ & CES3000000008 & 5 & 8 & FRED & Avg. Hourly Earnings of Prod. and Nonsuperv. Employees: Manufacturing, $\$$ per Hour, SA \\
\hline FedFunds & FEDFUNDS & 2 & 9 & FRED & Effective Federal Funds Rate, $\%$ per annum, NSA \\
\hline 3mo T-bill & TB3MS & 2 & 9 & FRED & 3-Month Treasury Bill: Secondary Market Rate, $\%$ per annum, NSA \\
\hline 3mo T-bill & TB6MS & 2 & 9 & FRED & 6-Month Treasury Bill: Secondary Market Rate, $\%$ per annum, NSA \\
\hline M1 & M1SL & 6 & 10 & FRED & M1 Money Stock, Bil. of $\$$, SA \\
\hline M2 & M2SL & 6 & 10 & FRED & M2 Money Stock, Bil. of $\$$, SA \\
\hline MB & AMBSL & 6 & 10 & FRED & St. Louis Adjusted Monetary Base, Bil. of $\$$, SA \\
\hline Reserves tot. & TOTRESNS & 6 & 10 & FRED & Total Reserves of Depository Institutions, Bil. of $\$$, NSA \\
\hline BUSLOANS & BUSLOANS & 6 & 10 & FRED & Commercial and Industrial Loans, All Commercial Banks, Bil. of $\$$, SA \\
\hline Cons credit & NONREVSL & 6 & 10 & FRED & Total Nonrevolving Credit Owned and Securitized, Outstanding, Bil. of $\$$, SA \\
\hline Ex rate: avg & TWEXMMTH & 5 & 11 & FRED & Trade Weighted U.S. Dollar Index: Major Currencies, Index (Mar 1973=100), NSA \\
\hline Ex rate: Switz & EXSZUS & 5 & 11 & FRED & Switzerland / U.S. Foreign Exchange Rate Swiss Francs to 1 U.S., \$, NSA \\
\hline Ex rate: Japan & EXJPUS & 5 & 11 & FRED & Japan / U.S. Foreign Exchange Rate Japanese Yen to 1 U.S., \$, NSA \\
\hline Ex rate: UK & EXUSUK & 5 & 11 & FRED & U.S. / U.K. Foreign Exchange Rate U.S. $\$$ to 1 British Pound, £, NSA \\
\hline Ex rate: Canada & EXCAUS & 5 & 11 & FRED & Canada / U.S. Foreign Exchange Rate Canadian $\$$ to 1 U.S., $\$$, NSA \\
\hline
\end{tabular}




\begin{tabular}{|c|c|c|c|c|c|}
\hline Name & Code & $\mathrm{T}$ & Cat & Source & Description \\
\hline $\mathrm{S} \& \mathrm{P} 500$ & SP500 & 5 & 12 & FRED & S\&P 500, Index, NSA \\
\hline DJIA & USSHRPRCF & 5 & 12 & Datastream & Dow Jones Industrial Average \\
\hline Consumer expect & UMCSENT & 2 & 13 & FRED & University of Michigan: Consumer Sentiment, Index (1966Q1=100), NSA \\
\hline ADS & ADS & 1 & 14 & FRB of Phil. & Aruoba Diebold Scotti financial conditions index \\
\hline Sentiment & Sentiment & 1 & 14 & Author's website ${ }^{a}$ & Baker Wurgler paper \\
\hline Baltic Dry index & BALTICF & 1 & 14 & Datastream & Dry bulk shipping price \\
\hline Comm. vol. & CRBSPOT & 1 & 15 & Datastream & Volatility of Commodity Research Bureau (CRB) spot market price index \\
\hline HP WTI & hedging WTI & 1 & $16 \mathrm{~A}$ & CFTC & Hedging pressure computed from Commitment of Traders Reports \\
\hline HP gasoline & hedging GL & 1 & $16 \mathrm{~A}$ & CFTC & Hedging pressure computed from Commitment of Traders Reports \\
\hline HP heating oil & hedging $\mathrm{HO}$ & 1 & $16 \mathrm{~A}$ & CFTC & Hedging pressure computed from Commitment of Traders Reports \\
\hline HP natural gas & hedging NG & 1 & $16 \mathrm{~A}$ & CFTC & Hedging pressure computed from Commitment of Traders Reports \\
\hline HP copper & hedging $\mathrm{CP}$ & 1 & $16 \mathrm{~B}$ & CFTC & Hedging pressure computed from Commitment of Traders Reports \\
\hline HP cocoa & hedging $\mathrm{CC}$ & 1 & $16 \mathrm{C}$ & CFTC & Hedging pressure computed from Commitment of Traders Reports \\
\hline HP coffee & hedging $\mathrm{CF}$ & 1 & $16 \mathrm{C}$ & CFTC & Hedging pressure computed from Commitment of Traders Reports \\
\hline HP sugar & hedging SG & 1 & $16 \mathrm{C}$ & CFTC & Hedging pressure computed from Commitment of Traders Reports \\
\hline HP cotton & hedging $\mathrm{CT}$ & 1 & $16 \mathrm{C}$ & CFTC & Hedging pressure computed from Commitment of Traders Reports \\
\hline HP soybeans & hedging S & 1 & $16 \mathrm{D}$ & CFTC & Hedging pressure computed from Commitment of Traders Reports \\
\hline HP wheat & hedging $\mathrm{W}$ & 1 & $16 \mathrm{D}$ & CFTC & Hedging pressure computed from Commitment of Traders Reports \\
\hline HP corn & hedging $\mathrm{C}$ & 1 & $16 \mathrm{D}$ & CFTC & Hedging pressure computed from Commitment of Traders Reports \\
\hline HP feeder cattle & hedging $\mathrm{FC}$ & 1 & $16 \mathrm{E}$ & CFTC & Hedging pressure computed from Commitment of Traders Reports \\
\hline HP live cattle & hedging LC & 1 & $16 \mathrm{E}$ & CFTC & Hedging pressure computed from Commitment of Traders Reports \\
\hline HP lean hogs & hedging LH & 1 & $16 \mathrm{E}$ & CFTC & Hedging pressure computed from Commitment of Traders Reports \\
\hline inventory crude oil & inventory WTI & 5 & $17 \mathrm{~A}$ & DOE & U.S. ending stocks excluding SPR of crude oil, thousands of barrels ${ }^{b}$ \\
\hline inventory gasoline & inventory GL & 5 & $17 \mathrm{~A}$ & DOE & U.S. motor gasoline ending stocks, thousands of barrels ${ }^{b}$ \\
\hline inventory heating oil & inventory $\mathrm{HO}$ & 5 & $17 \mathrm{~A}$ & DOE & U.S. total stocks of distillate fuel oil ${ }^{b}$ \\
\hline inventory natural gas & inventory NG & 5 & $17 \mathrm{~A}$ & DOE & U.S. total natural gas in underground storage (working gas), millions of cubic feet ${ }^{b}$ \\
\hline inventory gold & COMXGOLD Index & 5 & $17 \mathrm{~B}$ & Bloomberg & Comex warehouse stocks ${ }^{b}$ \\
\hline inventory silver & COMXSILV Index & 5 & $17 \mathrm{~B}$ & Bloomberg & Comex warehouse stocks ${ }^{b}$ \\
\hline inventory copper & LSCA Index & 5 & $17 \mathrm{~B}$ & Bloomberg & LME warehouse stocks ${ }^{b}$ \\
\hline inventory aluminum & LSAH Index & 5 & $17 \mathrm{~B}$ & Bloomberg & LME warehouse stocks ${ }^{b}$ \\
\hline inventory lead & LSPB Index & 5 & $17 \mathrm{~B}$ & Bloomberg & LME warehouse stocks ${ }^{b}$ \\
\hline inventory nickel & LSNI Index & 5 & $17 \mathrm{~B}$ & Bloomberg & LME warehouse stocks ${ }^{b}$ \\
\hline inventory zinc & LSZS Index & 5 & $17 \mathrm{~B}$ & Bloomberg & LME warehouse stocks ${ }^{b}$ \\
\hline inventory cocoa & inventory $\mathrm{CC}$ & 5 & $17 \mathrm{C}$ & $\mathrm{ICE}$ & ICE wareh. stocks (ports of New York, Delaware River, Hampton Roads, Albany, Baltimore) $)^{b}$ \\
\hline inventory coffee & inventory $\mathrm{CF}$ & 5 & $17 \mathrm{C}$ & ICE & ICE wareh. stocks (ports of New York, New Orleans, Houston, Miami, Antwerp, Hamburg, Barcelona) \\
\hline inventory cotton & inventory CT & 5 & $17 \mathrm{C}$ & ICE & Hist. Certif. Stock Report (ports of Dallas, Galveston, Greenville, Houston, Memphis, New Orleans) ${ }^{b}$ \\
\hline inventory sugar & inventory SG & 5 & $17 \mathrm{C}$ & USDA & U.S. sugar stocks held by primary distributors ${ }^{b}$ \\
\hline inventory corn & inventory $\mathrm{C}$ & 5 & $17 \mathrm{D}$ & USDA & Stocks of Grain at Selected Terminals and Elevator Sites, thousands of bushels ${ }^{b}$ \\
\hline inventory soybeans & inventory S & 5 & $17 \mathrm{D}$ & USDA & Stocks of Grain at Selected Terminals and Elevator Sites, Thousands of Bushels ${ }^{b}$ \\
\hline inventory wheat & inventory $\mathrm{W}$ & 5 & $17 \mathrm{D}$ & USDA & Stocks of Grain at Selected Terminals and Elevator Sites, Thousands of Bushels ${ }^{b}$ \\
\hline inventory feeder cattle & inventory FC & 5 & $17 \mathrm{E}$ & USDA & United States Cattle Placed on Feed in 7 States $^{b}$ \\
\hline
\end{tabular}




\begin{tabular}{|c|c|c|c|c|c|}
\hline Name & Code & $\mathrm{T}$ & Cat & Source & Description \\
\hline inventory live cattle & inventory LC & 5 & $17 \mathrm{E}$ & USDA & Frozen beef stocks in cold storage in the U.S. ${ }^{b}$ \\
\hline inventory lean hogs & inventory LH & 5 & $17 \mathrm{E}$ & USDA & Frozen pork stocks in cold storage in the U.S. ${ }^{b}$ \\
\hline
\end{tabular}


Table E.2 Data categories

The table presents the data category codes (following Stock and Watson, 2012).

\begin{tabular}{cc}
\hline Category code & Category name \\
\hline 1 & GDP components \\
2 & Industrial production \\
3 & Employment \\
4 & Unemployment rate \\
5 & Housing \\
6 & Prices \\
7 & Wages \\
8 & Interest rates \\
9 & Money \\
10 & Exchange rates \\
11 & Stock prices \\
12 & Consumer expectations \\
13 & Financial conditions \\
14 & Commodity volatility \\
15 & Hedging pressure \\
16 & Commodity inventories \\
17 &
\end{tabular}

\section{Table E.3 Data transformations}

The table presents the data transformation codes (following Stock and Watson, 2012). $Z_{t}$ denotes the raw series and $X_{t}$ the transformed series used to compute the principal components.

\begin{tabular}{cc}
\hline Transformation code & $X_{t}$ \\
\hline 1 & $Z_{t}$ \\
2 & $Z_{t}-Z_{t-1}$ \\
3 & $\left(Z_{t}-Z_{t-1}\right)-\left(Z_{t-1}-Z_{t-2}\right)$ \\
4 & $\ln \left(Z_{t}\right)$ \\
5 & $\ln \left(Z_{t} / Z_{t-1}\right)$ \\
6 & $\ln \left(Z_{t} / Z_{t-1}\right)-\ln \left(Z_{t-1} / Z_{t-2}\right)$ \\
\hline
\end{tabular}

